Portland State University

PDXScholar

Summer 8-26-2019

\title{
Understanding the Politicization of Oromo Identity in the Diaspora: Re/ Locating the Bones of the Oromo
}

Madeline Jaye Bass

Portland State University

Follow this and additional works at: https://pdxscholar.library.pdx.edu/open_access_etds

Part of the Ethnic Studies Commons, and the Sociology Commons Let us know how access to this document benefits you.

Recommended Citation

Bass, Madeline Jaye, "Understanding the Politicization of Oromo Identity in the Diaspora: Re/ Locating the Bones of the Oromo" (2019). Dissertations and Theses. Paper 5308.

https://doi.org/10.15760/etd.7181

This Thesis is brought to you for free and open access. It has been accepted for inclusion in Dissertations and Theses by an authorized administrator of PDXScholar. Please contact us if we can make this document more accessible: pdxscholar@pdx.edu. 
Understanding the Politicization of Oromo Identity in the Diaspora:

$\mathrm{Re} /$ Locating the Bones of the Oromo

by

Madeline Jaye Bass

A thesis submitted in partial fulfillment of the requirements for the degree of

\author{
Master of Science \\ in \\ Sociology
}

Thesis Committee:

José Padín, Chair

Grant Farr

Daniel Jaffee

Portland State University

2019 
(C) Copyright by

Madeline Jaye Bass

2019 


\begin{abstract}
The Oromo people of Ethiopia share a common language, worldview, set of sacred meanings, and a historic system of governance. The rise of the Abyssinian Empire in the late 1800s led to the colonization of the Oromo; their language and religion were made illegal, their homeland was expropriated and renamed, and they were forced to live as slaves on their own land. After the end of the Abyssinian colonial era, historic discrimination was institutionalized into the new Ethiopian state form through the politicization of identities. Ethnic identities become political identities when cultural traits are used by the state as criteria for a differential allocation of rights. This thesis studies how the identity of the Oromo people (Oromumma) has been shaped over time by economic, political, and cultural dynamics of oppression and resistance, and how it has developed among Oromo in the diaspora. Field observations in Ethiopia and interviews of Oromo immigrants in the U.S. are the basis for the study. This thesis is a unique contribution to research of marginalized Indigenous populations living under a settler colonial state in that it examines the unusual case where both the oppressor and oppressed populations are African. It also makes a contribution to the literature understanding the politicization of Oromumma in Ethiopia and across the diaspora.
\end{abstract}




\section{ACKNOWLEDGEMENTS}

I am endlessly grateful for maatii koo, hiriyoota koo, baratoota koo, barsiisoota koo, fi garaa koo: Abera, Abiyot, Abrish, Ahmed, Badhaassaa, Barbara, Bona, Dan, Dereje, Dinqo, Emily, Ermiyas, Gudeta, Jay, Makiya, Mamitu, Nejat, Nebu, Nihaal, Roza, Sa'ada, and Senna. Ani kanan bilisoomuu gaafa Oromiyaan bilisoomte qofaa dha. Without the guidance, wisdom, and support of José, Dan, and Grant, this project would have taken another five years, at least. Baay'ee isin galateefadha. Thank you. 


\section{TABLE OF CONTENTS}







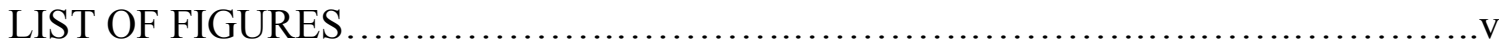

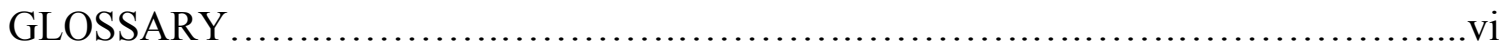

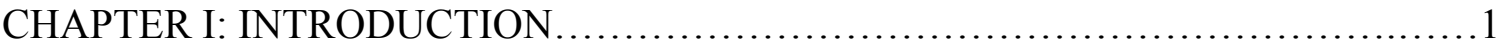

CHAPTER II: ANALYTICAL FRAMEWORK...................................... 14

CHAPTER III: METHODS.....................................................

CHAPTER IV: POLITICIZATION OF OROMUMMA OVER TIME....................55

CHAPTER V: KEY THEMES AND FINDINGS ..................................95

CHAPTER VI: DISCUSSION AND CONCLUSION..................................126

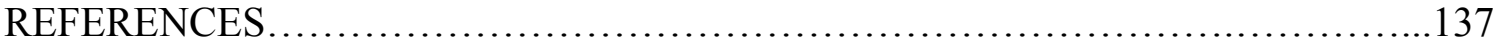



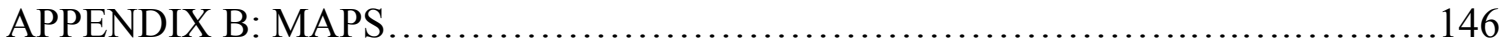

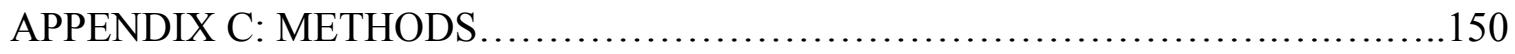




\section{LIST OF TABLES}

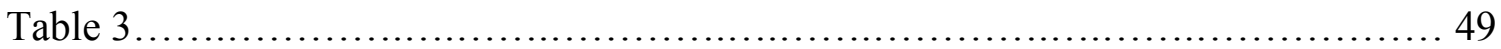




\section{LIST OF FIGURES}





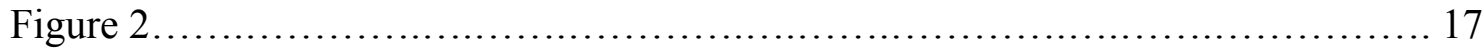

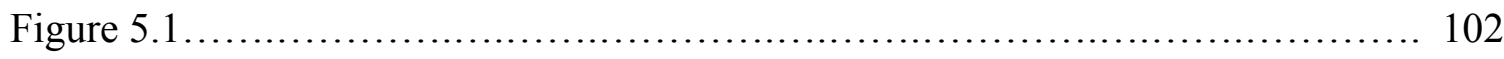

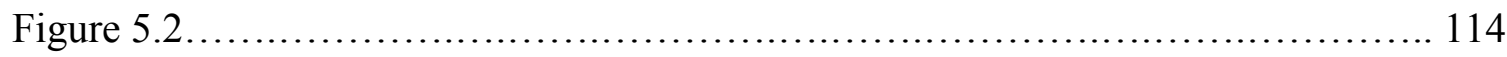

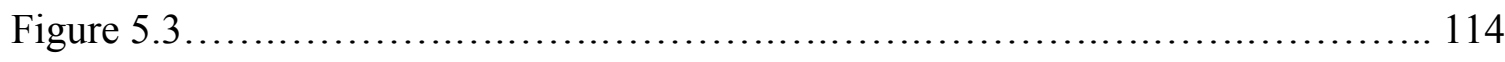

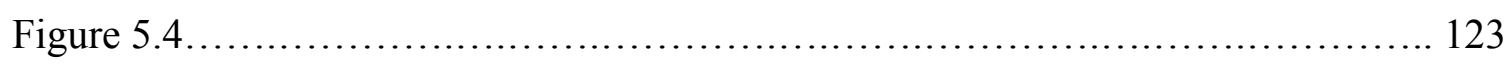

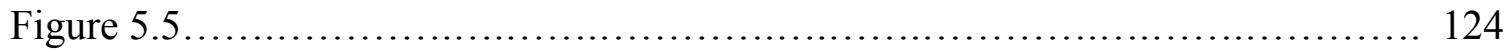

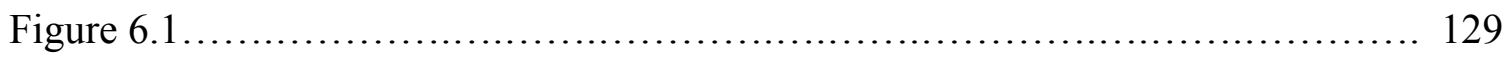

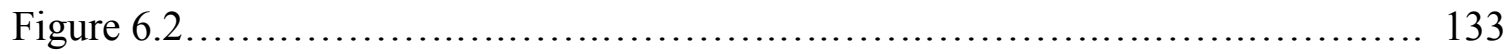




\section{GLOSSARY OF TERMS}

Abyssinia, or the Abyssinian Empire: Ethiopia's former name

Dergue: the fascist regime that ruled from 1974 until 1991

EPRDF: Ethiopian People's Revolutionary Democratic Front

FDRE: Federal Democratic Republic of Ethiopia, the state's current, formal name

Finfinnee: the original Afan Oromo name for the capital city, Addis Ababa

MTSHA: Macha Tulama Self-Help Association

Nafxanya-Gabbar System: feudal land and labor system. Nafxanya is the landlord and the Gabbar is the serf, or slave.

$O L F$ : Oromo Liberation Front

TGE: Transitional Government of Ethiopia

TPLF: Tigrayan People's Liberation Front

WOC: Western Oromo Confederation 


\section{CHAPTER I: INTRODUCTION}

\section{Re/ Locating the Bones of the Oromo}

Relationships between the Oromo people of the Horn of Africa and the leaders of the empires, kingdoms, and post-colonial states who have sought to rule them over the past two centuries have been characterized by violence. The Oromo people, from the beginning of their cultural consciousness, practiced a land-based religion and were governed using a democratic system of rule called the Gadaa. The rise of the Abyssinian Empire, the predecessor to the Ethiopian state, led to unrelenting violence against the Oromo since their colonization in the late 1880s. Despite this violence, Oromo culture and Oromo people have continued to survive, demonstrating an extraordinary resilience.

In the last few years of the Oromo protest movement a slogan was created, a way of expressing generations of frustrations, trauma, and death: "Our land is our bones, we won't be dislocated." This phrase responds to the Oromo experience of erasure, marginalization, and discriminatory political policies, an experience that has been ignored for too long. Re/locating the bones of the Oromo can be understood as an attempt to address this violence while also working to dismantle the intersecting forms of political oppression that made dislocation possible. The state of Ethiopia was founded in part on the stolen land of the Oromo people, and governed using manipulation and violence; this continues to impact Oromo life today. Fully understanding the history behind Oromo and Ethiopian relationships means first making sense of the Oromo "bones," and the dislocations that still take place on their homeland.

Some scholars trace the etymology of Gadaa, the name of the system of democratic governance historically used by the Oromo people of the Horn of Africa, to 
the Afan Oromo word gaddisuu; to shelter, shade, or protect from the sun. This protection kept Oromo society functioning peacefully for generations, and covered a land space that reached across and into Kenya, South Sudan, Djibouti, Somalia, and vast areas of Ethiopia. When faced with the well-armed attacks of the Abyssinian empire, however, this centuries old practice was nearly made extinct. After state consolidation in the 1890s, the Abyssinians' physical attacks were re-created as economic practices, legal systems, and cultural exclusion. The free land of Oromiya and the culture that had thrived there is visible now only in pockets and pieces, a skeletal form of her former glory.

This colonizing force caused the expulsion and creation of a vibrant Oromo diaspora, one that remains in conversation with this trauma, asking the same questions: Does the forced dislocation from the homeland change the way one attaches to it? In a market-driven, neoliberal world, where the fields the ancestors sang through are plowed for luxury condos, what does "Mother" Oromiya say, how can she respond? Does her voice, and the voice of the diaspora, and the stories told of this shared history hinder progress and sow divisiveness, preventing the actualization of some elusive ultra-modern Ethiopia? How has the act of speaking, believing, living, and remembering Oromumma become an international political project, and how does this resistance, once awakened, work in dialect with the violences that silence, spread ignorance and death, that would have one forget? What can be done with the bones of the Oromo, with the remnants of a former freedom?

This thesis project, with these questions in mind, intends to understand most centrally how the Oromo people experience and define their lives within and despite the political violence of the post-colonial nation-state of Ethiopia. Understanding this 
experience necessitates deconstructing the economic, political, and cultural tools employed by the state, as well as the way the Oromo people resist and counteract these forces, continuing to fight for liberation. These domains, and the technologies of oppression and resistance embedded within them, serve as the analytical framework for this paper. They are also key mechanisms for identifying changes in identity and group relations since the end of the colonial era. Given this framework, and the underlying issues, this research project has aimed to answer the following questions:

1. What factors most strongly shaped historical Oromumma, Oromo cultural identity?

2. What factors have most influenced Oromumma in the Oromo diaspora?

\section{Background Information}

For the purpose of this research, it is necessary to make clear the distinctions between Oromo, Abyssinian, Ethiopian, Amharan, Tigrayan, and Habesha as groups of people and legal identities. These distinctions are discussed more extensively in their historical context later. Oromo people, the focus of this project, are an ethnic group whose indigenous homeland, Oromiya, makes up the largest regional state in modern Ethiopia. Historic Oromiya, including the pastoralist lands along the Southeastern border, stretched even further. Oromo people speak Afan Oromo, which translates as the mouth and language of the Oromo, informally called Oromiffa. Abyssinia and the Abyssinian Empire was the historic kingdom of Northern Ethiopia, and the name used during the consolidation of the settler colony. This empire combined the historic kingdoms of Shoa, Axum, and others. During the reign of Haile Selassie, from 1931-1974, the nation's name 
was changed to Ethiopia (Reid 2011:136). There is much debate about the origins of this name; some connect both Abyssinia and Ethiopia to biblical references, or Greek mythology, but there is not a clear consensus (Hussein and Ademo 2016; Yates 2016). Amhara is the name of the region and people of northern Ethiopia who have generally had the most access to state power and governance, and whose historic rulers were responsible for the consolidation of Ethiopia (Michael 2008). The Amhara are primarily Orthodox Christian, and were historically renowned for the might of the Shoa province and dynasty. The Amhara language, Amharic, is the national language of Ethiopia. It, along with Tigrigna, is in the same language family as Ge'ez, the language the bible was written in (Bulcha 1997). Tigray refers to both a region in Ethiopia and an ethnicity of peoples whose homeland includes parts of Ethiopia and Eritrea. These people speak Tigrigna, as do some non-Tigrayan Eritreans. In ancient history they were notable for the Axum Empire, as well as their Christianity (Orlowska 2013:309). Tigrayan people were major forces both in attempting to overthrow Haile Selassie in 1960, and in the downfall of the Dergue, the fascist regime, in 1991. Since state re-formation in the early 1990s they have seized the majority of state power and have seen hyper-development in their region, compared to the mismanagement of aid and resources across the rest of the country (Gudina 1997; Zegeye 2017). Habesha as an identity marker includes both of these peoples, as well as other ethnic groups from Eritrea.

More specifically, Habesha identity typically refers to Orthodox Christian speakers of Semitic languages descended from Ge'ez and living in the Horn of Africa. Some southern peoples of Ethiopia claim this identity marker, particularly those who have converted to Orthodox Christianity or adopted the national language as their mother 
tongue. These more nationalistic Ethiopians sometimes take these steps in order to increase their access to state power, both in the Menelik era and into the current day. There are also many Ethiopians who were forcibly Habeshized or Amharized under the law of Haile Selassie. Habeshization or Amharization is most strongly characterized by the adoption of Orthodox Christianity and the use of Semitic languages, particularly Amharic and Tigrigna (Markakis 1989; Bulcha 1997; Hassen 2002; Gebrewold 2009). Individuals who convert to Orthodox Christianity, like other major religions, will change their names or name their children with Habesha or Christian names. However, there is also a history of Oromo military leaders and politicians who changed their names in order to further their careers, such as Tadesse Biru (Keller 1995:627). All Amhara and Tigrayan people are Habesha, and we can understand the Abyssinian Empire as a Habesha empire. Even today there are legal and cultural pressures that constrain expressions of Oromo identity such as the perpetuation of Orthodox Christianity as a national religion. While individually these religious and linguistic characteristics seem fairly innocuous, it is the way they have been used that threatens Oromo survival in the Ethiopian state, as this thesis project details at length. Understanding Amhara, Tigrayan, and Habesha dominance throughout history necessitates unpacking the unifying traits and qualities that connected these empires, most notably the particular brand of nationalistic Orthodox Christianity that motivated and justified their violence.

A belief in the superior nature of Orthodox Christianity was a driving force behind Abyssinian practices of colonization during the late 1880s, including the state's active role in the slave market, which were partially justified by their views on nonChristians (Tolossa 1997; Jalata 2009; Hassen 2012). As a form of religious nationalism, 
this ideological underpinning used religion to justify the creation of a new nation, often through violent means. Habesha people also believed themselves to be more akin to "civilized Caucasian," while the southerners were "primitive Blacks" (Yates 2013:86). The Abyssinians considered the groups of people southern to them, the majority of who practiced land-based or pagan religions at the time of colonization, to be immoral savages (Hassen 2012:21). Orthodox Christianity was one of the only pathways to power for an Oromo, or other Southerner. Promoting themselves as an island of Christianity within the growing threat of Islam was a tactical and rhetorical strategy employed successfully by the Abyssinian Empire throughout the reign of Haile Selassie in the mid-1900s, as well as the Axumite and Shoan kingdoms before it (Jalata 2009). This increased their international access and encouraged closer relations with Christian nations and former empires, including support from the British and French during conflicts along each of their borders (Jalata 2009:192; Reid 2011:141). Furthermore, cultural symbols like the "romantic image" of Queen of Sheba, and the fair skinned and European-adjacent Ethiopians would remain the model for generations to come (Tibebu 1996:417).

Overview of Ethiopia-Oromo Relations

As a post-empire, Ethiopia has consistently failed to treat the Oromo people with respect and dignity. The Abyssinian model for state development did not leave room for alternative epistemologies, lifeways, or societies. The Oromo traditionally practiced a land-based religion called Waaqeeffanna, were governed by the Gadaa ruling system, and communicated using the language Afan Oromo (Knutsson 1963; Keller 1995). The rise of the Abyssinian Empire challenged each of these core facets of Oromo life, including 
their right to the land itself. By the height of Emperor Haile Selassie's rule in the 1950s, the Oromo had been colonized into the Ethiopian state, and their religion, language, freedom, and cultural practices had all been suppressed or outlawed. This time period, from the late 1880 s until state consolidation, is best described as colonization and the creation of a settler colony. The colonizing tactics of the Emperors are discussed at length in Chapter IV. Settler colonialism differs from other forms of colonialism in that it is driven by the "pursuit of land, not just labor or resources," and it leads to the creation of a "persistent societal structure" and the "reconfiguring of Indigenous land into settler property" (Rowe and Tuck 2017:4). The creation of Ethiopia, and particularly its treatment of Indigenous peoples, bears many similarities to that of the United States and other settler colonies.

Historically, Emperor Selassie engaged in systematic oppression against the Oromo, justified by the promotion of a new Habesha nationalism and a citizenry of Amharic-speaking Orthodox Christians (Gebissa 2002; Mains 2004). Under his rule Ethiopian geography was rewritten and reshaped to fit a settler state model (Hassen 2002). The Dergue, a fascist regime whose rule is described as the "Red Terror," overthrew the Emperor in 1974 and began a period of extreme nation-wide repression (Joireman 1997). This authoritarian rule led to the growth of ethnic-based revolutionary liberation fronts, the most prominent of which, the Tigrayan People's Liberation Front, was given primary credit for overthrowing the Dergue in 1991 (Tolossa 1997; Jalata 2003). After a brief transition period, the Ethiopian People's Revolutionary Democratic Front came to power in 1994, describing itself as a coalition government that would break with past discriminations and reform the Ethiopian state under an ethnic federal 
system. Each ethnic group was proclaimed to have equal rights to free speech, cultural practices, and (equal) representation in government, and the country was divided into regions and city-states based on historic ethnic territories (Yusuf 2009). Though promising in theory, this system in many ways served to enforce historic inequities.

Throughout each regime, the governing tactics of the Ethiopian state have been primarily responsible for the growth and evolution of a vocal Oromo diaspora. While state violence, ethnic conflicts along the borders, and natural disasters such as drought have all contributed to upsurges and growth in the Ethiopian refugee population, the unique tactics used in each era have increased the number of exiles. Menelik's prominence in the slave market was directly responsible for the first written records of the Oromo people living outside of Ethiopia, liberated and living in Europe in the late $19^{\text {th }}$ century (Edwards 1982; Sibilu and Barnes 2015). Emperor Selassie's targeting of Oromo culture strengthened these communities, who began to spread the language and voice of the Oromo internationally (Keller 1995). While the Dergue's attacks on intellectuals had an immediate impact on the Oromo people nationally, they also led to a flourishing of Oromo culture overseas, as college students and professionals fled (Ruda 1993). In addition, the religious aspects of Oromumma, and the intimacy with which the Oromo people view their homeland, referring to Oromiya as Haadhi, or mother, made their forced entry into the diaspora more violent. Leaving behind family, tradition, and society further exacerbates this separation. Oromumma as a belief system sees attacks against the land as attacks against its own national body (Ruda 1993). This way of interacting with the world has remained influential despite religious conversion; Oromos maintain a deep and vocal intimacy with their homeland. The response to this violence 
has thus far largely resulted in a diaspora whose level of political activity is reflexive of cultural identity, as Oromos are actively engaged with and haunted by the home they left (Matsuoka and Sorenson 2001).

According to a 2007 census report, over 33\% of the current Ethiopian population identifies as Oromo, and their homeland is the largest of the regional states (Central Statistical Agency 2007). Some scholars have suggested that the Ethiopian government's history of selective reporting may mean that the actual numbers are in fact much higher (Bulcha 2002; Zahorik 2011; Jalata 2015). There is also little motivation for careful work or accountability in these government positions. Government officials who are placed in Oromiya are not trained on language or culture, and typically use these stations as a way to gain higher status as a politician (Ruda 1993:249; personal observation).

In the diaspora, identifying and mapping Oromo populations requires overcoming a number of obstacles. Certain political and social structures make the identification of Oromo populations difficult, as attempted in the work of Gow 2001 and Virtanen 2009. The way incoming states classify migrants, based on nationality rather than ethnicity, is one major challenge (Deffa 2016:354). Bulcha makes the claim that over 500,000 Oromos fled Ethiopia during the Dergue regime, from 1974-1991, but has no clear estimate for the years following (2002:16). It has been suggested that the EPRDF has led to displacement and forced migration of Oromo people across the Horn of Africa and beyond, but the focus has been on the experience of specific groups, rather than the total population size (Hassen 2002; Feyissa and Lawrence 2014). There are some identifiable Oromo diaspora populations in the United States, but they also tend to correspond with diaspora groups from other Horn countries such as Eritrea and Somalia (Deffa 2016; 
Dugo 2016). Even with the lack of reliable data, what is known of the lived reality of the Oromo and their historic exclusion from power is troubling.

The Ethiopian state has yet to produce a system of governance that is equal, let alone equitable. Instead, the ruling party won the 2015 election with an astounding $100 \%$ of the vote, members of a minority ethnic group occupy the majority of political and military leadership positions, and there has been a steady stream of state-sponsored violence targeting Oromo institutions and people since 2014 (Horne 2015; Africa Research Bulletin 2016; Gebissa 2017). The violence is in many ways cyclical: the more Oromo students and civilians are killed, the more the people protest, and each wave of protests brings with it more death. Existing within this system means a constant defense against these relenting attacks, and pressure on the resiliency of Oromumma, or Oromoness. It has also had an influence on the size and shape of the Oromo diaspora, evidenced by their growing international voice. The resignation of Prime Minister Hailemariam Desalegn in early 2018, and the rise to power of Dr. Abiy Ahmed, an ethnic Oromo, appeared to be the turning point in Ethiopia-Oromo relations. The symbolism itself has been widely discussed, similar to the impact of the election of Barack Obama in 2008 relations (Mohammed, Lemma, Giorgis, Nega, Shide 2018). Not all Oromos are impressed by his heritage, though, and it will be decisions such as the scheduling of the coming elections and census, his management of the increasing numbers of Internally Displaced Peoples, and other challenges that truly determine his legacy in Oromiya. Despite the potential power of Dr. Abiy, as he is affectionately known, a more thorough elucidation of the ways identity has been politicized for Ethiopian people, both domestically and within the diaspora, is necessary to make solid claims about his impact. 
Furthermore, fully conceptualizing the condition of Oromumma within this system is key to resisting and repairing historical damage. 




Figure 1.1: Ethiopia Administrative Map 2017 Map has been rotated 90 degrees counterclockwise for better visibility. Oromia is indicated in a yellow-green color. 


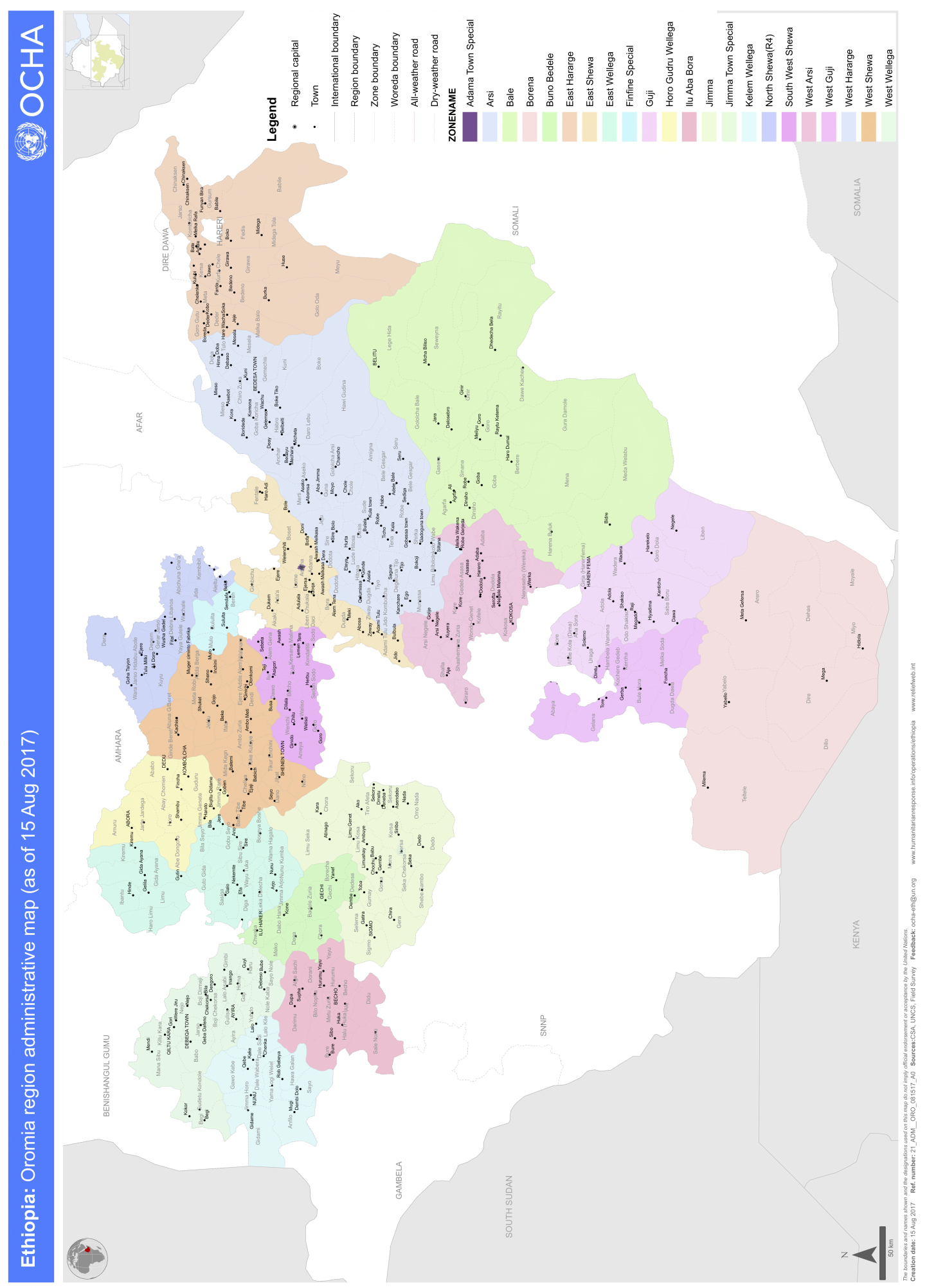

Figure 1.2: Oromiya Administrative Map 2017 Map has been rotated 90 degrees counterclockwise for better visibility. 


\section{CHAPTER II: THEORETICAL FRAMEWORK}

\section{Politicization of Identity as a Tool for Oppression and Resistance}

In the process of state formation after colonialism, indigenous, enslaved, and other marginalized peoples were forcibly integrated into the new national law and order. In order to understand the way group identities are altered in post-colonial states, this section will explicate an analytical framework based on the concept of political identities, as drawn from the works of Mamdani. In nation states that emerged from the aftermath of colonial empires, minority groups typically maintained systems of oppression and secured their power through the legal subjugation of other peoples (Mamdani 1996:73). This type of reform incorporated communities and ethnic groups into the state and reproduced their identities along the lines of a "state-enforced customary order," transforming them from cultural to political groups (Mamdani 1996:17). The Oromo people share a common language, set of sacred meanings, and historical inheritance. Mamdani calls this their cultural identity. After their colonization by the Abyssinian Empire, the Oromo were subject to legalized oppression that systematically targeted their way of life, transforming Oromo into a political identity. Restated, although Afan Oromo-speaking practitioners of Waaqeeffanna are culturally Oromo, the nature of their relationship with the Ethiopian state determines whether they are politically Oromo. Oromo people living in the Ethiopian state function under an ethnic federal system in which their access to political power and rights is filtered through their ethnic identity; they are always politically Oromo. Mamdani describes this quality as the "resolve to forge a common future under a single political roof" (2001b:661). This "roof" is the shared identity under which people connect, organize, and resist. For members of the 
diaspora, their relationship to the political project of the Oromo is altered and influenced by their relationship to their new nation, and its own political constructs. Political identities that emerged in the post-colonial transition are still characterized by their position in what Byrd calls the "transit of empire" (2011).

Byrd uses the empire to describe the way colonial projects and systems "brought the world, its peoples, and their own structures of power and hegemony to indigenous lands" causing damage that has remained long colonialism's formal end (2011:xxvi). Analyzing the indigenous experience through the lens of the "transit of empire" is a way of acknowledging that there is a "difference between [a culture that is] recovered and never having lost in the first place" (Byrd 2011:xi). Identifying political identities that have emerged out of the transit of empire is a way of reading and interpreting the logics of colonialism through their continuing cultural, intellectual, and political harm. Similar to Mamdani, Byrd describes the way that politicization delineates subjected categories of people, forcing them to inhabit a marginalized legal space that secures minority dominance "through time, property, and notions of self" (2011:xxiii). In Ethiopia, the ethnic federalist system has worked to dichotomize, restrict, or falsely conflate groups into stagnant categories. As a settler colony, Ethiopia has built discrimination into the foundation of its state and refused to reconcile its historic violence.

An analysis that uses the transit of empire to guide understandings of politicization in the post-colonial era thus emphasizes to the imbrication of colonial constructs into current forms of governance. It does not let the post- signify an ending; rather it refers to what paperson describes as the post+colonial, recognizing that "colonization is not over... yet we act, dream, and live in ways that are not limited to its 
horizons" (2010:8). paperson further notes that the use of the post + colonial is part of a project of recovering and uncovering the body of the marginalized homeland "within, despite, and because of the colonial exercise" (2010:7). Overall, I understand the process of politicization to be a system that maintains minority power and transits the empire into the post-colony. For the Oromo, politicization has led to disparate shares of power, increased tension with groups like the Somali with whom they share a number of cultural commonalities, and legally justified discrimination.

\section{Politicization as a means of analysis}

Given the extreme potential for political violence in post-colonial nations, as is true of the Oromo context, I develop a framework that seeks to understand the way institutions and state bodies oppressively politicize identities, and simultaneously how oppressed or marginalized peoples can reclaim or revitalize their group identity as a form of political resistance. I understand the political tactics employed by the Ethiopian state to be an oppressive force, working dialectically with the forces of resistance, political acts through which groups like the Oromo seek to reclaim sovereignty and work towards justice. The model also follows the work of Iris Marion Young and her "five faces of oppression," a concept meant to elucidate the multidimensional way that oppression attacks marginalized peoples (2011). The final framework used here goes beyond Young to incorporate more explicitly global (Mbembé 2003) and anticolonial (Fanon 1986; Vizenor 2009) literature, as well as expanding on some of the Marxist (Wright 1997) concepts used by Young. 
The thick center line in Figure 2 below represents the division between oppression and resistance. The parts of this model that represent the domains where tactics of oppression and resistance play out are noted in bold italic text. The terms that are italicized represent the motivating ideologies that characterize each of the subsequent actions. Although there are many theoretical contributions to this model and the terms used, discussed at length below, the model itself and the connections between these theories represent my unique contribution.

\section{Figure 2: Analytical Model}

\begin{tabular}{|c|c|c|c|c|}
\hline \multirow[b]{2}{*}{ Oppression } & \multirow[b]{2}{*}{ Violence } & Economic & State & Civil \\
\hline & & $\begin{array}{c}\text { Exploitation } \\
\text { Marginalization }\end{array}$ & $\begin{array}{l}\text { Necropower } \\
\text { Subordination }\end{array}$ & $\begin{array}{c}\text { Cultural Imperialism } \\
\text { Other-ing }\end{array}$ \\
\hline \multirow[t]{2}{*}{ Resistance } & \multirow[t]{2}{*}{ Healing } & $\begin{array}{c}\text { Mobilization } \\
\text { Decommodification } \\
\text { Transformation }\end{array}$ & $\begin{array}{l}\text { Organization } \\
\text { Sovereignty }\end{array}$ & $\begin{array}{l}\text { Reclaiming } \\
\text { Survivance }\end{array}$ \\
\hline & & & Decolonization & \\
\hline
\end{tabular}

\section{Motivating Ideologies}

As stated earlier, a group whose potential for existence has been restrictively shaped by the state becomes politicized (Mamdani 2001a). Political resistance takes place when oppressed groups work against oppressive forces to revive, reclaim, and deny the power of their marginalization. A reclaimed identity and resistance movement uses a praxis of healing to create a reconstructed national body or reimagined sovereignty that is inclusive of their lived experiences and denounces systematic segregation and oppression. This reclaiming builds the base for an opposition to the ideology of violence that characterizes both colonial and post-colonial systems. These motivating ideologies 
are what normalize, support, or legitimize the actions of oppressive and resistancebased movements, respectively.

\section{Violence}

The key motivating ideology of an oppressive political force is that of violence. An ideology of violence differs from violence in practice in that the ultimate goal of the former in any relationship is destruction and domination. Blackhawk describes violence as both subject and method, noting that violence and relations to violence had a major impact on the history of Native peoples (2006:7). It is also important to note that not all acts of violence entail an ideology of violence, as is the case in violent acts of self defense borne of desperation, as the slave killing their master. An ideology of violence is necessary for the implementation of an oppressive regime, and thus it was violence which overwhelmingly defined colonial and indigenous relationships, wedding the groups together through this mutilation (Blackhawk 2006). By inflicting extreme violences, the colonial forces themselves were altered, demarcated by this violent trait. Blackhawk notes that "one of the most lasting legacies of conquest" is the way in which it has "erased violence and colonialism from discussions" about the status of modern nation states (2006:13). This absence of critical analysis of legacies of historical violence in post-colonial countries is in many ways a consequence of its overwhelming presence; violence played a part in determining each aspect of colonial and post-colonial relations, and thus identifying its role in each instance can be challenging. Violent ideologies see erasure and destruction as the only option through which to accomplish their ends. 
Sarah Deer, in writing about the rape of indigenous bodies, subjects, and lives, notes that both rape and colonial violence "share a common history and language of dehumanization, power, dominance, and conquest" (2015:51). This "language" is a way of justifying harm by reframing horrific acts as a necessary part of expanding and achieving the aims of the empire. Furthermore, the extensive reach of this violence, and the seeds of shame and fear that it sows, become embedded into norms of behavior, traumatizing community psyches over the course of generations (2015:21). Violence as an ideological underpinning to a set of practices can "manifest as systemic yet invisible structures that accomplish the trauma of violence on a large scale" (2015:xvii). These definitions work together to create an ideology of violence that characterizes each aspect of oppressive politicization.

\section{Healing}

As puzzling, ubiquitous, and permeating as violence is, healing can be even more difficult to explicate. Accountability, reconciliation, and moves towards decolonization have received less study than violence itself, and too often liberation attempts simply replace oppressive ideologies with alternative forms of violence. In the Ethiopian context, Eritrea is the most salient example; long after Eritrea's expulsion of invading Ethiopian forces in 2000, the people still suffer with fear, starvation, and oppression (Reid 2011; Weldemichael 2013). However, in order to truly counteract and resist structures of violence, epistemologies of healing must be given this same careful analysis and prioritization. Smith describes the process of resistance as a "recovery of ourselves," noting that by taking back the institutions through which imperialism is implemented and 
made possible, we contribute to the struggle for self-determination (paraphrased 2012:8). I build my epistemology of healing through a combination of several scholars who have lived under and fought against colonial empires and post-colonial settler states across the globe.

Throughout her description of the decolonizing project, Smith identifies societal repair as a central priority; recovery and healing are both key parts of the indigenous research model she constructs (2012:121). Several of Smith's recommendations are particularly salient here as part of the act of healing: the need for claiming and reclaiming indigenous culture, reframing indigenous narratives, and re-membering (2012:144-155). The latter term warrants some unpacking, as it is a unique way of understanding the healing potential of undoing the settler colonial project. Re-membering is both a reliving and strengthening of community memories, and a way of "connecting bodies with place and experience" (Smith 2012:147). This type of collective and intentional remembering acts to legitimize collective group trauma, in order that it may be processed and dealt with. Byrd describes this process as mnemonic methods, placing disparate views into conversation with the goal of strengthening community knowledge (2011:xii). Healing involves acknowledging the real historic relationships of violence between peoples, then working to address and redress these specific harms.

Understanding healing as a response and challenge to forces of oppressive violence is further developed by the work of Saidiya Hartman and her discussion of the resistance politics of the enslaved. Hartman notes that no strategies of domination are able to "exhaust all possibilities of intervention, resistance, or transformation" despite their multilateral tactics (1997:56). Although violence seeks to deny it, practices of 
healing have always existed, unconquerable. Thus our exploration of healing resistance is "less concerned with issues of heroic action... than with the inadvertent, contingent, and submerged forms of contestation" that make up everyday life (1997:62). Restated, healing and resisting extreme oppressive violence is more than enacting grand legal policies and state-defined modes of justice; instead it is with the multitude of small resistances that we can best create decolonizing strategies. Fugitive justice as a form of healing exists "between the necessity of legal remedy and the impossibility of redress" by the state (Best and Hartman 2005:3). In the "interval between the destruction of the old world and the awaited hour of deliverance," fugitive justice allows for the processing of grief and grievance and the denial of violence (Best and Hartman 2005:3). While understanding that formal apologies and reparations may never come, fugitive justice is used as a way to heal, and to reframe the possibilities of what healing is. As forces that denies state power without being of the state, fugitive justice, resistance, and the practices of healing are politicizing mechanisms with the most potential to decolonize the oppressive state.

\section{Domains of Oppression/Resistance}

\section{Economic}

Economic oppression turns the practices, homelands, and bodies of a nation into instruments that generate wealth for the state, and allow dominant groups to secure their interests through state systems. A group whose identity is being politicized in an oppressive direction will face exploitation and marginalization justified by their group traits, practices, or worldviews. Theorist Erik Olin Wright separates exploitation and 
what I name marginalization by explicating the logic of two different abhorrent ideologies: the only good X (ethnic group) is a dead X, and the only good worker is a dead worker. The logic of the first statement, when applied to a class or political group, represents a system where the elites have no use for the subordinate people; they are sent to the margins of power, and thus lose economic access. Wright goes further to argue that marginalization as a practice suggests that "the oppressors would be happy if the oppressed simply disappeared" (1997:11). Iris Marion Young sees marginalization as building the "growing class of people permanently confined to lives of social marginality," because the "system of labor cannot or will not use" them (2011:49).

The example of the worker does not fit the logic of marginalization, but shares its violence. An exploitative reorganization would likely note that "the only good worker is an obedient and conscientious worker" who can be oppressed in the hierarchy of the market to feed the elites (Wright 1997:11). Wright understands an exploitative system as one in which the material welfare of the elite class "causally depends on the material deprivation" of the marginalized, relations are demarcated by "the asymmetrical exclusion of the exploited," and the mechanism by which this is accomplished involves "appropriation of the fruits of labor" (1997:10). Young's analysis follows this same line of thinking, but adds that exploitation "enacts a structural relation between social groups" within which the results of effort are appropriated to reproduce systems of inequality (2011:46). In both marginalizing and exploitative economic practices there is a systematic oppression of group agency, an oppressive politicization. Although exploitation is built on the appropriation and dispossession of materials, marginalized peoples are typically left out of the equation entirely. In the case of autochthonous or 
Indigenous nations, their land is considered inherently dispossessed because they are so marginal as to not exist in discourse. This dispossession is often a precursor to the commodification of Indigenous lands and bodies. For the Oromo, their issues are only given attention or respect when they are tied into the economic prosperity of the nation; I understand this devaluing to be a form of commodification (used interchangeably here with commoditization).

Economic oppression was central to the original accomplishments of colonialism and is still present in the post-colonial state. Therefore, as Fanon notes, in order to properly decolonize or "disalienate," we must first recognize the double process of economic and socially produced inferiorities (1986:13). Resisting economic oppression means taking actions that undermine neoliberal, commodifying, and extractive state tactics; successful resistance is thus a way for exploited and marginalized peoples to organize both against and outside the formal labor market. Harvey notes that a "disposable workforce inevitably turns to other institutional forms through which to construct social solidarities" when the marginalization of the market-based economy becomes untenable (2005:171). Within the oppressive system, social relationships and identities are defined by their ability to contribute to the market and their social class; they are commoditized. Thus, these "other forms" are the space where decolonization and decommodification take place, and "fill the void left behind as... other institutional forms are actively dismantled" (Harvey 2005:171).

Creating strategies that allow for the development of relationships and institutions outside of the oppressive state system is essential to decommodifying and resisting these tactics. Under Vail's definition, decommodification is “any political, social, or cultural 
process that reduces the scope and influence of the market" (2010:313). Understanding that control over the market is often a tool used to maintain elite power, it is important to further note that practices of economic resistance may also combine markets with "other diverse non-market methods of organizing economic activity" in order to mitigate the harm of economic hierarchies, while taking advantage of any potential benefits (Vail 2010:317). These combinations "fill the void" referenced by Harvey, cited above, in that they use economic processes to facilitate solidarity and increase social protections $(2005: 171)$.

The Indigenous Oromo homeland was expropriated and turned into coffee plantations that took advantage of Oromo knowledge and skills for profit, without returning the benefits of this to Oromo communities; this can be understood as an act of exploitative commodification (Hassen 2002:21). Thus, decommodification would include Oromo people taking control of their homeland in a way that sees Oromo land as a vital part of the community and its life rather than exploiting its profit potential. On a smaller scale, I personally witnessed Oromo business people who took advantage of the informal nature of the local economy to set higher prices for those who spoke Amharic instead of Afan Oromo at the market. These exchanges demonstrate a refusal to let the stateenforced values that have seeped from the market into social life continue to dominate. These actions are a type of decommodification because they show that the solidarity of the marginalized many has the potential to interrupt the elite's control over the market. While the scope and impact of decommodification can be difficult to track and identify from the outside, the core ideology of these practices is also seen in more organized resistance. 
Gene Sharp describes forms of economic resistance at length in his guide to nonviolent struggle (2013). Some of the forms of economic resistance discussed by Sharp include boycotts and a variety of strikes that target laws, institutions, and elite classes. $\mathrm{He}$ defines boycotts here as a "refusal to buy, sell, handle, or distribute specific goods and services" (2013:31). Strikes are similarly "designed to enact pressure" on the oppressive economic structure, and thus force open the possibility of alternative market forms (2013:37). Stay-at-home strikes are a particular example of economic noncooperation that establishes new behaviors, relationships, or policies; if individuals are to be punished for the act of existence, they will show what their absence means to the economic function of a country (2013:43). This tactic was used successfully by the Oromo people on several occasions. Refusing to cooperate with the boundaries of market relationships allows for marginalized people to decommodify the social structures created by greedy states.

\section{Political}

A group whose identity is being politicized at the hands of the state faces legal, systematic, and institutional oppression. During state creation after colonialism's end, determinations of citizenship, subjecthood, and the right to exist in certain land spaces were highly politicized and often violent processes (Mamdani 1996; Byrd 2011). Furthermore, by following the aberration that allows oppressive political forces to feel justified using genocidal ends, one is better able to understand the potential for resistance against them. Mamdani's extended analysis of indirect rule provides insight into the more explicitly legal aspect of political politicization. He notes that the controlling mindset of 
the post-colonial state actor was that "if popular resistance could not be smashed frontally it would have to be fragmented through reform" (1996:90). This included the creation of narrowly defined intermediary groups, usually a numerical minority, who ruled majority populations by using the authority of their hierarchal legal system to maintain order and retain privileges denied to the majority. Although ultimately dependent on violence, this type of politicization relied primarily on forms of law that were presented as integral to the greater goals of the state (Mamdani 2001a:654). Postcolonial states that built themselves on a structure of indirect rule used legal means to politicize identities and maintain control.

Using the concept of necropolitics, Mbembé describes a state whose violent ideologies and tactics have led to the employment of a legally sanctioned death sentence as a means of achieving state ends. States who have necropower (similarly described as necropolitical regimes or states) can be understood as possessing a monopoly over the control of life and death, a sort of super-sovereignty that denies the possibility of corporeal agency. Stated otherwise, there is no guarantee that the life of the marginalized, of those deemed "Other," will not end at any moment. Rather, the "perception of the existence of the Other as an attempt on my life, as a mortal threat or absolute danger whose biophysical elimination would strengthen my potential to life and security... is one of the many imaginaries of sovereignty" in a necropowerful state (Mbembé 2003:18).

Understood as a governing tactic, necropolitics are the expression of a state that has evolved into a terror formation and thus discriminates along the boundaries of who should live or die (2003:22). This is key to understanding both colonization and postcolonial state building because of the way state and political powers like the law were 
used to justify and actualize mass death. Mbembé uses necropower to refer to "figures of sovereignty whose central project... [is] the generalized instrumentalization of human existence and the material destruction of human bodies" (2003:14). In both the metaphoric/ ideological and the physical/ infrastructural construction of a nation, he writes the labor and the bodies of the masses are kept under tight control by the ruling elites. Colonized subjects are "given a status that enshrined their despoilment" (Mbembé 2003:25). In the Ethiopian example, the government's decisions to enact a "State of Emergency" in response to nonviolent Oromo protests in 2010 s were a way to justify the terror regime of oppression. Most egregiously in 2016 following the "Irreecha Massacre," after dozens of Oromo people were killed by government forces while celebrating a religious holiday, the government responded by enacting a State of Emergency, shutting down internet and mobile communications and closing roads. Under the cloak of a legally and politically legitimate darkness, elite forces were able to use extreme ends to reinstate order. Activating the necropowerful potential of the state is the whim of the elite and the constant lurking fear of the marginalized.

Colonial and post-colonial ways of thinking place imaginary restrictions on the possibilities for resisting these vastly encompassing state structures. However, scholars like Byrd remind us that sovereignty is "unconquered and unconquerable" (2011:xvi). Restated, if we take the modern nation state to be the norm, any other organizing political structure is viewed as "other," alternative, or secondary. But oppressed and marginalized people have lived their lives on the "other" side of justice and the law; they function and operate according to structures that colonial powers have not been able to permeate. These forms of organization and sovereignty exist outside of the formal state structures, 
in the shadows, the undercommons, and the fourth world (Vizenor 2009; Harney and Moten 2013; paperson 2017). Understanding sovereignty as a mode of resistance therefore means keeping in mind the ways that "sovereignty is found... through relation, kinship, and intimacy" just as much as it is in democratic and legal decisions (Byrd 2011:xvi). Analyzing sovereignty s a means of resistance outside of state structures sheds light on the potential for organization and transformation outside of the post-colonial national organization.

Mbembé describes sovereignty as "a two-fold process of self-institution and selflimitation" that eventually demonstrates "society's capacity for self-creation" (2003:13). With the ability to institutionalize their chosen mode of organization, a nation is demonstrating its sovereign status. Taking as a starting point the legitimacy of groups and nations that do not have statehood, Deer sees sovereignty as a crucial way of addressing abusive power. They note that sovereignty can take both a political and personal form, but clarify that in both senses "self-determination necessarily implies the development of concrete solutions to problems" (2015:xv). This sovereignty is a sovereignty of the soul, and operates outside of formal state-recognized limits. Furthermore, in creating the "legal framework of the soul," Deer explains that the soul can be thought of as the "deep, fundamental aspects of identity" that are most damaged by state violence (2015:xvi). By asserting a sovereignty for the soul, oppressed groups subvert nation-state forms to build a sovereignty that fully addresses the damage of colonial violence. Holistically one can view resistance sovereignty as a form of self-determination that moves around and despite neocolonial nation-states. Sovereignty is when a group asserts its voice, and 
demands the legitimization of its right to do so. Organization is evidenced by structures, gatherings, groups, and more formal non-governmental groups (Deer 2015).

\section{Cultural}

Elites in colonial and post-colonial societies manufactured cultural norms and policies to dominate subordinate populations. Cultural imperialism is one of the more easily obscured forms of oppression. Whereas the other oppressive forces have fairly explicit legal or economic impacts, the process of norm creation through which cultural imperialism is implemented often obfuscates its impact. Young sees cultural imperialism as a system of norms that render a group's experience invisible, entrench it with stereotypes, or relegate it to a position of "Other" within society (2011:56). The standard of the empire is designed to limit what is right and what is possible in the cultural domain. Groups that are imperialized by these norms thus face "paradoxical oppressions;" either they are forgotten entirely, "stamped with an essence" that defines them as remarkable or deviant, or boxed in by stereotypes that "so permeate the society that they are not noticed as contestable" (Young 2011:55). These boundaries are placed on behavior, actions, ways of knowing, worldviews; every aspect of existence. As a form of oppression, cultural imperialism compounds the other forms and expands their reach.

A useful framework for looking at the Oromo in the context of a racialized settler state is the concept of "controlling images," as developed by Collins (2000:69). These archetypes define the bounds of Black women's existence in civil society. In the Ethiopian example, the Habesha as an ideal type left little room for Oromo assertions of self to be taken as legitimate or respected. The Other-ing project of the empire works 
diligently to push the customs, cultures, and ideologies of indigenous peoples into the realm of the savage, the outside, and the dangerous. It works with state systems to render people kill-able, it interacts with economic systems to make identities un-hirable, and it suppresses tradition from all sides. As Hill Collins notes, "when faced with this structural injustice... many Black women have insisted on our right to define our own reality, establish our own identities, and name our history" (2000:72). Without this insistence, the Other-ing and controlling nature of the colonial settler state would overwhelm authentic narratives. Further challenging the ability of marginalized people to express their authentic identity is the state's imposition of identity formations under the law, such as with Ethiopia's ethnic federal system.

Byrd describes how cultural imperialism creates "cultural productions and political movements" that are born of the "violences and genocides of colonization," and bear their wounds (2011:xii). These new identities and ways of knowing thus create new modes of oppression, and an increasingly marginalized population as a result. This "cacophony" creates false subjecthoods and roles that permit indigenous experience only through a corrupted and coopted version, suppressing a priori indigenous existence for an imperialized norm that can be shuffled back into the cacophony of the neocolony (Byrd 2011:xviii). In a violent political system, this cacophony serves to obscure the original violence: the creation of the settler colonial state on top of and despite the wishes of the colonized masses. This cacophony further silences the voices of the Oromo, as their cries for help are relocated as local, political issues, rather than as a set of holistic violences against them as a people. 
Resistance to cultural and civil oppression thus takes the form of survivance, a term created by Gerald Vizenor. Survivance is described in the simplest terms as a hybrid between survival and resistance; the act of survival itself being a way to challenge the oppressive forces who continue to try to erase you (2009). bell hooks frames the sharing of marginalized voices as "an act of resistance" undertaken by "those who understand the power of voice as gesture of rebellion and resistance" (2015:36). Asserting authentic, resilient group identity speaks with a "liberatory voice," a "way of speaking that is no longer determined by one's status as object- as oppressed being" and instead counteracts misappropriation and domination (2015:38). By speaking up and speaking out, denying attempts to oppress and silence, marginalized people resist and reclaim their culture. The liberatory potential of the voices of the oppressed is the same radical potential that Vizenor points to with the term survivance: oppressed and marginalized people who speak are asserting their right to thrive.

For oppressed people, survivance, once awakened, emerges as an "active, creative force" that refuses any tendency to sink into "tragic victimry" (Vizenor 2009:24). Vizenor further notes that "Native survivance is an active sense of presence over absence, deracination, and oblivion; survivance is the continuance of stories, not a mere reaction" (2009:85). This latter point is essential to the ance of survivance; without the conscious decision of the indigenous national body to thrive, there is no potential for life as resistance. Instead oppression and trauma too often become normalized, a reaction to the penetrative presence of violent conditions. Vizenor describes "active resistance and repudiation of dominance" in part as the assertion of indigenous peoples' authentic presence in the face of appropriation and silencing (2009:88). Survivance as a way of 
refuting the imperial culture and cacophony of the Ethiopian empire is identifiable every time Waaqa, the Oromo god, is praised, when the city of Finfinnee is called by her name, and in each instance that Oromo people continue to exist, despite.

\section{Intersections Between Domains}

I have set up an analytical distinction between three domains of politicization of subordinate identities not to suggest that they act independently of each other. Rather, forms of oppression often lead to and allow for additional violence. There are a few institutions and tactics that bear further explanation here for their unique abilities to share technologies, and the reach of their harm. Most prescient in the modern post-colonial context is the neoliberal state model, which reimagines social and legal relationships along the priorities of the markets. I draw my understanding of neoliberalism from the Southern perspective brought forth by Connell and Dados (2014:124). Neoliberalism can be understood as a development strategy that reorients the economy to international trade, uses economic growth as a way to demonstrate state legitimacy, and is characterized by de-regulation and privatization (Connell and Dados 2014:122). Neoliberal agendas redesign a society around the needs of the market and elevate market values, and the interests of those of elites who most benefit, above all others (Connell and Dados 2014:118). Their analysis describes neoliberalism as a "re-weaving of worldwide economic and social relationships," within which trade, agriculture, and industry are only pieces (2014:124). The difference of this "Southern" read on neoliberalism is its identification of neoliberal thinking as a strategy of oppression used similarly by postempires, rather than limited to Northern post-colonial powers. 
Education as a means of oppression and resistance also serves to confound the categories above for its direct political, economic, and cultural implications. These politicizing processes can be found in the subject matter, the perception of education, the means of testing, and the barriers to access, including cultural, infrastructural, and physical. Freire's Pedagogy of the Oppressed provides a model for what an educational praxis of resistance looks like, and embedded in his argument is the idea that education is a tool for counteracting ideological and political violence (2000). As a political strategy, implementing differential access to education has both immediate and long-term impacts on the resistance potential of marginalized peoples; however, the course content itself also reflects and reiterates oppressive ideologies in a way that is not always interrogated. Mamdani provides an example of history classes in post-genocide Rwandan public schools: "because there is no agreement on what should be taught as history" after the mass violence, all teaching of the subject had stopped (2001b:267). Mamdani therefore calls for a process of contextualizing the truth, which can be undertaken only with the support of a just and equitable historic reconciliation (2001b:268). Understanding education as a project with serious cultural consequences is key to recognizing its force as a state power.

As paperson notes, oftentimes the "dislocation of people into subordinated positions [is] part of the modern school system, rather than an accident of discrimination" (2010:9). Going further, they explicate the dialectic concepts of "imperial education" and "colonial schooling;" the former is "training for inclusion into the metropole," whereas the latter is merely a "form of management" (2010:24). Inclusion into the metropole, given that the metropolitan center is one of a market-driven settler state, is an economic 
undertaking, whereas management through education is a more explicitly political aim. Through these constructs we can see how the educational project and the institutions that undertake it serve to confound and overlap with economic, political, and cultural forms of oppression and resistance. For the primary purpose of this research project, education is understood as a state-implemented project that serves to subordinate or provides opportunities to organize.

Land confounds the boundaries between the domains of legal, economic, and cultural politicization. The way land is viewed and interacted with differs dramatically between peoples, both within and alongside the settler/ native binary. That land should "produce" at all is the typical imperialist view, whereas many indigenous peoples see the land as a relative or part of a sacred kinship connection, as is the case with the Oromo (Ruda 1993). Even before the rise of colonialism, Polanyi notes that "land, the pivotal element in the feudal order, was the basis" for all other aspects of societal organization (1944:69). As societies transitioned into colonial and post-colonial models, these relationships were reframed. Strategic underdevelopment as a concept provides an example of the manipulative tactics of the settler colonial state in regards to land. Gunder Frank describes strategic underdevelopment as the intentional distribution or withholding of resources across the empire (1969:77). These resources include necessary infrastructure such as roads, schools, and hospitals. By first occupying the land, cutting off indigenous lifeways and technologies, and then refusing access to modern resources, settler colonists like the Abyssinians turned the land from kin, to product, to source of alienation. This is legally justified, economically impactful, and harmful to native peoples and to a priori culture. 
As a politicizing force, losing access to indigenous land has long-term negative impacts on communities who for generations struggle to process and comprehend kinships and tradition within newly enforced colonial boundaries (Byrd 2011). Polanyi further notes that the moment labor, "the human beings themselves of which every society consists," and land, "the natural surroundings in which it exists" are included in the market mechanism, the very "substance of society itself" has been subordinated to the laws of the market (1944:71). Land therefore always operates in the liminal space within and across the domains demarcated above. For the primary purpose of this paper, land will be understood in the terms by which it has been politicized: as an economic resource and a political tool. In the Oromo example, the rapid modernization of Addis Ababa and the way farmers and rural residents have been treated in the process demonstrates the potential danger of economic politicization. In rural Oromiya, when the Meles Zenawi government refused to build key infrastructure like schools and hospitals in West Wollega throughout the 1990s, as punishment for the revolutionary history of the previous decades, land became a political weapon. In all cases, Oromo land is intertwined with Oromumma, but in this project it is framed primarily in economic terms.

\section{The Role of Diaspora}

A major focus of this work is the politicization of Oromumma, as understood by Oromo people in the diaspora. In other words, I am seeking to understand how departure from their homeland has changed the way Oromo people relate to and understand the conditions of their Oromo-ness. At its core, Oromumma is the cultural inheritance, lifeways, language, and spirit of the Oromo people, one that was birthed by the Haadha 
(Mother) Oromiya and has survived each attempt against it. Diaspora as a space, identity, and community complicates this relationship. Although Oromo people in the diaspora have entered different racialized, classed, and legal subject positions, their journeys are still very much rooted in the homeland. Within Ethiopia, the Oromo people remain exploited and disenfranchised. To be Oromo anywhere, to claim Oromo identity from the myriad identities available (Ethiopian, African, Black), is to connect with the global struggle for the Oromo, an identity that remains under attack.

Brah notes that the very construct of diaspora, or diaspora space, necessitates the interlocking of a journey and the "socio-economic, political and cultural conditions [that] mark the trajectories of these journeys" (1996:182). A diaspora therefore needs to be understood through the confluence of narratives that the population carries, lives, produces, and reproduces, as well as the international politics that influence this heritage (1996:183). As a politicizing process, both the individual's identity and the way they interact with their homeland are influential. As an analytical framework, Brah's conceptualization of diaspora elucidates the way the a priori and adopted homeland both carry politicizing forces that bear unpacking (1996:190). While the formation of the diaspora itself has important consequences on group social power and ways of knowing, it is also the root of this exodus that influences the nature of their politicization. The emphasis on what is carried is reminiscent of a concept suggested by Gilroy, that of rooted routes (1993).

The primary focus for this project is the root, rather than the route: I am looking at Oromumma in transit, with close attention to where the journey began. The interview questions probe the way the Ethiopian state has used and manipulated pieces of Oromo 
identity to determine access to power. Conceptualizing this power from the position of the diaspora also necessitates unpacking the way diaspora as a positionality is a response to state violence, regardless of the form of transit. Being in the diaspora is a potentially radical subject position because it contests state power on a number of levels. When thinking through the way identities are politicized and re-politicized in transit, I find it useful to compare two extreme Oromo reactions to Ethiopian state violence: the decision to join the armed liberation struggle, and entering the diaspora. How are both of these acts of resistance? How do they reflect a shadowy sovereignty made possible only within conditions of extreme state violence? Both of these actions sever the normative relations between the people and the state, but those norms are violent, and borne of violence. Leaving the Oromo homeland, and exiting the city in favor of the alternative sovereignty of the jungle (where the resistance lives) and its liberatory potential, both demonstrate the inability for Oromo existence in the settler colonial state; one either functions despite its wishes, or actively works against it. This exile is thus inherently politicizing; as long as Oromo people maintain their identity as Oromos, they reimagine the boundaries of Oromumma and its potential. Gilroy notes that diaspora as a concept has the "ability to pose the relationship between ethnic sameness and differentiation: a changing same" (1993:xi). Understanding the changes to identity and the nature of politicization in transit is best done by following the three domains of oppression presented above.

In the political domain, diaspora as a temporality allows for room and potential to organize not found in the homeland. Politically, Oromo people find new spaces, systems, and opportunities to work for change while living in the diaspora ("Angry Ethiopians" 1997; Matsuoaka and Sorenson 2001). These spaces include social groups and societies, 
as much as digital communities (Zahorik 2011). The rise of social media and the platforms it provides for Oromos with dissenting political beliefs has had a major influence on the politicization of identity in the diaspora. While Oromo people in the homeland are restricted in their ability to express, act, organize around, or even hear beliefs that go against the government, with the punishment being imprisonment or death, the open internet access of diasporas in the global North gives a voice and political power to people, often for the first time (Virtanen 2009; Dugo 2016). Practices that demonstrate the diaspora's potential to transform the oppressive home state include the lobbying of prominent officials and embassies in Northern nations (Feyissa and Lawrence 2014). The voice of the Oromo diaspora is so strong that new Prime Minister Abiy Ahmed made Minnesota a stop on his first U.S. tour. As a part of a collective effort, these actions allow Oromo people to use their resources as an ethnic group to regain or find a voice for Oromumma outside of the homeland. This organizing leverages their shared cultural identity as a way to gain rights and political power against the wishes of the subordinating Ethiopian state.

Economically and socially-produced inferiorities are intertwined in the colonial and post-colonial state. Entering the diaspora removes these connections, and shifts the class position and agency of previously marginalized ethnic peoples like the Oromo (Yusuf 2009:310). In the diaspora, the strategic and selective attacks that characterize Ethiopia's treatment of the Oromo no longer exist; access to goods, services, and opportunities for Oromos and other Ethiopian ethnic groups in the diaspora is no longer being determined by their ethnic traits (Sorenson 1996:441; Gibb 2002:56). The Ethiopian state functions by profiting off the labor and land of the Oromo; Oromo 
identity has been commodified due to the decades-long association between Oromo land as product, and Oromo people as serfs or slaves. People in the diaspora are no longer economically punishable by their home state, and instead through actions like sending remittances become a force of resistance; they are able to use their position outside of the state to support economic causes and independence (Antwi-Boateng 2011:10). In the Ethiopian example, this means that Oromo identity in the diaspora is partially decommodified and transformed. The land issue, the government's expropriation of Oromo homeland for private development, has created internal displacement and marginalization in Oromiya. The definition of marginalization becomes salient here; the state would prefer if they simply disappeared. By leaving the nation state but maintaining their Oromumma, Oromo people fight erasure, and simultaneously refuse to be economically excluded. The diaspora as a space makes this resistance possible.

When removed from Ethiopia's oppression, Oromo people, who share a common language and historical inheritance, have the ability to use these shared traits as a way to increase access, build community, and gain rights. Expressions of Oromo identity in the diaspora are a way to stay rooted in the homeland while expressing the changes and evolution caused by the route. As Gilroy notes, identities formed in the diaspora are "always unfinished, always being remade" (1993:xi). This process of construction speaks to the way Oromo identity in the diaspora is actively politicized and reclaimed by Oromo people as a means to counteract historic violence. In the diaspora, survivance is made tangible; the passport, new address, new citizenship are all proof that you have survived despite the myriad forces hoping to bury you. The first publications and proclamations of Oromo pride in the Oromo language, many of which are still available today, were all 
written or disseminated by members of the Oromo diaspora. One of the few heroes in Oromo folklore was a diasporic figure, Onesimos Nesib, who translated the bible into Afan Oromo while being trained as a missionary in Sweden; using his exile as a way to reclaim culture, and the value of the Oromo language as a form of expression (Jalata 2002:137). By succeeding despite Ethiopia's violence, diasporic conceptualizations of Oromumma are politicized and activated as a resistance, or at least rebuttal, to Ethiopia's state violence. 


\section{CHAPTER III: METHODS}

\section{Introduction}

This study is guided by two key research questions: 1) What factors most strongly shaped historical Oromumma, Oromo cultural and political identity? 2) What factors have most influenced Oromumma in the diaspora? More specifically, this study explores the politicizing tactics of a post-colonial state, as understood and resisted by members of the diaspora. Understanding Ethiopia as a violent former empire that has consistently used ethnic traits to maintain a power hierarchy is a key part of my analytical strategy. The methodology I use connects each piece of the research project. Following this chapter will come a historical analysis that serves to answer the first research question.

\section{A Decolonizing Methodology}

The methods for this project are grounded in a decolonizing framework.

Decolonization as an aspect of research design and practice prioritizes healing and repair, and seeks to empower the oppressed. Given violent post-colonial relationships like that of the Ethiopian state and the Oromo people, the work of rereading, rewriting, and recentering historical imperial narratives is central to decolonization (Smith 2012). Each aspect of my research design gives attention to this primary need. Smith identifies "imperialism, history, writing, and theory" as four often overlooked aspects of the research process that despite being constantly present in the lives of indigenous peoples and contributing heavily to the "underlying assumptions, motivations, and values which inform research practices," are not often given careful attention (2012:21). In order to learn how Oromo people, as an indigenous group still living the effects of the Abyssinian 
empire, understand their politicization, this methodology continually probed for the traces that the transit of empire left behind. The politicization of the Oromo was initiated by the empire, and thus unpacking the empire's lingering presence, and the way it has controlled the narrative, is key to a decolonial project. Addressing the imperial tendencies of both the state and its cultural elites, critically examining what history was written and by whom, and theorizing a resistance project that emerges from Oromo epistemologies are all features of this research project. These practices also demonstrate the decolonial potential of this project, and the topic itself.

\section{Data and Analysis}

This study uses a qualitative approach that focuses on the participants' lived understandings, experiences, and perspectives. Three years of informal participant observation, from July 2014- September 2017, laid the groundwork for the datacollection phase. Data analyzed were of two types: secondary sources (academic literature and research reports), and semi-structured interviews. I conducted interviews with individuals who identified as Oromo and lived in the diaspora. I sought triangulation as much as possible, that is, to identify confirmation across the different data types and the informal participant observation.

\section{The Researcher's Positionality - Advantages and Liabilities}

The three years I spent in Oromiya and my linguistic skills were a significant part of the interview process - they allowed me to build trust, rapport, and legitimacy with my interview participants. I lived for two years in a rural town in the Illubabor Zone, 
working full time as a $9^{\text {th }}$ grade English teacher. My community was majority Muslim Oromo, with large pockets of Protestants, especially in the town center. This ethnic division was also reflective of my neighbors, coworkers, and close friends during this time. After these two years (2014-2016), I moved to Jimma Town and worked as a Regional Leader for Peace Corps. In this role I travelled extensively throughout Southwestern Oromiya, and Western SNNPR. There were myriad occasions where I was the first, or only non-Ethiopian an individual had ever met. My Ethiopian coworkers were primarily Oromo, from both West and Eastern Oromiya. As such my experiences in Oromiya were diverse, and deeply immersive. Also worth noting is that many of my friends and colleagues in Ethiopia were generally aware of my research as it was taking shape, though I explained it more broadly as an exploration of Oromo histories and experiences. I had extensive conversations on many of these same topics with friends and colleagues, in part because this same period, in particular the summer and fall of 2016, was marked by intensifying state violence and repression of the Oromo. For example, my organization directed us to cancel a regional summer camp in 2016 because travel across rural Oromiya was considered too unsafe. As was the case with my research participants, my Oromo friends in Ethiopia spoke with surprising bluntness and candor when discussing their relationship with the Ethiopian state.

Despite the strengths of my research methodology, there are limitations that should be discussed. One limitation of my research is a potential for bias due to the amount of time I spent in the field and the high amount of involvement I have in Oromo issues. This bias is a limit to the study's validity because another researcher would not likely share these same experiences or develop the same perspective. However, my larger 
research project is grounded in a rigorous theoretical framework. By understanding my specific focus within a larger global context and using this framework as a tool, I have been able to legitimize my claims. Another limitation, arguably, is that although my sample size is fairly representative of the Oromo population, a larger sample size would strengthen the case. This point has some merit, but I believe that using the literature as a foundation of the piece makes up for this slight limitation. The depth of my observation and the time I've spent in the field also compensates partly for the sample size.

\section{Data Collection}

\section{Informal participant observation}

I spent three years living and working in Western Oromiya, from 2014-2017: two years in Illubabor Zone and one year in the Jimma Zone. During this time I also traveled extensively throughout Bedele and Showa Zones, made nearly two dozen trips to the capital city of Addis Ababa, including an extended two-week period during the State of Emergency in 2016, and travelled briefly to major cities around the country. Throughout this time I kept note of actions and interactions that related to Oromo identity in public. These were not formal field notes, but I did keep a written record of some observations, which I recorded in private. This includes the use of Afan Oromo, Oromo signs and symbols, or anti-Oromo sentiment. I started to form a conception of Oromo identity early on and continued to refine it over time. The events that I considered to be open to the public and part of permissible observations without formal IRB approval included markets, community meetings, public transportation, and public holidays. Observing these events and public interactions shed light on the way Oromo people act and interact 
with other members of the Ethiopian population, as well as the way the Ethiopian state polices and regulates Oromo behavior in public. Spending time travelling in rural Oromiya gave me insight into the reach and nature of the Ethiopian police state in different areas. My knowledge of Afan Oromo also legitimized and supported these observations. I was able to take note of the way language is used and by whom, which contributed to my understanding of the way Oromo culture is filtered through the Ethiopian state.

Throughout the time I lived and worked in Oromiya I reflected extensively on the subject matter of this thesis project, even though it was not my primarily endeavor at the time. In my role as a high school teacher, and as regional leader for Peace Corps, I had the opportunity to work intimately with diverse groups of Oromo people. I also had many lengthy conversations with Oromo friends and colleagues around the topic of my thesis. Although I did not record these conversations, they were heavily influential in shaping the way I approached the subject and my research intent. Of the public events I witnessed I kept reflective records even if they did not seem immediately relevant to Oromo identity. These descriptions were typically handwritten, due to a lack of consistent electricity or computer access. While I did not analyze these reflections methodically, they were a useful resource later. Throughout the entirety of my 39 months in Ethiopia I struggled with finding open, available internet access. Therefore, while I was able to observe events taking place around me, and connect with friends in other parts of the country via mobile phone when the network connection was available, it was difficult to construct an accurate picture of events taking place across the nation. It was challenging at times to confirm the violent rumors swirling around, due to the lack of news on state- 
sponsored TV or radio. As best as I could, I compared personal notes with news timelines to get a fuller understanding of how my reflections fit in the larger scheme and timeline of the Oromo protests.

The justification behind using informal participant observation as opposed to a more involved form of participant observation stems back to the issues of state violence and oppression discussed throughout this thesis. Rules governing journalists and terrorism have been loosely applied to persecute any forms of dissent. Putting my friends and colleagues in a position where they could be associated with any anti-state sentiment was simply not safe. The same concern led to the choice I made to interview members of the diaspora only, and not include Oromos in the homeland. The Ethiopian government owns and controls every form of telecommunication and has been known to listen in on, selectively shut off, and otherwise manipulate communication. While living in Ethiopia I personally experienced telecom issues with suspicious connections. This included dropped phone calls while discussing protests, and a several week period where I was unable to access my email after sending some potentially controversial documents. It's impossible to determine whether these issues were legitimately connected or coincidental, but they were sufficient to discourage me from pursuing other more engaged research methods.

\section{Analysis of secondary sources}

In order to interpret, compare, and confirm the conclusions drawn during the other forms of data collection, I also conducted a critical review of the existing literature. The secondary sources were also the focus of my historical analysis of the development of 
Oromumma as a political identity. The interpretation of secondary sources was an important contribution to the research project for several reasons. First, in line with my theoretical commitment to decolonizing methodologies, my analysis was a critical rereading of Ethiopian history for its injustices and biases. To assess the way Oromumma has been reclaimed and politicized by the Oromo people, and in the context of the Oromo struggle, I relied primarily on the reporting found in Oromo-language or Oromo-run media sources, reports from Oromo scholars, and social media accounts. For a view of the international perspective on the politicization of Oromo identity, I relied on reporting by English-language broadcasts and news sources. To analyze how Oromo identity has been conceptualized or understood over time, I conducted interpretations and re-readings of historical reporting and anthropological studies, with an attention to the bias of the hegemonic Ethiopian narrative on the nature of the reporting, particularly in the early days of state formation. For example, usage of the term Galla, a pejorative, to describe the Oromo people without an acknowledgement of their feelings toward the term or selfidentification as Oromo is a demonstration of researcher bias. It is identifiable in academic journal articles as well as popular news media and newspapers, and was a common practice until the late 1970s. Smith describes this process as "coming to know the past;" as an aspect of the larger methodological project of decolonization the research will revisit sites of imperial history in order to "engage with, understand, and act upon" these narrative spaces (2012:36). The results of this analysis can be found in the following chapter.

\section{In-depth interviews}

During the winter and spring of 2019, I conducted 12 semi-structured interviews. The participants were selected using snowball sampling. I began the snowball with 
Oromo people I knew personally who lived in the diaspora. Following the interviews I asked participants to refer me to other Oromo people in the diaspora. Because the snowball sample began with individuals I knew personally, each participant was aware of my background as a researcher and my history with the Oromo people. I also communicated with each respondent primarily in Afan Oromo prior to beginning the interview, which built trust and early rapport. The interviews probed into four key thematic categories:

- Background: questions about the individuals' family background, history, and the logistics behind their movement into the diaspora;

- Economic: questions relating to work, business, trade, access to goods and services, and the neoliberal tendencies of the state;

- Political: questions that probe the politics and law of Ethiopia, including how the country is run, and how the Oromo people feel about this;

- Cultural: questions dealing with the culture of Ethiopia, Oromo culture, and interactions between the two;

The following table provides an overview of the demographic characteristics of all interviewees, as well as their pseudonyms. The sample is fairly diverse, and I hope it represents the diaspora experience relatively well but, given the sample size and the qualitative nature of the study, the sample is not statistically representative. I did not collect the participants' ages, however determining the era they were born, and the approximate age they were when they left paints a rough picture of how old they are. The eras are named after the ruling force of each period, with the following approximate timelines: Haile pre-1974, Dergue 1974-1991, EPRDF 1991-2018, Abiy 2018- now. As a 
specific example, Wayissa left Ethiopia near the end of the Haile Selassie era as a college student in his early 20 s. This means he is approximately 70 years old. "Region" refers to the Ethiopian Zone where the individual was born or spent the majority of their childhood, as it is located on the 2017 map. This distinction is important to note, as Ethiopia has undergone several re-mappings over the past 75 year, with a new zone districted into Oromiya in 2017. A map of the Oromiya region can be found in at the end of the first chapter. However, as I discuss in the following chapters, I found that despite differences in approximate age, childhood, and other traits, individuals shared similar experiences and beliefs about Oromo identity.

Table 3: Research Participants

\begin{tabular}{|c|c|c|c|c|}
\hline NAME & GENDER & REGION & BORN & LEFT \\
\hline Obsee & $\mathrm{W}$ & Illubabor & Dergue & EPRDF \\
\hline Chalchissa & $\mathrm{M}$ & E. Wollega & Dergue & EPRDF \\
\hline Ebba & $\mathrm{M}$ & W. Wollega & Haile & EPRDF \\
\hline Sanyii & $\mathrm{M}$ & Illubabor & EPRDF & Abiy \\
\hline Wayissa & $\mathrm{M}$ & Arsi & Haile & Haile \\
\hline Ayantu & $\mathrm{W}$ & Bedele & Haile & EPRDF \\
\hline Gifti & $\mathrm{W}$ & N. Showa & Dergue & EPRDF \\
\hline Badhaassaa & $\mathrm{M}$ & Bale & Dergue & EPRDF \\
\hline Bontu & $\mathrm{W}$ & Illubabor & Haile & EPRDF \\
\hline Tolera & $\mathrm{M}$ & W. Wollega & EPRDF & EPRDF \\
\hline Biiftu & $\mathrm{W}$ & Illubabor & Dergue & EPRDF \\
\hline Abdi & $\mathrm{M}$ & W. Wollega & Haile & Haile \\
\hline
\end{tabular}

\section{Analysis of Interviews}

In order to analyze and code the interviews I used a process called thematic network analysis, based on the work of Attride-Stirling 2001. I originally intended to transcribe and then code the interviews using Dedoose, but for several reasons I decided 
to do the transcriptions myself, and to analyze the data without using any qualitative analysis software. This decision is justified and explained in the Coding section.

\section{Transcription}

The language barrier shaped my transcription practice. Several participants either spoke no English, or heavily accented English, which made it impossible to rely on the accurate transcription of an outside program. There is no existing software to transcribe in Afan Oromo, and the work of correcting a transcription was comparable to transcribing myself. There were also some issues of sound quality during the interviews. Because the interviews took place over the phone, there were occasional network interruptions or outside noises that affected the quality of the recording. This further discouraged me from using an outside transcription program. Although I originally used Microsoft Word to create my transcriptions, I switched to Excel after my first two interviews, and did all further transcribing there. After conducting the interviews, I played them back once to familiarize myself with the materials, and made notes of key topics or moments. On the third pass, I did a more complete transcription. Certain sections were not transcribed fully, but simply noted for content matter. The nature of this transcription process was also influential in my coding system, and will be explained further here.

As stated above, certain sections were not transcribed fully. When a participant described the geographic location of where they grew up, I would write a summary of their statement and add a brief time stamp so I could refer back to it later. I also used this method with longer tangents or anecdotes that were not necessarily pertinent to the conversation. For example, one participant told a lengthy story about a historic Oromo 
general, Tadesse Biru. This retelling included details about his birth, political ascent, and other information that, although factual, I was already familiar with. As I listened the first time I noted "Tadesse Biru anecdote" and the start and end times as a line on the coding sheet. On the second listen, I added some relevant details, but I did not transcribe the full, three-minute anecdote. This strategic transcription simplified and streamlined the coding process, and because each recording was listened to multiple times after the original conversation, I feel the process was valid.

Abbreviated transcriptions were noted in the document, typically in [brackets] or italic text. There were some sections or anecdotes I reviewed further, after full transcription, to make sure the process was trustworthy. During these reviews I rarely found the need to further transcribe an abbreviated section. This demonstrates the reliability of the method, as I was not leaving out key pieces. An example of a section of a transcription, with the Tadesse Biru interview mentioned above, can be found in the appendix under the Methods section. The excerpts in that section were part of the response to the prompt "Did you feel that there was equal access to work and jobs for Oromos and other Ethiopians?"

\section{Coding}

The nature of the transcription was very influential on the coding process. After the transcriptions were finished, the text was already in sections, or what Dedoose would title "excerpts." As such, to input this data into Dedoose would involve uploading it one "excerpt" at a time, and adding the codes; over 1,000 pieces of individual excerpt data in total. In many ways the process I used mirrors what Dedoose does, as will be explained 
here. I feel confident that the model I used, my familiarity with the text due to my transcription, and the way the codes were developed and applied reflects an accurate analysis of the data.

I completed the coding of my transcriptions using the method of Thematic Network Analysis outlined by Attride-Stirling, a way to explore the significance of an idea and how it is being understood by a group (2001:388). This is a systematic way of identifying the more abstract ideas that organize themes and common statements, as well as the larger overarching ideas that emerge from these themes. The starting categories, what Attride-Stirling calls "basic themes," were developed after an extensive review of the literature. More specifically, these codes encompass the common features of postcolonial state development, as well as the historical tactics of Ethiopian politicization. The themes were organized within four domains: Economic, Social, Cultural, and Background. The latter category encompasses statements that were factual and apolitical in nature, for example the year a respondent was born. This data was not analyzed, but used as a reference.

Once the preliminary codes delineating "basic themes" (Economic, State, Cultural, Background) were applied, the excerpts were moved to a separate Excel sheet, one for each thematic category. This is essentially a manual way of doing what a program like Dedoose would do automatically. It also follows Attride-Stirling's model (2001:392). Within their thematic sheet, these excerpts were further coded for examples of the different features of each of these domains. By reading through the excerpts again in the context of their thematic category and coding for specific examples, I was able to refine the coding process. If an excerpt originally coded as Political was not actually an 
example of a specific political act, for example, I typically found that it may have actually been a background piece, such as a timeline of monarchs. I also took note of intersections with the other thematic categories, and explored these. A list of codes and terms can be found in the appendix in the Methods section.

It is important to note that these codes were developed during the completion of both the substantive literature review and the analytical framework. They therefore reflect both the theoretical features of a post-colonial state and the ways this has historically manifested itself in Ethiopia, each piece of which is explained elsewhere. I used a "Key Definitions" sheet to guide this process, which can be found in the appendix, alongside an example of a series of excerpts that were coded as "Political" and then further coded for their particular feature: Necropower, Subordination, Othering, or Sovereignty.

In order to deconstruct the information in these basic thematic categories, they were read as a unit, and thus analyzed for patterns and commonalities. In the sample text below, the first excerpt was coded as Necropower because it was an example of the institutionalization and state sponsoring of death, as it speaks of the "eradicating" of Oromos due to government policy. When all of the Necropower codes are grouped together, certain themes and patterns emerged. These patterns were rewritten and combined into Organizing Themes. Organizing Themes are more abstract, and both "group the main ideas proposed by several Basic Themes, and dissect the main assumptions underlying a broader theme" (Attride-Stirling 2001:389). Here I deviated somewhat from Attride-Stirling in that I created Organizing Themes from within each "Basic" thematic or analytical category (Economic, Social, Political). For example, an Organizing Theme was created around the common features of Political codes. When 
Necropower is discussed, in what context, by which actors, and how it interrupts the lives of Oromo people are all pieces of the larger Political puzzle, and help explicate the nature of politicization; Organizing Themes connect and help make sense of these patterns.

The coding guide I used lists the basic themes as well as the specific features of these themes, which follow directly from the analytical model and an analysis of the substantive literature. These features, particularly the theoretical category, encompass a number of actions and interactions. For example, the code "education" includes discussion of specific content (what was studied), infrastructure of educational institutions (number of schools and their location), and access to education, among other things. Each of these pieces is part of the Political domain of politicization. As part of the process of creating Organizing Themes, the role of education within the larger Political or state project was made clearer. What Attride-Stirling calls "Global Themes" are the ideas that group together and make sense of each of these Organizing Themes. Global Themes reveal the underlying issues connecting each unique domain and form one cohesive network. These are explained at the conclusion of the thesis. 


\section{CHAPTER IV: POLITICIZATION OF OROMUMMA OVER TIME}

\section{Introduction}

This section provides a critical analysis of the way Oromumma has been politicized over time, using the framework presented above. Looking at the changes in the politicization of identity over time elucidates the way the Abyssinian/ Ethiopian state manipulates ethnic identity to maintain hierarchal power, as well as the way oppressed people create forms of resistance that counteract this strategy of state domination. The Oromo people have changed their tactics of resistance to react to the constantly evolving oppression of the state. They have also developed their own proactive methods of denying and fighting against the necropower of the various Ethiopian regimes. Looking at these relationships through the lens of the politicization of identity is a key component of understanding how current Oromo identity in the diaspora is constructed, and what it is rooted in. This chapter is divided into sections based on shifts in governance or forms of politicization, as follows:

1. Free Oromiya: a broad overview of the Oromo people and key cultural characteristics prior to colonization

2. Menelik: the colonization of the Oromo and the embedding of historic prejudice into law

3. Haile Selassie: the reformation of Abyssinia into modern day Ethiopia

4. The Dergue: a fascist regime responsible for mass death

5. Revolution/ State formation: analysis of the key challenges and early work in recreating the state

6. \#OromoProtests: identity politicization as resistance to state violence 


\section{Section I: Free Oromiya}

The Oromo have been living in the highlands and plains of the Horn of Africa since the beginning of their cultural consciousness. Reports by Islamic travelers in the $10^{\text {th }}$ and $11^{\text {th }}$ century provide some of the first written documentation of Oromo existence, referencing their territory as expanding into or bordering modern-day Somalia (Tasamma and Waaqwayya 1995:21). Historically, Oromo society was made up of six tribes, interconnected by a shared religion and Oromo language, and governed by a system of equal representation called the Gadaa system. Each of these features makes up a core part of the Oromo historical inheritance, and an understanding of these elements is one of the shared traits of the Oromo cultural community (Jalata 2012). Prior to colonization by the Shoan Emperor Menelik in the late 1880s, Oromumma was the spiritual connecting force across a vast land space. Once consolidated, the Abyssinian empire disrupted these systems of governance and kinship, but the legacies of each are visible in modern-day expressions of Oromumma. Language, religion, governance, and land are the foundational elements of Oromumma, each with a unique relationship to the resilience and shape of Oromo cultural identity over time.

The Oromo religious system before Abyssinian colonization is indicative of the Oromo worldview and set of meanings. Known as Waaqeeffanna or Waqqayya, it is based on a belief in Waaqa, the Oromo concept for God. Waaqa for the Oromo is a part of the land and nature as much as spiritual being; practicing Waaqeeffanna is recognizing that Waaqa is both one and many, inhabiting the seven skies above and below the ground (Ruda 1993:97). This conception of the world places the value of the natural world and process as equal or greater in importance to that of the people (Orlowska 2013:312). 
Evidence of this behavior is seen is sustainable land use practices that characterize Oromo agriculture in rural areas, and the significance given to animal and plant life (Tufa and Gebremariam 2017). During Waaqeeffanna celebrations and Gadaa meetings Oromo people gather around Odaa trees, one of nearly a dozen trees thought to have a distinct spirit, or ayana (Mergo 2012:107). The unique nature of Oromo relationships to and treatment of land was noted even by Abyssinian invaders in the 1840s (Hassen 2007:151). Language use also reflects the sustenance of Oromo concepts, as names that come from Waaqeeffanna beliefs and concepts are still popular today, even among Muslims and Christians. Ayana, meaning spirit, Urgeessa, a scented ceremonial plant, and Ateetee are all examples of names that came from pre-colonial religious and cultural practices and are still common across generations, despite religious conversion. Furthermore, there is no concept of the "wilderness" in the Oromo worldview or language, even today. Although the majority of the Oromo people currently practice Islam or a type of Christianity, the symbolic meaning of Waaqa is still a part of Oromo life, and many Oromo celebrate Waaqeeffanna holidays, like Irreecha, alongside that of their primary religion (Gebissa 2008). In addition, in rural Northwestern Oromiya, one of the most remote and underdeveloped regions, the Horro Oromo still use customary rituals related to forest resources in response to outside social problems (Mergo 2012:111).

Prior to colonization, the Oromo people were entirely governed by the Gadaa system, and some vestiges of it are at least ceremonially active today. Under this model, each local Oromo group subdivided the population into age categories, and children were raised alongside their peers and "educated in Oromo history, military strategy, law, and governance" as they moved towards higher levels of power and societal importance 
(Keller 1995:624). There was one central leadership forum of elders responsible for settling disputes and addressing issues of justice, and its leader was called the Abba Gadaa, or Father of the Gadaa. The women's council, which worked in conjunction with the men's, though often litigating different issues, was called the Siqqee. This Siqqee system was separate, and had functional independence, which allowed for women to protect "themselves and each other from abuse and allowed women to control essential economic assets" (Jalata and Schaffer 2013:282). Though not an entirely and equitable society, the importance of women was firmly established in its forms of governance. The tribal identity of the leadership position rotated so that each tribe was equally represented in power (Knutsson 1963).

Like Oromo religious beliefs, the Gadaa system emphasized community, sharing, and group membership, and functions as a "system of cooperation, social integration, and enforcement of moral conduct" (Gebissa 2008:2). During times of conflict with nonOromo tribes, conquered people were given the option to maintain their own belief systems but were considered Oromo if they adapted Oromo beliefs and learned the Oromo language (Ruda 1993:288). Currently, the symbol of the Odaa tree, the sycamore under which gatherings were held during the Gadaa era, is featured on the flags of both the state-sponsored and resistance-based parties, making it one of the most highly politicized elements of Oromo cultural identity (Jalata 2001). This structure of Oromo community was a direct contrast to the beliefs of the Abyssinian Empire, who were directly responsible for the hierarchal nature of Ethiopian state and interstate politics today. A foundational piece of Orthodox Christian state rule was church-owned land, leased only to elites and church leaders (Hassen 2012:276). This practice of hoarding 
power was mirrored in other forms of governance. Towards the end of the era of a free Oromiya, accommodating Oromo leaders, and the collaborative upper class in Shoa, sought to reform the Gadaa to meet the needs of those encroaching. These attempts changed the structure but not the core values of the system (Flintan 2010:155). Today, the Gadaa still elects leadership and leads seasonal prayers, but it is largely a ceremonial role (BBC 2017). The intersecting roles of religion and governance, threaded together by a shared language, work in conjunction to create the basis of what is generally recognized as Oromumma.

Land for the Oromo people has been a site of political, economic, and cultural battles since the time of colonization. The historic Oromo religion and worldview were centered on Mother Oromiya (Haadha), and their relationship with her. Addis Ababa, which became the capital of the empire, was Oromiya's haandhura (bellybutton or umbilical cord) the heart of the land (Ararssa 2018:1). Colonizing forces saw land as a source of income, a pathway to the markets at Khartoum, and a breeding ground for slaves (Edwards 1982). This commodification of land and human labor seeped into relations across the country. Since the end of the Free Oromo era, the Oromo homeland has been used and manipulated by state powers for economic and political gain. There has been little respect or acknowledgment of the psychological losses felt by attacks on the Haadha, or the factories built on the haandhura. In approaching my analysis from a decolonizing perspective, I therefore seek to highlight the cultural impacts of Abyssinian colonial domination. As discussed further, the land grabs and appropriation of land by the Ethiopian state have been economically motivated, but their implementation would not have been possible without the initial cognitive separation between the native land and 
the Native people who came from that land. Failing to recognize the transit of empire over time, and the traces of the colonial into the post-colonial era, produces a narrow and inadequate understanding of the relationship between Oromo land and the Ethiopian state, reducing it to legal terms and political maps. Seeing the way the empire and its tactics of oppression are reified and given new life in modern systems is necessary to fully understand the conditions of the Oromo. The roots of Oromo cultural identity I have described in this section became the basis of subsequent Oromo political identities of resistance over time.

Section II: Colonization (1880s-1930)

Until the late 1800s, Oromiya remained relatively undisturbed by both foreign conquerors and travellers, and those outsiders who had entered Oromo land had not noticeably interrupted Oromo cultural practices. Islam had both infiltrated and been welcomed in to varying extents, and in general did little to disrupt the traditional lifeways of the Oromo. Instead, many Oromo people began converting to Islam as a check on rising Amhara nationalism in Shoa and Christian violence in areas like Harar (Jaenen 1956:177; Bariagaber 1998:1060). British explorers in the 1860s crafted entire missions with the intention of entering Oromo country, describing it as a site ripe for colonization and Christianization (Dufton 1862:488). Menelik, the emperor of Shoa at the time, had similar values and intentions. Thus the subjugation and eventual colonization of the Oromo was in some ways a Muslim-Christian conflict as much as one that was motivated by imperial interests. The most notable legacy of this era was the full consolidation of what comprises modern day Ethiopia. During the reign of Menelik the last Oromo rebels 
were negotiated with, suppressed, or slaughtered. National borders were redrawn and land was redistributed to maintain hierarchal, Habesha power.

Although subsequent regimes have gained more notoriety internationally, the consolidated Abyssinian state was responsible for extensive, strategic and organized political violence. Jalata describes five institutions that were the foundation of Ethiopian settler colonialism: slavery, the Nafxanya-Gabbar system (semi-slavery), garrison cities, an Oromo collaborative class, and the colonial landholding system (2001:2). The primary two institutions listed by Jalata, slavery and the Nafxanya-Gabbar system, are most pertinent to this discussion, and had the most uniform impact across the country. Whereas the Oromo collaborative class was present most strongly in Shoa, and with certain examples standing out as more egregious like that of Ras Gobana, the Gadaa system managed to resist most of this colonial infiltration and divisive tactics (Ta'a 2008:74). In the Nafxanya-Gabbar system over two-thirds of the colonized land was expropriated and divided amongst wealthy landlords (Markakis 1989:119). The resettlement and implementation of the of the Nafxanya-Gabbar system has had the longest lasting impacts, and likely served as inspiration for resettlement projects undertaken by the Dergue and the reformist EPRDF government in the $20^{\text {th }}$ and $21^{\text {st }}$ centuries, discussed later. Under this model, the most fertile parts of the empire were systematically registered and redistributed under a land-tenure system that granted control to Amhara and Tigrayan outsiders, leaving Indigenous Oromo farmers landless and forced to toil for tribute rations (Bassi and Megerssa 2008:98).

Another important legacy of Menelik's was the beginning of the import of European weaponry, a key tool in his colonial pursuits. Christian empires in Europe 
exported rifles and other weaponry to Habesha colonists fighting pagan and Muslim southerners (Jalata and Schaffer 2013:281). The acquisition and distribution of guns was itself a highly politicized process. Early desires for weaponry and the process through which they were acquired "had important diplomatic consequences" for the very foundation of the Ethiopian nation, including determining future relationships with nations like France and Britain, and supporting the colonial invasion of the south (Pankhurst 1965:30). It was also this weaponry that helped Menelik to overthrow the Italian invaders during the Battle of Adwa. Memorialized in the Ethiopian historiography as an anti-colonial glory, many of these narratives leave out the role of enslaved Ethiopian people and subjects, in particular the Oromo, as key labor in this victory. Menelik had difficulty rousing colonial subjects by rhetorical means, with speeches from this era showing that he first sought to use Orthodox Christian nationalist ideas before conceding, "I don't think I have treated you badly... if you decide to do nothing after you had [sic] heard this proclamation, I will punish you" (Giorgis 2010:86). Oromo slaves were thus brought from the south to fight for a colonial ruler they did not believe in. We can therefore see how Menelik framed the position of colonized Oromos and other people within Abyssinia: as weaponry, tools, and mechanisms for glory.

Fueling both Menelik's war chest and his motivation for continued violence was the economic potential of Oromiya and the Oromo people. Menelik exploited the wealth of the Oromo wherever possible, as a slave trader, mine contractor, and plantation owner. When people would not be kidnapped and sold, he simply killed them and took their land (Jalata 2001:100). This late colonial empire used some rhetorical tactics to justify its means, framing the Oromo as pagan savages, but in general the economic justification 
proved sufficient (Yates 2016:199). Oromiya and Oromumma were reduced to slave laborers, coffee farms, cattle ranches, and gold mines. It was reported that Menelik and his wife owned over 70,000 enslaved African people, while tributes from the last sovereign Oromo kingdom, Jimma's Abba Jifar, included "ivory, civet, honey, gold" and other products like coffee (Edwards 1982; Gemeda 2002:53). The Oromo people's worth as a community was limited to their economic value. Menelik and his policies took what was a sacred part of the Oromo community, their land and their bodies, and permanently reimagined it as a commodity. This pattern of alienation, commodification, and exploitation was justified by employing a savage narrative surrounding the "black" Oromo. Tibebu notes how Habesha people were "painted white" after their defeat of the Italians, later on in Menelik's rule, as a way for Europeans to reconcile this victory (1996:419). This cognitive separation thus became an internal and international rhetorical tool to justify the use of violence against the Oromo.

At the time of Menelik's death it was noted that Ethiopia would be a formidable challenge to any attempted conqueror, as "its mountainous people were very well armed" (Pankhurst 1965:32). The nation was cohering around a Habesha ideal and the country was well supplied with weaponry, including guns and cannons, and increasingly modernizing. Menelik named his successor towards the end of his reign in 1909, selecting Iyasu, the son of a Wollo prince and his own daughter (Reid 2011:129). Iyasu, known as Lij or Child Iyasu, began his rule in 1911 while his grandfather quietly died. He was a prominent slave trader, but beyond this he was a contrarian to Menelik's Shoan Abyssinian vision. Iyasu instead moved many power structures north from Addis to Wollo and Tigray, and spent large amounts of time with the Muslim people of the 
Ogaden and Ethiopian Somali, leaving the Shoa people feeling neglected and discontent (Reid 2011:131). This discontent would steep with the Shoan nobility for several decades, and while Iyasu ruled, his usurper was already in the process of planning his future rule.

Notably absent from this section is any account of Oromo resistance. This is an accurate reflection of the all-encompassing nature of Abyssinian colonization, as it strategically attacked each identifiable piece of Oromo culture. As an unintended consequence, it strengthened the Oromos' resolve to continue traditions, speak the language, and live with the land outside of Abyssinian control. Thus began the dialect between the Empire's repeated attempts to oppressively politicize the Oromo out of existence, and the Oromo working against and despite these laws to highlight and reinforce their values. As was the case with empires across the global South, "ethnicity (tribalism) thus came to be simultaneously the form of colonial control over natives and the form of revolt against it" (Mamdani 1996:24).

Section 3: Haile Selassie (1930-1974)

The reign of Emperor Haile Selassie solidified the tendencies and trends of the Abyssinian, Shoan, and Axumite Empires into a cohesive "Ethiopian" vision Amharic speaking, Orthodox Christian, and Habesha. It is this vision, of the last "African" King, that has endured; obfuscating the fact that the "Lion of Judah" owned African people as slaves, that he was intolerant of any deviance from his Habesha ideal, and that his victories were won with forced labor and the blood of the oppressed. While speaking to the United States Congress, Selassie described Ethiopia as "a Christian island 
in a sea of Islam," making explicit the historical inheritance he intended to carry forth, and his views on more than half of his own country (Markakis 1989:119). Challenging the legacy of Haile Selassie as a savior and acknowledging the violence he embedded into the state he built is a key aspect of analyzing Ethiopia's place in the post-colonial world, and as a settler colony. The process of state solidification in Ethiopia significantly altered the economic, cultural, and political landscape of the Horn of Africa.

Before assuming the throne in 1930, Ras (a title for a regional king or prince) Tafari Makonnen was the governor of the then-province of Harar and had a history of oppressing and profiting off Oromo land and labor (Pankhurst 1961:61). Tafari formed political alliances with leaders from Shoa, and throughout his career focused on Addis Ababa as the ultimate site of his political aspirations (Reid 2011:132). Tafari first found a position of power in 1916 with great support from Shoan nobility, eager to restore their rule back from the descendants of Menelik (Gebissa 2002:75). After deposing of the former emperor and leaving him incarcerated and in chains, Tafari was elevated to the title of Negus in 1928, and formally claimed the throne in November of 1930, crowned as Emperor Haile Selassie (Reid 2011:135). His claim to the throne was partially predicated on his ancestry; he claimed to be a descendent of the ancient Solomonic line, and when challenged he used his military connections to change minds. Despite proclaiming himself a modern ruler, reports show that during the 1920s and 1930s, slavery and the slave trade were key to the economic structure of the country (Bassi and Megerssa 2008:110; Edwards 1982:8). Some went further, noting that slavery as an institution was embedded into the Ethiopian social structure and ideology as well (Polson 1936:650). Based on his early actions as a leader, it is clear that Selassie long used the Pan-Ethiopian 
colonial vision as away of obscuring his strategic ethnic violence. Slavery as a

particular institution is unique in its complete dehumanization and violence. No rhetorical devices can obscure this fact, or what it conveys about the nature of Habesha-Oromo relations during this time.

Also important to understanding the condition of the Oromo during this era are the larger global events of the era of "Fascism and Appeasement" which saw modernized weaponry and war technology dramatically change the nature of international conflict (Pankhurst 1965:33). The Italians, led by Mussolini, conquered Abyssinia in 1935, with the intent to conquer the rest of the country, despite Selassie's considerable efforts "to avoid trouble" (Woolbert 1935:505). After the fall of Addis Ababa, the Emperor fled. While the Shoan stalwarts and established Amhara rulers took the invasion as a colonial threat, the colonized Oromo and southern peoples saw hope for liberation. There is a definite irony in seeking freedom from an invading colonial empire; this speaks to the extent of the violence of Abyssinian colonial rule. In some cases, Oromo leaders openly supported and provided soldiers to the Italians, or to anti-Abyssinian forces, and the Italians began to see that "anti-Amhara and therefore anti-Ethiopian" sentiments could be pulled out of "the peasantry" (Jesman 1963:58). There are reports that areas of the country where the Italians were unable to penetrate saw "the conquered people... beginning to take action to liberate themselves," particularly in the South (Gebissa 2002:79).

At the onset of the Italian invasion, the southwestern part of the country, including Gambella and modern day South Sudan, was a British protectorate, and thus Oromo elites with access to political power saw a British mandate as the ideal option for 
transitioning into a fully independent state (Ta'a 2008:68). While Selassie fled and sought protection from European allies, Oromo people organized and tried again to gain freedom. However, the international governing bodies they appealed to were slow to respond. While the Italians were being torn in different directions, and facing censure from international leaders, they were eventually ejected from the country in 1941, when Selassie returned to the throne (Gebissa 2002:76). It was during this era, from the 1940s until he was deposed during the 1970s, that Selassie refined his politicizing tactics into a cohesive force. Haile Selassie's finesse and ability to create narratives were one of his greatest strengths as a leader, particularly on the global stage. He used Pan-African rhetoric to obscure the devastation taking place at home, as each aspect of Oromo culture was politicized towards oppressive ends. As Hassen details, while Selassie was giving speeches at global assemblies:

Oromo cultural and religious shrines and places of worship were destroyed. Oromo place names were replaced by Amharic names. The Oromo language was banned from being used for preaching, teaching, and writing. The Oromo national identity was attacked and the Oromo way of life was condemned in every way. The regime's educational system, cultural institutions, and government bureaucracy were deployed for the express purpose of denigrating the Oromo people, their history, culture, and way of life (2002:21).

By identifying and subsequently restricting so many specific aspects of Oromo culture, Selassie turned ethnic identity into a political tool. While the Emperor did not go so far as to identify Oromumma as an enemy of the state, he created an idealized Abyssinian identity and left little room for characteristics that existed outside of it.

Selassie's tactics of economic politicization were tightly intertwined with his cultural narratives, in a way that was much more explicit and successful than his 
predecessors. He excluded Oromo people from the labor market and economic growth wherever possible. The methods used included permitting name-based discrimination, for example (Bulcha 1997:338). There were a few practices that were primarily economic in nature though, most notably his upholding of the Nafxanya-Gabbar semi-slavery system, and his use of tribute, bribes, and economic exploitation to maintain dominance over the last vestiges of Oromo legal sovereignty (Gemeda 2002:60; Hassen 2002:21). The Emperor also relied on Indigenous farming practices and expertise to grow and prepare the coffee that made up vast quantities of monthly tribute from Jimma, the last Oromo kingdom (Lewis 1965). This exploitative system maintained the Abyssinian position in the international markets.

Although the era of Emperor Selassie was distinct for some of its politicizing mechanisms, it was also a time of renewal in the spirit of Oromumma as a united political force. This politicization of Oromumma resulted in Oromo people organizing and drawing on the strengths of Oromo culture to assert themselves as a resistance to the violence of the Ethiopian state. The two most salient examples of this are the Western Oromo Confederation and the Macha Tulama Self-Help Association. That both of these groups came from the Western part of Oromiya speaks to the post-colonial condition of the country. While the North and East were occupied by Habesha invaders, the South was still primarily rural pastoralists, facing their own issues with the Somalis along British colonial lines, and the Central Oromo Shoan were largely assimilated or part of the collaborationist classes; thus Western Oromos had strategic historical and geographic advantages (Pankhurst 1961; Lewis 1965; Keller 1995). More importantly, Selassie and his collaborators were dependent on exports from the coffee-rich area, as well as the 
stability from the Jimma-Juba road, a major trade route (Gemeda 2002:58). Thus the Abyssinian imperial forces were reticent to enact extensive destruction. The attacks were generally more strategically political and legal in nature, relating to language and religion as discussed previously.

In May of 1936 several prominent community leaders formed the Western Oromo Confederation (WOC), uniting the provincial rulers of East and West Wollega, Jimma, and Beni-Shangul (Gebissa 2002:81). These leaders worked to form a more cohesive vision before submitting a formal letter to the British consul, stating that as a nation, the country of Western Oromia "had not benefited from its incorporation into the Abyssinian state" as the empire had now become, and thus wished for its own independence (Gebissa 2002:85). This was the first time the Oromo had been able to make explicit the nature of their relationships with the Ethiopian state, rather than having their voices filtered through the empire. The Macha Tulama Self-Help Association (MTSHA) was formed by the Oromo educated class in 1963 (Jalata 2002:138). Because they were "barred by the Ethiopian Constitution from establishing a political organization," the MTSHA's stated objectives focused on improving Oromo society more generally (Jalata 2002:138). State elites refused to accept the MTSHA's work, and believed they had a subversive political agenda, subjecting them to harassment and violence, and limiting their effectiveness (Gudina 2007:89). These organizations show that the Oromo began to resist Ethiopian state violence by organizing and following structural protocol, despite the state's response. This was an attempt to negotiate for peace and freedom through diplomatic efforts, rather than violence. 
Other notable resistance movements during this time include the guerilla struggles of Bale during the 1960s, during which the Ethiopian state "needed the aid of Israeli explosive experts, British Army bridge and road builders, and American Air Force advisers... to withstand the insurgents" (OLF 1974:7). In addition to these rebel movements, there is evidence to suggest that many of the more rural Oromo peoples, in particular the Borana pastoralists in the South, continued to practice a functional version of the Gadaa system throughout this era (Bassi 2010:222). The continuance of the Gadaa is exemplary of non-state sovereignty, allowing the Oromo people to self-govern in a form unrecognizable by the state. No organization fighting for Oromo freedom would see their dreams of liberation come to fruition during the Selassie era. However, the roots of these forces of resistance, as well as an awakening to the potential political power of the Oromo people, both within and outside of state models, would truly bear fruit during subsequent regimes.

In addition to his violence towards the Oromo, Emperor Selassie oppressed and mismanaged the state on multiple levels, ignoring or willfully mishandling famines in the late 1940s and 1950s (Dugassa 2008:185; Reid 2011:152). As his actions began to have a more pan-ethnic impact, he grew increasingly unpopular and insecure in his position. He managed to withstand a coup attempt while on a diplomatic trip in the 1960s, but could not quell the rising tide of protests which began to grow after this bold move (Tolossa 1997:10; Reid 2011:154). At that time, many of the key people in power, including many military officials, tended to be highly nationalistic but had little commitment to the imperial line, preferring the hierarchal nature of the system of governance and the continuance of Amhara dominance, but failing to see Selassie himself 
as the best means of preserving this system (Markakis 1989). After decades of violence, including another major famine in 1973, the brutal rule of the last Emperor came to an end. The population responsible for the final overthrow of Selassie came from among the "urban populace... university professors and high school teachers, students, young bureaucrats and public employees, industrial workers, daily laborers, unemployed youths, and soldiers," who worked within their limited means to put an end to his rule (Kebedde 1987:2). After several changes in leadership, a series of very public executions, and multiple ideological rebrandings, the Dergue came to power in the mid-1970s.

\section{Section 4: The Dergue (1974-1991)}

The rule of the Dergue is known in the Ethiopian cultural consciousness as the Red Terror. The shape and direction of this terror formation changed dramatically from its inception during a "bloodless revolution" to its violent end, as liberation fronts from all sides joined forces against it ("Slaughter in Ethiopia" 1974). Coming at the end of the brutal ethnonationalist reign of Haile Selassie, the Dergue was initially brimming with hope and new ideas, promising to restructure and listen to the needs of the marginalized. They did not claim any particular ethnic group, nor were they as explicitly anti-Oromo as their predecessors (Gudina 1997; Joireman 1997). Instead, they sought to unite the masses against the tyranny of the ruling class, promising "Ethiopia first, but without bloodshed" (Tareke 2008:189) When the Dergue took over in 1974, 90\% of the population lived as subsistence farmers, a large percent toiling away under the remnants of the Nafxanya-Gabbar system. Their first act was to disinherit "the predatory landed classes" and to divest the Orthodox Church of its vast land holdings (Tareke 2008:185). 
With all of this early promise, the Dergue's eventual failure can be blamed on a few key issues: their inability to reign in greed, violent internal and external conflict, and the inadequacy of their investments into the institutions needed to implement their grand goals.

The goals and intentions of the Dergue regime, although filled with a revolutionary and anti-monarchal sentiment, were not made clear until nearly a quarter of the way into their reign, and even then they were tenuous. The first five years were mostly characterized by a pacification campaign, actually riddled with violence. After uniting enough of the key governing factions the Dergue produced an outline of their intended program: land reform (after pressure from the peasantry and urban poor), an improvement of material conditions across the country, and the destruction of the "socioeconomic foundations of the old regime" (Halliday and Molyneaux 1982:5). Each of these ideas appealed to the Ethiopian masses, but the regime's failure to turn these ideas into concrete, practical policies was part of their undoing. During this era, Oromumma became militarized and organized through the work of the Oromo Liberation Front, who retained popular legitimacy as other movements fell to divisiveness, continually drawing on their social and cultural network as a unifying force (Bariagaber 1998:1063). In general, the Dergue era's politicization of identity heightened existing and historic tensions, though in some cases it served to mollify previous disagreements by creating a newer, greater evil.

Politicization of culture during the Dergue era was an explicit state project. In contrast to Emperor Selassie's policies targeting cultural practice that were hyper-focused against the Oromo, the Dergue acted broadly, suppressing any potential ethnic 
politicization. Sentiments that seemed to reflect specific ethnic projects were decried as "narrow nationalism," and political activists marked with this label were jailed or killed (Hassen 2002:25). The Dergue method for dealing with the so-called nationalities problem was "scientific socialism," which ignored ethnicity and instead uses socioeconomic roles and positions in order to classify people (Keller 1995:628). In some ways The Dergue had a much keener understanding of the power of historical inheritance and culture, as their "policy towards ethnic groups was to allow, and even to stimulate, cultural articulation of ethnicity, but to suppress political expressions of it" (Aalen 2006:246). Cultural articulation includes language use, which turns into political expression when used as a way to organize or form non-governmental groups.

The Dergue's attempts to redistribute wealth under a reformed system of governance were unsuccessful in part because this system itself was never made intelligible. It nationalized the land without having a strategy in place for redistribution. It sent students on a mobilization campaign without having an institutional structure in place for these new nationalists to organize around (paraphrased Holliday and Molyneaux 1982:7). Beyond these organizational shortcomings, this attempt at a socialist reorganization failed in part because the deeply entrenched nature of ethnic identity was so connected to wealth and capital (Bariagaber 1998:1061). Attempts at wealth redistribution through the government collectivization of land and other techniques failed because the capitalist class and industry were left untouched in each reform. Although it lacked organizing principles, there were pieces of the Dergue rule that showed promise for a brighter Oromo future. The Dergue lifted Selassie's ban on printing and broadcasting local languages and made Islam an official state religion (Markakis 
1989:123). They also strategically severed the monopoly of Amhara political rule, a step meant to make state/ national identity more powerful than ethnicity (Markakis 1989:124; Tolossa 1997:4). Also promising was their support of some Pan-African liberation struggles taking place at the time (Orlowska 2013:303). These actions had an important impact on linguistic and cultural development, and show some evidence of the Dergue's attempts to actualize the revolutionary ideals it proclaimed.

Although the feudal land system had been eliminated, the villagization projects and nationalization of other resources in Oromia caused a "widespread feeling that the Oromo were... treated as "second-class citizens"” (Joireman 1997:394). In addition to resettlement on existing land holdings, some villages were developed or constructed as a strategic way of controlling the activities of the Oromo people, and were located in former rebel strongholds like Wollega (Cohen and Isakson 1988:329; Dugassa 2008:132). As these systems were put into place, the coordinated movements of the Dergue were "the first time in the twentieth century that Oromos in six provinces were attacked simultaneously" (Hassen 2002:23). The Dergue originally attempted to "harness Oromo nationalist sentiment to the class struggle" but had underestimated the cultural roots and relations of the Oromo (Markakis 1989:125). This strategic violence crystallized the revolutionary tendencies of groups like the Oromo Liberation Front and reaffirmed their belief that life in the Ethiopian nation-state was untenable (OLF 1974). The type of sovereignty that these values necessitate would not bend to the constructs of the post-colonial state, regardless of its leadership. The Oromo saw the ruling party and in particular the Habesha elites as settler colonists, living and working on stolen land (Jalata 2001:2). Negotiating for freedom from this tyranny reaffirmed the kinship values 
of the Oromo and the necessity for an Oromumma that could resist future violence. As Dugassa notes, "the motto they died for — unity—is the aspiration of millions of young Oromos" (2008:127).

Section 5: State Reformation and Solidification Post-1991

The overthrow of the Dergue regime in 1991 both reaffirmed and challenged some of the historical political constructs of the Ethiopian state. Although ultimately unable to truly reform the state, it was the first time Oromo people were given a real political voice. It also demonstrated the potential of cross-ethnic and diverse religious forces in implementing sustainable change, as the success of the 1991 revolution necessitated collaboration between liberation fronts across border, ethnic, and religious lines (Dugassa 2008:176; Reid 2011; Weldemichael 2013). In the years immediately following the revolution, there was little clear sense of what the future of the Ethiopian political or legal landscape would look like. It is important to note that just two years prior to the 1991 revolution, potential dissidents who attempted a coup were "tortured to death before their mutilated bodies were tied to cars and dragged through the streets" (Weldemichael 2013:257). During the process of state formation, ethnicity hung like a shadow in every conversation, whether or not it was being explicitly addressed; the reputations, histories, and core cultural differences of the major groups imbued each interaction with a particular tension (Hassen 2002; Michael 2008; Hagmann and Abbink 2011). The Transitional Government of Ethiopia (TGE), made up primarily of EPRDF members, eventually "came to the conclusion that the role of ethnicity could not be ignored in the peace that was now to be administered" (Joireman 1997:397). This made 
ethnicity a key factor in the re-organization of Ethiopia. The decisions made during this brief period give insight into the deeply entrenched nature of elite Ethiopian political power, as groups were forced back or firmly inscribed into the margins under the new laws.

Although representatives from all ethnic groups and parties were initially invited to the national sessions for negotiating and writing state policy, these invitations did not actually translate into an equitable voice (Orlowska 2013:299). During the 1992 elections groups such as the Oromo Liberation Front were accused of terrorist activities and swiftly excluded from participation, and the socialist movement, Islamic organizations, and other parties either boycotted the elections in response to this or were excluded for other reasons (Gudina 2011:668). The Ethiopian Peoples Revolutionary Democratic Front, the group given the most credit for the revolution quickly rose to power. Although pan-ethnic in name, the EPRDF was "anchored by the Tigrayan Peoples Liberation Fronts which provided 50 percent of its fighters and played a controlling role on its executive committee" (Joireman 1997:393). Thus a seemingly apolitical and pan-ethnic movement was actually been a means of obfuscating the continued violence of the elites (Clapham 2009; Feyissa and Lawrence 2014; Arriola and Lyons 2016:77). Many sources from this era report that the EPRDF created puppet parties like the Oromo People's Democratic Organization (OPDO) with the primary intent of undermining the political power and reach of the OLF, and manufacturing mouthpieces for the ruling party (Keller 1995; Sorensen 1996; Ayele 2017). The early organization of the OPDO by former EPRDF fighters was forceful and manipulative. Membership was non-negotiable for many people, and often work or loss of property were the consequences of a refusal to join. 
Soon, openly supporting the OLF was a crime punishable by imprisonment, torture, or death, and OLF members were held in remote internment camps to guarantee EPRDF victory in the center (Dugassa 2008:175; Weldemichael 2013:278). The EPRDF and its satellite parties were able to set up power structures across the state immediately following this election, which was widely considered a sham, and by the time the constitution was drawn in 1994, its loyal council approved every article of the new draft constitution with minimal dissent (Gudina 2011:669).

Amidst this widespread ethnic manipulation and reorganization, the roots of later political violence and oppression were implanted in the central political model. One of the first acts of the post-revolutionary government was to reorganize Ethiopia under an ethnic federalist system. The implementation of this system was reportedly an attempt to address, redress, and minimalize historic violence; even the most staunchly nationalist thinkers admit that the eras prior to the revolution were "audacious pretensions of empire building, masquerading 'modernization' as social progress" (Zegeye 2017:280). The new ethnic federal system sought to rectify this past division by establishing nine regions and two special city zones, each "designated as the ethnic homelands of single ethnic groups or combinations thereof" (Mozaffar \& Scarritt 2007: 246). In theory this system maintained some of the autonomy or self-actualization potential of each individual ethnic group, while in practice it subjugated them to and unified them under the umbrella of Ethiopia national identity (Semela 2012). Using ethnic federalism as a way to quell ethnic tensions was described as a way of "maintaining unity" and "enhancing the political participation" of the people (Aalen 2006:245). 
Political elites from Tigray and former EPRDF soldiers were able to manipulate the circumstances by making a cautionary tale out of the historic power-hoarding of Amhara elites, with whom the Dergue had become associated. Made explicit in the country's first charter was the prohibition of Amhara dominance, and nothing was said of the Tigrayan people, who constituted a mere $6 \%$ of the population at the time (Keller 1995:630). During the Dergue rule, the Tigrayan people were described as not only "the junior branch of the Abyssinian family, but also the poorest province" (Markakis 1989:124). In contrast, there is also reporting that the Tigrayan leadership strategically manipulated foreign aid during a famine in the late 1980s as a way to "recruit displaced and starving people to their military" (Dugassa 2016:182). Over time the TPLF involved into an intimidating political force, identifiable from the other state-sponsored parties by its staunch Orthodox Christian roots and values (Tadesse and Young 2003:395). These same TPLF leaders ended state negotiations with their own Meles Zenawi as the face of the emerging nation, and intended to leverage his international appeal to strengthen Ethiopia's image globally (Clapham 2009:183). This background provides important insight into the reactionary nature of this "new" state, rechristened as the Federal Democratic Republic of Ethiopia. The core values of hierarchal state rule entrenched in conservative Orthodox Christianity which had guided Ethiopia throughout much of its past were imbricated into legal and cultural norms. This hidden side of state formation demonstrates the way other ethnic groups used their cultural background to increase their own power at the expense of people like the Oromo. Mamdani describes these as tactics used to stabilize and cement minority rule, by grounding culture "in a politically enforced 
system of ethnic pluralism... so that everyone, victims no less than beneficiaries, may appear as minorities" (1996:6).

The new constitution and ethnic federal model also had important consequences for the treatment of indigenous peoples in relation to land. It was prescribed that the right to own land and all natural resources was exclusively the entitlement of the Ethiopian state, which is permitted to lease it to private parties or relocate people despite any adverse affects, with no requirement of informed consent (paraphrased Mesfin 2017:252). These clauses serve to directly undermine the autonomy of the indigenous peoples whose land was colonized by the Ethiopian state. This post-colonial condition allows for the legalized oppression and recurring violence of the governing powers, as long as it is properly justified by the neoliberal aims of the state (Donovan and Assefa 2003:506). As a set of strategies, Meles' preferred type of economic policy is better labeled as strategic underdevelopment under the guise of neoliberal expansion (Ellison 2009). Ethiopia is imagined as a "champion of the developmental state," while engaging in land grabs and privatization funded by foreign investors that serve to further oppress marginalized peoples like the Oromo (Feyissa and Lawrence 2014:301). Furthermore, although the governing framework allows for some regional autonomy, the majority of revenues are still channeled to the federal government, who then provides grants and services (Aalen 2006:248). Thus the state continues to profit off of indigenous people and lifeways, as with the exploitative coffee and tea plantations in West Oromiya, without fair or even adequate compensation; all is done in the name of the nation. It is clear that the ethnic federal model, even if run effectively, would do little to address the core injustices of the Ethiopian settler state. However, under the rule of Prime Minister Meles Zenawi this 
system was used as a tool for cultural imperialism, and neoliberal development that exploited rural resources and ruined any real chance for indigenous autonomy. Leaders who disagreed with Meles' attempts at economic liberalism were sent back to local parties in order to maintain this narrow vision (Clapham 2009:186).

Within these new state conditions, parts of Oromumma evolved both as a response and as a form of resistance. The vast majority of Meles' politicization tactics were intended to maintain elite Habesha power, and push Ethiopia onto the global stage as a modernized nation, whatever the cost. The elections he oversaw were described as shams, with ruling parties taking home victories in the high $90^{\text {th }}$ percentile (Gudina 2011; Hagmann and Abbink 2011). Leading up to the 2005 elections Meles declared a ban on "demonstrations and outdoor meetings," law which critics charge was arbitrary, subjective, and malleable at the hands of a violent state (Aalen 2006:252). More specifically, the mention of "outdoor meetings" includes the traditional form of Oromo gathering, a practice still used in smaller and rural communities. Gathering around the Odaa tree is also a way to celebrate holidays or special events, and is still practiced by Oromo people today. Thus Meles used Oromo culture as a means for limiting group organization and attempts to fight back against state injustice. Following a near-loss in 2005 that led to mass protests, a further series of laws were enacted that prevented protests and restricted freedom of speech — under the guise of an "Anti-terrorism Proclamation" (Dugo 2016:398). Oromos and other ethnic groups were expected to be appeased by the symbolism of the ethnic-based state parties, and thus ignore the entrenched elitism and violence of these institutions, the laws restricting free speech, or the problematic nature of the policies they presented (Dugassa 2016:189). 
One of the most problematic pieces was the focus on market expansion, despite the costs. The EPRDF quickly "discarded the military regime's [The Dergue] command economy and announced a more free market-oriented policy" (Gudina 2011:664). Soon after establishing state power, the Meles government began privatizing industries on a broad scale starting with hotels and hospitality (Henze 2003:194). Despite receiving increasing amounts of foreign investments as the government showed signs of stability, the results were not spread equally across the country. Some sources suggest, and it is popularly believed among rural Oromos, that this allocation was a form of punishment for the revolutionary tendencies of the prior generation (Hassen 2002:37; Bassi and Megerssa 2008:83). This is made more plausible by the direct connections between former OLF strongholds and elites and the rates of deaths and disappearances in these areas (Dugassa 2008:187).

Furthermore, although Ethiopia received high amounts of foreign aid, this money was often directed towards "emergency assistance" and the government was notably "adept at pursuing its interests and ideological commitments" within the bounds of international relations (Clapham 2009:189). Underdevelopment as an Ethiopian state practice seeks to exclude Oromo people from equitable presences in trade and the economy, and is often justified in sociopolitical, legal, or even geographical terms. The latter cause was used by Menelik to justify withholding aid, and this was also a partial explanation for decreases in road density and political instability (Herbst 2000:166). Whereas prior regimes would openly push Oromos to the margins of society for cultural reasons, these seemingly apolitical actions still target specific pieces of Oromo identity, and similarly serve to silence Oromo resistance. In discussing the difference between the 
EPRDF and past dictators, one exiled Oromo noted that while the Dergue killed with impunity, 'the Meles government kills and asks 'who killed him?' And then sets up an inquiry commission" (Dugassa 2008:196). The tactics have not changed, only the rhetorical framing.

While the drought of the early 2000s reportedly did similar damage across the country, there is substantial evidence to support the idea that Meles distributed the vast majority of the aid received to the Tigrayan province, even withholding fertilizer and agricultural support from Southern people as a political tool to squash dissent (Ejara 2003; Dugassa 2008). The rule of Meles also saw an increase in the expropriation and commercialization of indigenous land, both within and beyond Oromiya (Mesfin 2017:254). The year 2005 was the beginning of another resettlement campaign and Tigrayan and Amhara settlers were given tracts of land in Gambella, bordering West Oromiya (Lavers 2012; Mesfin 2017:255). These practices demonstrate a legally enforced manipulation and politicization of people like the Oromo and the Gambella through selective land use and forced relocations.

Meles employed many tactics of intentional disinformation and symbolic manipulation in order to present and maintain certain state ideals, and this erasure and rewriting continued after his untimely death. Although dying in Ethiopia at a state hospital, there is a mythology around Meles' death that leads in part to his continued significance today. Popular rumor (across Ethiopia) suggests that soon before his death Meles took a trip to Washington D.C. to conduct diplomatic relations. While greeting members of the diaspora, someone from the crowd broke out and screamed that he was a murderer, with Oromo blood on his hands (“Angry Ethiopians” 1997). Nationalistic 
Ethiopians insist that this moment haunted him, maybe even cursed him, and led to his eventual death by heart attack. For Habesha elites, there was no way to comprehend a country without own group at the top and simultaneously no reason to believe that anyone could distrust this power. This lack of empathy and inability to compromise would create the cracks that led to the destruction of Haile Selassie's empire in 1974. The Oromo people suffered and were silenced under Meles, and although this violence continued throughout the reign of Prime Minister Hailemariam Desalegn, the next chosen son of the EPRDF, the silencing of the Oromo resistance would not stand.

\section{Section 7: \#OromoProtests (2014-Present)}

The Oromo Protest movement has been a key catalyst in creating the current conditions and potential for positive change in Ethiopia. Although Oromo people fought back and resisted throughout the Meles era, using a range of tactics, it was in the last decade that the movement became more cohesive, effective, and unified. Since the start of the \#OromoProtests in spring of 2014, the Oromo people have maintained their resistance against state violence by using their cultural traits to increase their access to state rights and power, undermine neoliberal extraction, and reclaim the value of their people. I use the phrase \#OromoProtests with the hashtag (\#) symbol to differentiate this iteration of resistance from former protests. Oromo people have a rich history of resistance, but it was during this particular set of protests that the Oromo people took their movement online as well as to the streets. Members of the diaspora and those Oromos with access to internet used the phrase to identify sites of resistance, celebrate progress, highlight state violence, and reiterate the reason for the struggle: a free 
Oromiya. Thus this movement added a digital resistance front into its fight against the state. As Fanon noted, "The rising generations are neither more flexible nor more tired than those who launched the struggle," and they continue to adapt to their circumstances $(1994: 26)$.

During this era the Oromo began to more explicitly politicize their identity as a means of resistance. After the death of Meles, the Ethiopian political elite and its replacement puppet leader continued to push for its image as a stable economic power in a troubled region, and neoliberal tendencies became firmly-embedded policies and directives (Ellison 2009; Lavers 2012; Aalen 2014). The glossy face the regime attempted to paint concealed but did nothing to address the growing disparities in wealth and violations of human rights internally. These disparities, compounded by the political inheritance of colonial relationships, would serve to trigger and justify continued protests. The government's violent and targeted response to each sign of insurrection is detailed at length in Amnesty International's 2014 report, "Because I Am Oromo.” These tactics include the strategic disappearance of reported rebels and their family members, arbitrary detention, sexual violence, and other horrific acts (Amnesty International 2014:56). While this activity was kept mainly away from the public eye and international media, the economic disparities during this era are not as easy to conceal. Examples of such stark inequalities include the African Union compound, with its manicured grounds and pristine green grass, which overlooks a neighborhood in Addis Ababa where the river runs grey with trash, and the citizens still have no better way to wash their clothes. These contrasts characterize the uneven growth practices of an oppressive neoliberal state; as long as the markets report progress, the country is presumed by its leadership to be 
following suit. Interrogating the financial motivations of the state is a useful starting point, but fully fleshing out the Oromo experience necessitates a closer analysis of the state policies which allowed these ideologies to become actions.

Since its advent in the early 1990s, the Oromo Peoples Democratic Organization has been an essential piece of the state politicization process. Its role as an arbiter of privilege and rights with a false Oromo-centric intent has deeply penetrated the daily lives of Ethiopians even in the most rural areas. Its lack of authenticity is identifiable by the limited number of Oromo leaders in the party who can speak Afan Oromo, among other features. After a near loss in the 2005 elections, the government parties launched a concurrent campaign to increase membership, "in some areas blatantly linking public employment, promotion, and preferment to party membership" (Gudina 2011:673). During my time in Ethiopia, I saw directly the infiltration of the OPDO into the education system, utilizing economic rhetoric to encourage teachers to integrate pro-government sentiment into their educational praxis. The OPDO would hold mandatory teacher meetings throughout the school year regardless of the political climate, sometimes closing school early to ensure teacher participation. The organization of these meetings is a testament to the party's illegitimacy and its deep disconnection from the local people, as observable and noted by my colleagues and myself. Party leaders were unable to complete even basic greetings in Afan Oromo, using an incorrect grammatical form to address a group of people, smiling and unknowingly. Taking advantage of this fault, teachers tended to ask questions in Afan Oromo, especially about more convoluted issues like testing. This forced the party leader to rely on the school administrators for 
translation, or left him out of the conversation entirely. Seemingly innocent, these actions were small but effective means of undermining the OPDO.

In general, the meetings I attended were not explicitly political in nature, and tended to deal more with bureaucratic needs like school breaks, pay, and policies; some were neighborhood or regional associations. However, following the upsurge in protests in the spring of 2016, the government called in school administrators and teachers of subjects like civics for mandatory education camps in places like Adama, an Oromo city near the capital. During these programs participants sat in sessions for upwards of 10 hours daily learning about the necessity of organization, unity, and peace for development (rhetoric discussed in Arriola and Lyons 2016). More specifically, these lessons focused on providing methods to implant these ideals into the youth (specifically student) population. Participants who I knew personally or heard of anecdotally had fairly different reactions to these trainings, speaking to the divergent nature of politicization within the country. Very few of the Oromo people in my extended network reported positive reactions to the mandatory trainings, and those that did tended to be more politically ambitious, Amharic-dominant, or Habesha-centric thinkers, and less attached to their Oromumma. These few said they felt inspired and uplifted, ready to unite Ethiopia despite the petty disagreements that were holding back progress. Many others saw the content and nature of these trainings as a thinly veiled attempt to discourage people from expressing just grievances and contestations against a violent state. Using education as a way to frame narratives around organization and access to rights demonstrates the way cultural prejudice is imbued into seemingly innocuous national policies. 
In addition to its somewhat more mundane political programs, Ethiopia has also continually used legal means to justify the oppressive politicization of the Oromo people. A necropowerful state is an extreme form of state power that acts as a mechanism for determining life and death itself while also seeking to stomp out any hopes of life despite. The enacting of the 2016 State of Emergency in response to legitimate peaceful protests is Ethiopia's most egregious use of necropower in the modern era, a power that continues to trouble Oromo struggles for survival, and only rarely allows for palpable change. The extreme form of violent state oppression is still widely felt and understood as the normative condition of Oromo life. It is a form of politicization because it uses laws in order to delineate the conditions of existence; legally founded discrimination wherein the consequence is death. At a basic level, understanding necropower necessitates constructing a narrative based on statistics and figures. The number of lives lost during the Irreecha and Chalanqo Massacres, the number of citizens disappeared during a regime of terror, the military budget (fortified and supported by outside forces under the guise of foreign aid) of the Ethiopian state; these mechanisms construct a necropolitical force in a quantifiable and transmittable way. The Irreecha Massacre killed anywhere from 50-100 people in a single day, depending on which source you trust, and deaths of student protestors at the primary-school level were frequently reported throughout 2014-2017 (Human Rights Watch 2015; ACLED 2016:53; Carboni 2016; Borkena 2017; Zelalem 2017). Even these supporting facts are shadowy, and the challenge in seeking accurate counts contributes to the fear-based nature of this system. However, a full understanding of the necropowerful state requires an attention to the reverberating impacts of this death, and the constant fear of more death, and the way that this haunts and defines the nature of 
group identity and existence. When the Ethiopian state declared a national emergency in response to mass protests, it was the very presence of the Oromo that was designated kill-able, and the security of the entire nation that was deemed a threat.

One of the most effective means of implementing Ethiopia's necropower is the Agazi and Liyu Special Police, the Tigrayan-led elite units, identifiable by their red berets. Since the rise of the Oromo Protests as an organized movement, the Agazi have played an increasing role in enforcing Ethiopia's state power (Dugo 2016:397). In order to contextualize the power of the Agazi, and the way they demonstrate a necropowerful state, I will provide a brief example of one of my experiences with them. The year 2016 was one of the bloodiest eras in Ethiopia's recent memory. The Armed Conflict Location and Event Data Project trend reports from this year described at least 50 deaths a month across the country beginning in January, many the result of government-sponsored clashes (ACLED 2016:48 and 53). The Oromo Protest movement that had grown rapidly during the fall of 2015 was maintaining pressure, getting more organized, and refusing to be silenced. Separate issues over territory and ethnicity in the northern part of the country had brought to light the depths of the nepotism, corruption, and elitism in the Ethiopian ruling class. The necropower of the Ethiopian political force was quickly becoming a looming presence in village, town, and in households across the country. The Agazi were deployed hundreds of miles from the capital city, while being granted increasing amounts of autonomy, despite the fact that they were essentially seen as foreigners, speaking little to none of the local languages and coming through towns in massive tanks and camouflaged trucks. 
It was during this time that the potential of Ethiopia's necropower first became personal. A scuffle between two students in the school where I taught had led to a broken window; one boy was named the perpetrator and taken to the county jail. This was spring of 2016, and reports of Oromo youth "disappearing" from jail, and being subjected to beatings and torture were widespread, if unconfirmed. The students in my school reacted to his incarceration by protesting, leaving campus two days in a row as a large group with their arms crossed above their heads. This is the gesture of the Oromo protest movement, a symbol of arms locked up, chained by the state. They shouted two things over and again, "Ararso, Ararso, ijoollee gaddississaa" and "Haadhi Oromiya nutti gaddississaa;" Ararso, (the name of the local police chief) Ararso release the children, Mother Oromiya release us. The next day, the Agazi showed up.

They pulled up in a pick-up truck, three Agazi soldiers in the front, five in the back. All were armed, and identifiable by their red berets. Mounted on the floor of the trunk were sniper rifles, facing in opposite directions. The high school in the town I worked in is located on the edge of picturesque cliff, overlooking endless mountains, jungle, and a verdant sea in every direction. On a foggy day the peak it rests on sits above the clouds, seeming to float over them. The only way out is up a single road, sloppily paved by jagged cobblestones leftover from the Italian occupation.

To understand the power of this panopticon, place yourself in the Agazis' position: parked sideways across the single road, armed and mounted, staring down the barrel of a gun into the eyes of hundreds of enemy soldiers in-the-making. They stopped being students, children, when they raised their voice in the wrong direction, raised their arms and crossed their wrists. To understand the horror of the panopticon, place yourself 
in the students' position: locked in an institution that is supposed to be building, nurturing, and educating you, surrounded by danger on all sides; staring up the barrel of a government-sponsored gun. You stopped feeling safe the minute your schoolmate was swept off to jail. On that day, I sat across the street from the truck, peering out a window with everyone else, horrified. I saw firsthand the potential violence of necrotic power. On the next day, I sat with my students within those same walls and same buildings, and tried to turn an English class into a form of escapism. I don't remember what we talked about.

Far from being an isolated incident, the deployment of federal police and Special Forces became normalized both before and during subsequent State of Emergency declarations. Evidence of this deployment comes primarily from firsthand witness account, and limited reporting available via social media. Reports from activist Girma Gutema, posting from Hararge and other Oromo cities, shows proof of Agazi violence stretching through to the end of $2017^{1}$. While denying it at the time, by the end of 2017 as the rule of Prime Minister Hailemariam Desalegn became increasingly untenable, the government admitted that at times "members of the federal police and the defense forces were deployed to restore peace in the institutions," including colleges and universities ${ }^{2}$. Reports by outside analysts suggest that at the end of 2017 roughly $50 \%$ of violent conflicts involved either federal or state security military and police forces, and of that around 30\% were the actions of elite special police (Burchard 2017:3). As one jailed opposition leader said during his sham hearing in federal court: "You smell of blood. For

\footnotetext{
${ }^{1}$ Girma Gutema's Twitter page (@Abbaacabsa), accessed March 1 2019, https://witter.com/Abbaacabsa/status/941680825317421056

2 Addis Standard, via twitter (@addisstandard), accessed March 1, 2019, https://witter.com/addisstandard/status/941224076575760386
} 
26 years you've (wrongly convinced [sic] and) killed the Oromo people; for 26 years, you've been drenched by the blood of the Ethiopian people." ${ }^{\prime 1}$ When Oromo people took to the streets to protest during the State of Emergency, especially in large college towns, they chanted "Down, Down, Woyane," a reference to the Tigrayan elites who attempted to initiate a rebellion during the Haile Selassie era (Zegeye 2017:281; personal observation). That this slogan, rather than an explicitly anti-government sentiment, was chosen, points to the Oromos' perceptions of real government power, and the legacy that the Tigrayan people had embedded into the state shape.

The necropowerful state need not actualize its violence. It is the ever-hanging threat in the air, the deeply ingrained knowledge that an Oromo life could disappear and not be counted. Children felt it, heard it, repeated it, shaped their entire worldviews around it. My friend's five-year-old child, when asked where he wants to attend college, tells me that he can't go because "they kill Oromos there." Necropolitics needs to be understood for its impact on the psyche as much as the corporeal harm it enacts. What Mbembé calls the "state of exception" takes place in the Ethiopian context as a state of emergency, and an emergency seems to creep around every corner (2003:12). The Oromo Protest movement did not begin when the hashtag first hit the internet. The roots of the resistance can be found as far back as the era of Kings and Emperors. As a model for non-state sovereignty, organizing around Oromumma has proven to be an effective tactic. Through their continued resistance and response to state tyranny, the \#OromoProtests successfully interrupted economic and social life to the point that they could no longer be

\footnotetext{
${ }^{1}$ Mohamed Ademo, via Twitter (@Opride), accessed on March 2019, https://twitter.com/OPride/status/951491391498137600
} 
ignored. The most radical tactics were their striking and nonviolent protests, which demonstrated the effectiveness of the core Oromo values of community and peace, as a way of resisting state violence.

The Oromo resistance, both formally and informally, has employed a number of nonviolent resistance tactics, but its most prominent or effective moments have been its attempts to communicate with wider audiences by employing symbolic public acts such as the display of flags, gestures, and mass action. Oromos work within the means given to them to share their message with the public, despite a lack of access to spaces of mass communication outside of the diaspora community. This is particularly true of the runner Feyisa Lilesa's protest during the Rio Olympics in 2016. Lilesa garnered the first real international attention for the Oromo cause, finally bringing the protests that had been taking place across the country for over two years to a global stage. During the last few meters of his silver medal performance in the Olympic Marathon, Lilesa lifted his arms above his head and crossed them at the wrists. This gesture is symbolic of the Oromo struggle in a very visceral way; the gesturer appears to be chained up at the wrists, locked together like a prisoner, the same way the Oromo people have been locked down and restricted by the Ethiopian state. This action was both incredibly brave, and incredibly dangerous. As Lilesa himself recounts, he knew that this was not merely a cry for help, it was also a sentencing; he may never get to see his country again (2017). This gesture, made illegal by the Ethiopian government's State of Emergency policies, finally triggered international conversations about the Oromo condition.

On a more local scale, the Oromo resistance began employing stay-at-home strikes during the spring of 2017, after the first State of Emergency had been lifted, The 
decision to strike is typically spread among members of the resistance by way of social media when it is available, and more generally by word of mouth or informal communication networks. During these strikes Oromo students, workers, and business owners refuse to work or learn. Businesses are shuttered, schools are open but not attended, and government employees stay home. Sometimes during these strike periods, members of the resistance will take a more active stance and block roads as a deterrent to those who would break the strike. The key impact of the stay-at-home strikes is a demonstration of the strength of Oromo social power. While they have been systematically denied access to political power or military might, the Oromo people have fought on. By employing a stay-at-home strike, the Oromo people are clearly demonstrating to the government the impact that they have on the economy. Doing so also reiterates this message to the Oromo people, and highlights the strength they have has a community. Any attempt to interfere with economic progress is particularly threatening to the ruling class, who have long attempted to use the rhetoric of "peace for development" to quell uprisings.

Each of these tactics differs in its scope, publicity, and effectiveness. However what makes this era unique in the history of the Oromo is the strategic decision to use Oromo culture as the catalyst through which to decolonize the Ethiopian state. Although the Oromo have long resisted oppressive violence, they formerly relied on reactionary tactics to achieve radical ends, appealing for freedom from colonial tyranny to European colonial empires, or creating rebel military groups to fight internationally-funded militias. These campaigns failed to achieve significant results because they lacked the decolonial imagination necessary to see a sovereignty beyond Ethiopian nation-state lines. The 
current \#OromoProtests make it clear that the Oromo will no longer be denied access to rights, power, and a public voice, and when the state is unwilling or unable to provide this space they will create it.

\section{Conclusion}

Throughout the history of the Oromo people in the Horn of Africa, the Ethiopian state has been a source of violent oppression, manipulative governance, and exploitation against them. Recognizing this history and legitimizing these challenges is part of the process of resisting the future violence of this nation-state. Furthermore, identifying Oromo practices of resistance within and despite Ethiopia is only possible with a clear comprehension of what they are working against. This chapter has aimed to address my first research question, looking at the way Oromumma has been politicized over time, as drawing on a careful analysis of literature and my personal observations. The following chapter will explore the way this politicization and the nature of these relationships are understood by Oromo people living in the diaspora. 


\section{CHAPTER V: KEY THEMES AND FINDINGS}

\section{Introduction}

This chapter describes and organizes the main ideas and themes that emerged during the interview process. They provide an answer to the research question: What factors have most influenced Oromumma in the diaspora? In order to understand how members of the Oromo diaspora understand and define the nature of their politicization, I asked questions about their histories, and the way they had experienced Oromo-Ethiopia relations. Their answers were coded for examples of economic, political, and cultural phenomena. This process is explained in Chapter III. At the end of each section I present Organizing Themes that unite and make sense of the responses within each section of codes.

\section{Economic Politicization}

\section{Becoming the Gabbar}

In the economic domain, one of the most consistently described abuses of the Oromo people was the exploitation of the Oromo homeland and the Ethiopian state's practice of withholding profits from Oromo people. Each era of Ethiopian governance brought with it certain forms of exploitation. Notable however was the way that participants across demographics described similarly the ways in which their homeland and their bodies were viewed by the state only in terms of economic production. The era of Haile Selassie and the Nafxanya-Gabbar system had particular impacts on the Oromos' economic position. It was during this era that a common expression, which also neatly sums up the nature of state relations, was "One Amhara person should have two Oromo 
slaves," as Gifti shared. As a state-sponsored economic system, this meant completely rearranging social relationships, as well as relationships to the land. Ebba, now in his late 40s and born at the end of the Selassie era in Western Wellega, describes his experiences growing up:

Oromos who participated in the war [against the Italians] when they come back to their country...the northern regions [Habesha elites] they came, and they took over their land. And the Oromos who had been there, it doesn't matter... you lose your land. Those people by the name of heroes, they come and conquer, they take over your land, and you become the Gabbar.

By "becom[ing] the Gabbar," Ebba means that the Oromo people went from free landowners to tenants and laborers, forced to pay rent and give contributions to Habesha elites and the favored friends of Emperor Selassie. This policy disrupted Oromo religious practices and agricultural land use, while also legitimizing the exploitative economic tactics of the Ethiopian state. Although only two of the interview participants lived through the Nafxanya-Gabbar system of feudal land control in their teenage years, the ideologies necessary to implement it remained present and influential in current narratives.

When describing the way the Ethiopian state treated Oromo people, the respondents explicitly noted its commoditizing tendencies: "they just use Oromiya as a resource center but they don't invest back on it" as Chalchissa said, similar to Ebba's view that "they only use you to farm and field you, to pay rent on the land." Oromo people were stuck in exploitative roles that never rewarded or acknowledged their labor or their historic relationships to the land. Even Sanyii, only six weeks into his life in America and born in the early 1990s, during the current EPRDF system, understood and 
had witnessed exploitation by state elites: "Those people from Addis, from anywhere, they buy products from Oromo people with cheap money and they sell it for expensive money [sic]." By taking advantage of the resources, fertile land, and bodies of the Oromo people, state elites profit off and exploit the Oromo.

In cases where the Ethiopian government could not legally separate Oromos from their homeland nor effectively profit off of them, the state has proceeded to marginalize and exclude Oromos from accessing the benefits of their land and labor; in many ways the economic wishes of elites would be better filled if Oromos simply died. This understanding was echoed by participants across the group. Gifti, born in North Showa during the Dergue era, stated it the most pointedly, "There was a time when you were not even allowed to live anywhere, as if you were not even born on this planet." This mirrors Ebba's description, as the farmland his family had lived on for generations was given to Northern settlers. When respondents discussed the marginalizing tactics of the Ethiopian state in terms of land, urban development was a common issue. Chalchissa notes that one of the perceived motivations behind the government's forcible implementation of the Master Plan was that the state elites

Wanted to add and pile up the land they had, just to make a lot of profits. And they wanted to take Finfinnee or the capital city out of Oromiya and wanted it to be a region by itself, and then Oromiya wouldn't benefit from any income that Finfinnee generates.

This attempted remapping demonstrates the way elites exclude Others from joining the upper class. A Finfinnee that is legally separated from Oromiya would not have any connection to the Oromo people or language. This system allows for elites to maintain control and continue to marginalize the masses. 
In every aspect, the economic benefit that Finfinnee produces is both withheld from Oromiya as a region, and from Oromos specifically. Many participants discussed how hotels, shopping centers, and other modern businesses were exclusively owned by Tigrayans. Chalchissa, who was born in East Wollega at the end of the Dergue regime, in the 1980s, explained at length:

Starting from the whole income generating thing all the way out to electronics. That import, export, you know, they're all in control by the Tigrayans... If you go to Finfinnee now and if you go down Bole, which is the most expensive part of the city, there are so many hotels, and almost all of those hotels are owned by the Tigrayans.

Chalchissa was not alone in his description of these economic disparities. Many participants described the way only Northern elites had access to modern industry. Abdi describes all of these new developments and selective modernization as "a kind of colonial project that is for the economy to amass money, and send out, and to finance the development of Tigray." Finfinnee's land is given to Tigrayan business owners who develop it, modernize it, use the space to set up international trade, and funnel the benefits only back to the North, or their own pockets. This elite ownership was identified by respondents in each major industry: technology, natural resources, and trade in general were all described as Northern-owned. When explaining the Addis Ababa Master Plan, Bontu, who grew up in the 1960s in Illubabor, immediately identified the underlying ethnic base: "All these rich people, they are not Oromo. They are maybe Tigray people, or maybe Amhara, and they are just like moving the population of Oromo all the time." This strategy enforces the economic dominance of the few at the expense of the Oromo. Over time, the exploitation of Finfinnee by government elites, and "Northerners" in particular, became increasingly untenable because, as Gifti explained; "The land in 
Finfinnee, or Addis, is getting smaller and smaller by day because all these rich people from the north wanted more land, and the profit you get from land is enormous." As the land "got smaller," the limits of exploitation began to stagnate, and the government's response was to forcibly evict Oromo people from the surrounding areas to allow the continuance of profit. This economic strategy demonstrates the prioritization of profit over people, as well as giving proof of the influence of elites in state institutions, with economic consequences.

In addition to the elites' chokehold on economic power in the capital city, the marginalization of the Oromo people through exclusionary tactics was described as a national, systematic issue. Badhaassaa, coming from Bale Region and raised during the Dergue era of the late 1980s, when asked about Oromo's access to work and jobs, said: "If you get a job you're not promoted to high position, to lead or something. It doesn't matter. Regardless of your success or how much activity or productive you could be, they don't allow you." In this description, the "they" indicates Habesha elites, referred to also as "Northerners," who are described as having monopolies on power and business across the country. Sanyii made his opinion much more explicit: "It was only Tigrayans who had a chance to work and some big companies. Oromos were denied of the right to work with them because even though we are hired we might do bad things... we didn't have equal chance." In this specific example, elite ideologies have embedded themselves into business practices and are used to permit Oromo exclusion.

Marginalization has generational impacts on the people it oppresses. Biiftu examined the results of this strategy closely: "You don't find Oromo real estate owner, Oromo investor, you don't find a lot of those people, because politically and financially 
they are marginalized. In that way, the community has nobody to look up to." A key point is made clear here: no promise of economic change will have a meaningful impact unless it addresses the generational disadvantages of the previous systems. However, no participants shared a genuine hope for or belief in the possibility for change emerging from the economic domain. The market-driven nature of the state is demonstrated in the way investment is pumped into Oromiya but never returned to Oromo people, as Badhaassaa shared: "There is no service that is designed or planned from the government to serve those areas [rural Oromiya]. All that what they care is they care for the resources. That's it." These feudal, post-colonial, and now increasingly neoliberal actions and policies have irrevocably changed the way ethnic groups relate to each other within the Ethiopian state. Both marginalization and exploitation were implemented to specifically benefit Tigrayan elites, and these effects are felt and identified by the Oromo generations after.

\section{Organizing Themes}

Within the economic domain, a few organizing themes emerge. These are displayed on page 102 as Figure 5.1. The key Organizing Theme, which unites the others, is that the Ethiopian state has sought to commoditize all social relationships. This commodification, most saliently between the Oromo people and their homeland, has become a foundational piece of the state and the way it relates to its subjects. The elites frame the place of the Oromo only in terms of their economic benefit. Under the Nafxanya-Gabbar system, vast areas of land that were once the Oromo people's home were populated by settler colonial cities and resettled Northerners. Although the system 
has formally ended, the cities and populations created as a result of it remain. Through these re-mappings, Oromo people are forced to stay the Gabbar, the second Economic Organizing Theme.

By staying the Gabbar, I suggest that even though the post-colonial state has eliminated the feudal labor system, its impact has done permanent damage to Oromo futures. Oromo people, though no longer slaves, still do not live freely on their historic homeland. Ayantu described this ongoing exclusion: "This is the issue of Oromos today, as yesterday. The struggle for the land still continues. People do not own the land." This profiteering serves to keep power and control in the hands of elites, who force Oromo people to the margins of society and deny their economic advancement. Biiftu, also quoted earlier, clearly described Oromos exclusion from real estate and land ownership as an example of Oromo people being "politically and financially... marginalized." This marginalization characterizes the place of the Oromo within the city. However, the economic practices of Ethiopian elites were also impactful in the design and structure Ethiopian cities. This is demonstrated by the third Economic Theme.

Finfinnee, known internationally as Addis Ababa, exemplifies the commoditizing and extractive tactics of the state, described as the manipulation of Finfinnee. Formerly the heart of the Oromo homeland, Finfinnee is now the site of Tigrayan-owned condos and never-ending construction projects. Chalchissa explained that "The economy is mainly controlled by the political elites from the north, the Tigrayans, so not many Oromos can find that financial strength." The control of an Oromo city by Northerners in a way that denies Oromo existence echoes the treatment of the Oromo under the feudal system. As the hub and metropole of the post-colonial state, Finfinnee has lost any 
connection to Oromiya, and become the property of greedy elites. The Oromo people do not see the results of Finfinnee's profit and are excluded from accessing these benefits; "even if they live there they're just doing the low class, they just take any type of low level of job," as Ebba explains. The geographic location of Finfinnee, in the center of Oromiya, and its access to Oromo goods and labor do not mean that these opportunities actually support Oromo people. Instead, as Sanyii shared, "Even though the resources, everything is from Oromo region, from Oromos, still they [Northern elites] don’t appreciate."

The liberation of Finfinnee from this system would require a radical re-imagining of the entire economic model that allowed for this marginalization to become institutionalized. If Finfinnee were to be a city that gives back to and sustains those who live there, or a city whose cultural heritage plays a part in determining its future, hope for an economic resistance may be a more realistic possibility. This, however, is not the case, and this version of Finfinnee only exists in speculation and dreams. As a set of Organizing Themes, we can understand the economic relationships to be uneven, exploitative, and contributing to Oromo oppression. There was little suggestion of Oromo resistance in the economic domain in the lived experiences of my participants.
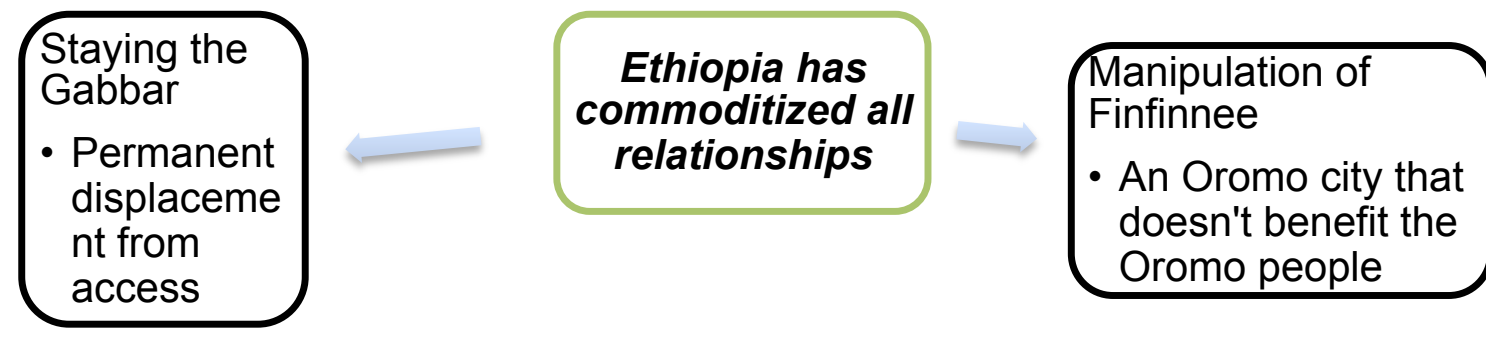

FIGURE 5.1: Organizing Theme- Economic 


\section{Political Politicization}

\section{One Country in the Sky Above Us All}

The Ethiopian state has used subordinating tactics to prevent Oromo people from gaining or accessing political power since its initial formation. When exclusion and strategic underdevelopment were not enough to maintain elite power, the government turned to necropower, killing and using the threat of death to control the population. In response to these types of violence, the Oromo people have reorganized and found forms of sovereignty that function outside of the state model. The presence of these phenomena shed light on the way that the state has used law and legality to restrict Oromo futures, as well as the way the Oromo people interviewed for this project have used the strength of their culture to undermine oppressive state formations and imagine alternate models. Many participants spoke openly about the violent political strategies employed by the state. As Ayantu, born in the early 1970s in Bedele Region, described: "There are two differences within one country... two different kinds of citizens, actually. The northern part... Amhara and Tigrayans. And the others, which is western, southern... The Oromos and all other tribes are kind of second level citizen."

First-level citizens are the only ones allowed access to a harm-free Ethiopian state system. In a more poetic portrayal, Tolera explains that when it comes to Habeshas and the state, "They are one country in the sky above us all. The rest of the people are in a hole." Both of these acknowledgements and experiences demonstrate the way subordinating political practices have been embedded into the system of governance. More specifically, education and access to resources were the most commonly shared strategies of state subordination, and will be discussed further here. 
Limiting access to education is one key mechanism through which the Ethiopian state has kept Oromo people subordinate. My participants both alluded to challenges in access, and spoke about them outright. Obsee, who grew up in the western part of the country in the late 1980s and 1990s, explained her experiences: "He [the government] don't want the Oromo people to organize... he knows if they get education they are going to learn they were treated in a bad way, that they don't have anything or any rights." Specific examples of restrictions placed on educational access include the bans placed on Afan Oromo in schools and the generational disparities in literacy this has produced, as well as a lack of infrastructure necessary to attend schools, including unavailable or unpaved roads. Participants from all eras, genders, and religions spoke similarly of the hindrances to their educational achievement. Abdi explained that the "government was sabotaging the Oromo's education. They don't want us to come to knowledge." The government system was portrayed as working against Oromo education from every angle. State subordination was similarly enacted through other institutions.

Discriminatory access to equal rights was also embedded in the legal system, where linguistic discrimination was mandated; all legal proceedings were historically held in Amharic. Wayissa recalled that throughout the Dergue era and into the EPRDF years, "This court could be Oromo, but he's not allowed to hear you speak in Oromo. He wouldn't let you speak in your own language, even though he can understand. That's how much the Oromos were excluded." Although Afan Oromo is now a legally recognized language, rural Oromo people who travel to major cities like Finfinnee to contest land grabs in court may struggle to find an Oromo interpreter. Thus legal policies and tactics continue to allow the Ethiopian state to suppress Oromos' ability to get fair access to 
rights. Discussed more extensively by the participants was the extreme end on the spectrum of state control: the state's deployment of necropower against the Oromo.

The necropowerful potential of the state was activated in two ways: through narrative creation that justifies the death and over-policing of Oromo people, and open, large-scale violence. The educational system's treatment of the Oromo people has vacillated between erasure and demonization, both of which play a key role in justifying violence. Erasure permits destruction, but threats of violence against the state permit and beget violence. Unanswered demands for more representation in state systems have allowed for Ethiopian elites to deny the positive contributions of Oromo people over time. Silence is a drastic difference from the state's typical treatment of Oromo people, as Bontu notes: “They'll say they [Oromos] are criminals who tried to overcome, to overthrow the government and take power. They will teach you someone bad, like terrorist... they tell you that they're trying to kill the Amhara people, that's what they teach." This framing of the Oromo as inherently against the Ethiopian state project, and in need of taming, is a necessary piece of the violent Othering and suppression of Oromo existence. It is these types of ideologies that are responsible for the waves of mass imprisonment against the Oromo. Ebba described the set of circumstances that led to his escape from Ethiopia in the early 1990s, as a direct result of this construct:

As soon as they [the EPRDF] came in they just put me in jail. There is no reason, just because I am Oromo.... I wasn't supporting anyone, but automatically they decide I am supporting OLF and they put me in jail. When I came out, they came after me again. They were trying to recruit me. I refused. And then finally they gave me a warning... that if I don't be with them [the EPRDF] then there is a chance of going back to jail again.

Rather than face this cycle of imprisonment, he escaped. It is important to remember, 
here, the notoriety of policing and prisons throughout Ethiopian history. Documents over the past two decades include extensive reporting of this violence, detailing disappearances, starvation, and torture in state prisons (Hassen 2002; Amnesty International 2014; Africa Research Bulletin 2016). A jail sentence could just as likely mean a death sentence, and the only necessary justification was a trace of Oromumma. Wayissa spoke with candor about his experience in prison:

They took us to this remote area they detained us there for almost like a year. Torturing, doing all these kind of bad stuff in that detention center... They have done all like the bad things human beings can do.

This type of incident, far from being isolated, was reflected on openly by several participants, while others alluded to stories, rumors, and memories they did not want to elaborate on. The general portrayal was that the imprisonment of Oromo people also had deathly consequences.

Biiftu, growing up in Illubabor at the end of the 1980s and early 1990s, described this era similarly, though she was much younger at the time. As an elementary school student, she recalls, "we were in a time where being Oromo was considered a crime by itself. And that was part of that regime." The criminalization of Oromo identity was necessary to justify further oppression and violence, and was found across institutions, with consequences that damaged Oromo identity as well as Oromo bodies. Each of the participants who lived under Haile Selassie's educational system shared similar stories of ostracism targeting their language and culture: being forced to change their name and language to get through these institutions without harm. Abdi, who left the country at the end of the Selassie era in the early 1970s, traces the formation of resistance movements directly to this harmful educational system: "Their [Oromo resistance organizations] 
demand was land rights and education, access to knowledge. And many of them died, were massacred. And the massacres still, until last year it didn't stop." In a direct, physical way, being Oromo was a punishable offense, and attempts to organize around this were some of the most egregious offenses. The Irreecha massacre, remembered sadly by many participants, is the most egregious example of this in recent history. In a single day, dozens of Oromos were killed, and the government has yet to fully acknowledge or make amends for this violence. Ethiopia's use of death and the threat of more death to enact state rule was a consistent theme from the interviews, across political experiences.

When asked about the government's response to the Oromo protests, compared to the other examples of government oppression, participants spoke of the deadly nature of state governance. As Chalchissa stated:

I wish sometimes it was a fight between two military groups. It was just the government, a lunatic government, against innocent people, innocent civilians who are asking for representation in the government, who want their culture to be entertained in the country, who want their identity also to be seen.

This "lunatic" government is well armed, well funded, and notoriously violent. Speaking to the same question, Tolera responded, "The way the government had been handling all these questions... was through bullets." The Ethiopian state's use of force to maintain state rule is clearly understood by Oromo people. The narratives of "violent Oromos" and future terrorists that defined the educational system contradict sharply with the historical relations between Oromo people and the state that colonized them. This is made more evident the more Oromo history is given proper attention and analysis. The ideology of violence by a state which seeks to justify its use of necropower is hypocritical, and the Oromo people feel this hypocrisy. As Obsee explained: "They say 'oh everybody has a 
right to exercise... to speak his language, to write in his language' but when they see writing [in Afan Oromo] they either kill you or you have to leave that country or they put you in jail.” These experiences illustrate how the Ethiopian state criminalizes and then kills Oromo identity.

\section{Political resistance: sovereignty gone underground}

Despite this extensive violence, the Oromo people I interviewed identified practices of freedom and resistance that exist outside of the state. These examples of nonstate organization demonstrate a healing potential that speaks to Oromo history and futures. Although a few participants mentioned the Macha Tulama and its work, it was the OLF who truly captured the resistance spirit of the Oromo. Their origins were spoken of highly, as Ayantu remembers from her childhood "The OLF was fighting for many years... educating the Oromos about our rights, about everything, the politics, our history, our culture." Creating alternate institutions that serve and meet the needs of the people is an example of non-state organization. This was a common practice of the OLF, and was identified by participants as one reason the Ethiopian state could not tolerate their existence.

Badhaassaa, like many other participants, blamed the removal of the OLF from state politics on the EPRDF, who "stopped the organization [the OLF] and they banned the organization simply because they wanted to make roads and clinics in the Oromo region." This explanation contrasts directly with the justifications provided by the Ethiopian state, which has long accused the OLF of violence. The illegality of the OLF, however, did not diminish their power and prevalence in Oromo communities. The 
legacy of their organizing, and the unified Oromo identity they promote, is seen in the rhetoric used by respondents. Chalchissa lamented, "If the Oromos, all the Oromos knew what they know right now, any government wouldn't exist or survive for a long time. But back then, even the Oromos were not aware of who they are or what OLF means for them." The OLF has long functioned as an alternate model to the Ethiopian state, with a reimagined sovereignty. As more Oromo people become aware of the real possibility for resisting state violence, the perception of the OLF in the Oromo cultural consciousness is elevated and strengthened. It is also important to add that the current moment in Ethiopian politics (particularly the existence of an Oromo Prime Minister and the re-entry of the OLF) is being watched closely by all Oromos. The coming election, which has yet to be officially scheduled, its legitimacy, and the nature of OLF participation are an opportunity to change the future of Ethiopian politics in a real way. A re-established OLF competing in a fair election could change the face of state relations.

Using cultural knowledge and traits to organize and practice a non-state sovereignty was a key aspect of both national and international resistance. The OLF organized Oromo people across Oromiya, and in doing so also served as an example for radical sovereignty as they left the metropole and started "establishing themselves underground," as Ebba explained. OLF base camps were exiled to Somalia and Eritrea until very recently, with only a few scattered groups in the deep Northwest and Southeast parts of Oromiya maintaining a presence. However, the fear of their existence and return has long motivated Ethiopian state action. I identify this resilience and the recognition of this resistance force as a type of sovereignty because it legitimizes the political power and sway of the Oromo people, despite existing outside of state boundaries. This, in many 
ways, is sovereignty of the soul, a way of keeping your community alive. As Sanyii notes, "They are afraid of Oromo because they [Oromo people] are dying, and still they [the protests] are not stopping." Oromo people are asserting their claim over their future, despite the violence.

Also threaded throughout descriptions of Oromo resistance were the ways in which the diaspora itself allowed Oromo people to counteract and fight back. Technology is one key piece of this: "Before they were still killing, but now it is on social media, on internet, on everything. People on Congress, the U.S. government, U.S. president, worldwide they see," Bontu explained. The diaspora makes the Oromo struggle more visible and puts it in closer contact with those who have the power to make change. This expansion changes the face of the Oromo resistance. In the early years, diaspora formation was a more reactionary process, as Wayissa explains: "There is a time when you cannot take it any more so then you either go and join this group [the OLF] or leave the country." Compared to the radical action of the OLF, entering the diaspora and its exile was seen as a back-up option, or weaker alternative. However, as the technological capabilities and organization of the diaspora have advanced over time, the potential resistance power of the diaspora has also grown. While the OLF has now re-entered the national mainstream, and will almost certainly be allowed to field candidates in the next election, it has also demonstrated its sovereignty and resistance potential outside of the state for decades.

\section{Organizing Themes}

As a domain of politicization the political project can often be the broadest 
reaching, because it is enacted through law and policy, as well as control of state institutions. Organizing Themes that emerged from participants' discussions of the state project demonstrate both the legacy of the settler colonial state, and the way Oromo resistance has learned to grow around, despite, and beneath this construct. By taking the land from its original owners, settling and then resettling it with outside people and imposing a violent education system, the Ethiopian state reveals itself to be a Habesha settler colony, the broadest Organizing Theme. Examples of the colonial nature of the Ethiopian state were prevalent. This "citizenship in the sky" is only accessible to elites, and marked by hypocrisy. Obsee gives an example of the capital city, where the settler ideologies are strongest “The northern party are still complaining Finfinnee doesn’t belong to Oromo. Whereas Finfinnee is at the center of Oromo, I don't know what else they can think." Recognizing this makes clear the way this project was both embedded into education and characterized by the idea of a "citizenship in the sky." The language of this latter theme, taken directly from an interview, paints a clear picture of what life under this state is like for non-elites, and highlights the oppressive tendencies of the state. Understanding the way education has enacted and supported this project makes clear the permissibility of other forms of violence. These are two tools of the settler colony which were also features of the Oromo resistance project.

The concept of the "citizenship in the sky" is a way of describing the clear disparities in rights and access provided by the state. As Biiftu declared, "If one is in upper position and one is like lower position, it's not gonna work... First-class Ethiopian, second-class Ethiopian, that's what I'm having a hard problem with." She was not alone in this frustration. Participants spoke at length about these gaps, and their difficulty in 
overcoming them. First-class Ethiopians were consistently the Northerners, Habesha, Tigrayan, Amharic-speakers; the same elites in every institution. Oromo people often faced a difficult choice, as Tolera explains: "If they [Oromos] play into their [Habesha] benefit or into their ideologies then they are part of Ethiopian culture. If they don't, then they don't write their culture or their history." The latter choice, to refuse assimilation, results in parts of the country where "Oromos were really neglected and basically abandoned," as Gifti notes. This conditional citizenship results in clear differences in the lived experiences under the Ethiopian state.

As is the case with the hierarchal nature of citizenship, education was a way to perpetuate anti-Oromo narratives and maintain Oromo oppression, and was central to maintaining the legitimacy of the settler colonial system. Even accessing education was politicized, as was explained at length by my participants. Sanyii summed up government resistance to providing educational opportunities as a well-designed plot: "That's what the government planned for them, to give them [Oromos] a lack of education so they can't understand each other, so they can't organize, they can't do something together." This intentional division helps legitimize Habesha rule. In cases where educational access was open, the subject matter and manner of operating was still of concern. Participants shared at length how the system punished Oromumma. Ebba explained:

If you say a word in Oromo at school then the class manager, as we call it, she write [sic] his name... Then you're gonna go to the principal and they will... gosh. That means they will whoop you like five, ten, fifteen times or something like that. Just because you said a word in your own language. And plus you don't know the word in the other language!

In each institution, Habesha culture and anti-Oromo sentiment worked together to promote, establish, and normalize the settler colony. 
Meeting, challenging, and in many ways working in dialect with the Habesha settler colonial project were Oromo practices that sought to reimagine statehood. As an Organizing Theme, this re-imagination is characterized by new understandings of sovereignty and solidarity, and institutions that exist outside of state reach and control. Abdi noted that "Oromos are really reinforcing now. The force is still... really forceful, demands are high, to control the land and the resources." These demands echo the organization and practices of groups like the OLF who refused to give in to the Ethiopian state's oppression. Where the Ethiopian educational system functioned through violence and erasure, Oromo people and groups turned to alternative organizations to carry their people forward. This includes both OLF schools and the oral traditions and narratives that survived on the margins of the state. These organizations, though not necessarily statelike, have the power to fill in the gaps left by formal state structures. Sanyii imagines a return to this way of life, an idyllic and ideal Oromiya: "Everyone guides you... even like people you don't know. Everyone will protect you. Whoever it is, what kind of child it is, it doesn't matter the race or their father, anything. Everyone will protect you. That's the kind of society." This collaborative system is a demonstration of Oromo visions for societal organization and operations in forms beyond the state. Oromos recognize a value in sharing knowledge that doesn't require submitting to violent institutions.

Stretching sovereignty is the other key mechanism through which the Oromo challenged statehood. By working together over and beyond state boundaries, Oromo people are legitimized and able to act as a free people. Tolera explains that "today's media and social media is worldwide. People are seeing. American people are seeing. Now this puts a huge pressure on the government of Ethiopia." If the Oromo people 
relied only on the Ethiopian state, Oromiya would remain underdeveloped. Within Ethiopia, "They don't have road, they don't have health care centers... compared to other regions Oromiya didn't benefit from the past 27 years, or even before that," Chalchissa explains. As such, the Oromo seek alternate institutions that can meet these needs. The diaspora gives the cause an international angle, and this attention opens up possibilities for what Ethiopia can and should mean for the people it rules. Returning to the larger category of political politicization, understanding both Ethiopia as a Habesha settler colony and Oromos reimagining statehood as Organizing Themes makes sense of the state's political actions, interactions with the Oromo, and nature of Oromo politicization over time. These networks are displayed as Figure 5.2 and 5.3 below.
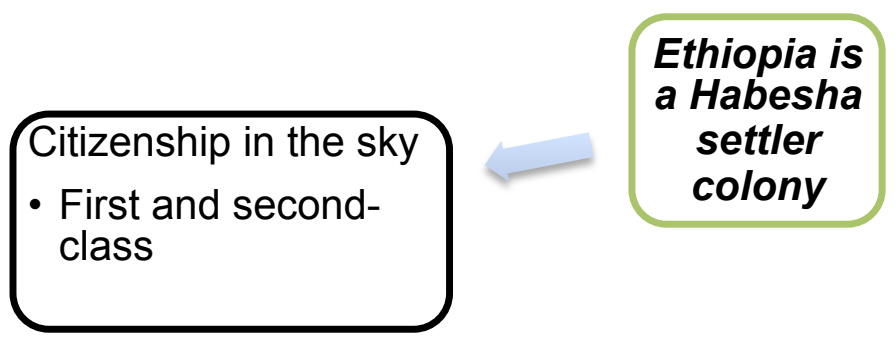

FIGURE 5.2: Organizing Themes- Political Oppression
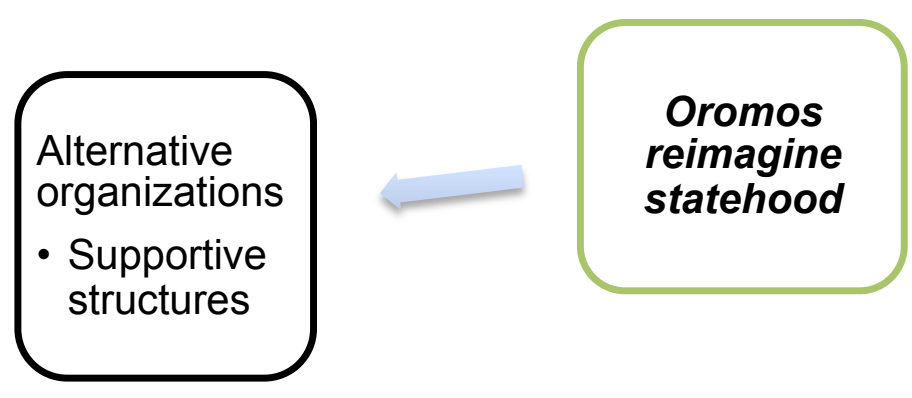

$$
\begin{aligned}
& \text { Stretching } \\
& \text { sovereignty } \\
& \text { - Role of the } \\
& \text { diaspora } \\
& \text { - Beyond } \\
& \text { state } \\
& \text { boundaries }
\end{aligned}
$$

FIGURE 5.3: Organizing Themes- Political Resistance 


\section{Cultural Politicization}

\section{Entertaining Amhara}

The Ethiopian state's manipulation of cultural traits and heritage as a way to exclude the Oromo people from justice is one of the most egregious and consistent forms of cultural imperialism and Other-ing used by the Ethiopian state was clearly identifiable. Ebba explained that "If you are Oromo, if they figure out you are Oromo, there is no way... [that you will] get an opportunity." Enforcing cultural imperialism ensures that only select cultural traits lead to power, and that the empire is responsible for enforcing these identities whenever possible. Where the Habesha elites could not convert or overwhelm cultural inheritance they enacted a campaign of shame and Othering, and those who did not conform to the mainstream were pushed to the margins of society (Jalata 2001; Feyissa and Lawrence 2014). Oromo people understand the cultural imperial project and felt its impact in a much more uniform and explicit way than any other form of oppression. Wayissa, who spent the first 20 years of his life under the reign of Haile Selassie in the 1950s and 60s, erupted into peals of laughter when asked whether he thought Habesha and Oromumma identity were equally represented in Ethiopia: "Ethiopian cultural identity? [laughter] Equal? [laughter] No! [laughter] Not at all!" Asked for a specific example, Wayissa referred to the way historic policies and social norms restricted Oromo cultural development. "If Oromo speaks on radio, it breaks radio' that's what they used to say," he added, though he was no longer laughing, pointing out that sources of Oromo culture, including churches and schools, were instead filled by Amharic-speakers and re-settled Amhara people. By placing value on one culture and set 
of practices above all others, disparities were legitimized and made transferrable.

Cultural imperialism in the Ethiopian settler colonial state embedded itself into state-run institutions as a way to further its violence.

The continual re-colonization and suppression of Oromo culture was both formal and informal. That is, it was both a result of explicit state policies, and reinforced by social structures. Obsee noted that

Even if one [Habesha] family comes in a town of two thousand, three thousand- 'Oh then you ... need to speak my language.' They used to do that! The law supported them, because that's called Ethiopian language. Then you have to give up on your culture, whatever, and you have to follow that particular person.

While societal pressure may contribute to some groups choosing to speak Amharic, the legacy of legality, wherein Amharic was the only option, was what originally legitimized this pressure. That the prevalence of Amharic and Habeshization in the post-colonial nation state were rooted in the entire colonial process was also well understood by my participants. Many participants noted that Ethiopian elites exemplified this minority ethnic rule. Despite the fact that some past leaders "might share blood line with Oromo they were, like, entertaining Amhara culture. That's why the federal working language in Ethiopia now is Amharic. Historically it's because of that ideology in the emperor and the kings' minds," Biiftu explained. This "ideology" was one of Habesha supremacy, and its reach was deeply penetrative.

Nevertheless, there were some cases where the economic and infrastructural development worked against this state project, as was the case in far Western Oromiya, the same place where the OLF resistance lasted the longest. Participants from this area 
had generally more positive experiences keeping their culture. However, this was seen as a rare privilege. Tolera acknowledged that that

I am lucky to be from far west side where it is a little bit more, where Oromos can keep their identity... But some of the rest, especially the eastern, southeast, and central part, I couldn't keep my name the way it is. I would've been forced to change my name to Amharic. That's where you start [oppressing Oromo culture].

As ideologies that embed themselves into governance, cultural imperialism and Othering work in tandem to keep Oromos from harnessing their power. Although the current Prime Minister was generally spoken of highly, it was noted that he hasn't really, fully reached the Oromo people yet, despite being Oromo himself. Geography was one specific example of this shortcoming, as Obsee explained: "When there are problems in rural Oromiya, he doesn't go. Only to places like Agaro [near Jimma] or Hawassa [major city near the capital]." Oromo people, and many other ethnic groups, have been geographically and culturally pushed to the margins. This example also demonstrates how one legacy of the imperial cultural project is a turn to Othering: when state elites are unable to enforce hegemony, they suppress or silence those who deviate. The Oromo people are Othered by the state in this relegation to the margins.. Chalchissa summed this up well: "So that's the plan: to just get rid of language, culture, and then identity. Then cancel the name of Oromos from that area." Despite the effectiveness of the cultural imperial project, the Othering of the Oromo was also a common practice.

Othering is seen in the systematic exclusion of certain identities from the mainstream. In practice, Oromo people identified Othering in instances where their history and their existence were misrepresented or left out of the conversation altogether because of their Oromo identity. This demonization was typically a counterpoint to the 
idealized Habesha identity cultivated by the state. Despite its ethnic diversity, and "all these cultures and all these things, all the whole world talks about in Ethiopia is the Northerns' culture" Sanyii explained. Going further, he added that "those people who call themselves Habesha, they don't include the other national people. They don't include like Gurage, Afar, Somali, all the others. Only Amhara and Tigray." This exclusion restricts the growth and cultural development of the Oromo.

As long as certain cultural values and norms are deemed unacceptable, marginalized groups are forced to either assimilate or face systematic challenges as the result of these traits. Connecting historic erasure to internalized shame and assimilation, Badhaassaa noted that the pressure to assimilate was rooted in a cultural imperial project:

It's because of the dominancy the [Habesha] culture had over the past 150 years, because it's from that culture that the emperor, the king, and everybody came from. Other cultures were forgotten. You have to merge into this culture to survive.

Requiring marginalized people and indigenous nations to assimilate into the dominant culture is characteristic of state-sponsored oppression.

\section{Cultural resistance: not a debatable topic}

The Oromo people do not simply accept state attempts to rewrite or erase their history. Instead, Oromo people are working to reclaim and critically interrogate the narratives and practices that have been built up against them. Abdi, who was born in the 1950s in Western Wollega, refused to even entertain the idea of a comparison between the nationalism of the Abyssinians and the Oromo resistance. When asked about his own Ethiopian national identity he said, clearly: "I am Oromian, I am an Oromo, born Oromo. 
I identify myself to the Oromo people and the Oromo nation, Oromiya.” By refusing any attempt to assimilate or even simply embed Oromiya into the Ethiopian state project, Abdi both reclaims control of the narrative and asserts Oromo autonomy. Though more radical than some other participants' perspectives, this assertion is exemplary of survivance. Despite all attempts by the Ethiopian state, Oromiya is still there, and its ability to survive is the result of this project of resistance.

By acknowledging historic erasure and challenging its perpetuation, Oromos resist Abyssinian hegemony. As Ayantu inquired about cultural clothing, "It looks like Amhara's dress. Does that mean Ethiopia's dress? That's a debatable topic.” These types of debates begin to probe deeper into the hegemonic nature of state culture. A generation or even a decade ago, this line of questioning could land one in jail or subject one to terrorism laws. Ethiopia had sought to perpetuate its Habesha hegemony to the extreme. As a modern force of resistance, however, reclaiming and reanalyzing these accepted ideas has led to concrete actions. Chalchissa explains:

Now the Oromos say no. We're supposed to be treated this way, as Ethiopians we're supposed to have this equal right, even if we are Oromos... If were not gonna be treated equally the same way, if we cannot practice our language, our religion, then we don't belong here.

Taking ownership over the value of Oromo culture is a key aspect of reclaiming it, and defining Oromumma on Oromo terms. Despite the Ethiopian state's myriad attempts to push Oromos out of the conversation, or demonize them, they continue to fight, and are shedding new light on these nationalistic narratives.

Understanding Oromo survival as an active part of the resistance movement is a way of acknowledging what it has taken to get to this point. "If according to the pressure 
from the government and from the system we would've been vanished," Gifti noted. Oromos from the most remote areas pointed to the ways that lack of access to Ethiopian modernity reinforced their culture, as Wayissa remembers: “We even don't know what is Ethiopia during childhood until we go to school... we know only Oromo.” From this perspective, Oromo Othering was reframed as a way of resisting state violence; in the margins of society, where the state tried to silence and forget, the resistance carried on. Elaborating on this same idea - the way exclusion from access in fact strengthened Oromo cultural qualities-Sanyii explains, "Even though you know about Ethiopia, you are not attached to Ethiopia, you were not grown up as Ethiopian. You were raised as Oromo." Reclaiming an independent identity despite the imperialist tactics of the state is a way to resist violence. The survival of Oromo language, culture, and heritage is in and of itself a resistance to erasure and Othering. Biiftu makes this clear, "We don't know what will happen, but Oromos are silent no more."

A close read of the way my participants related to Ethiopia also revealed some deeper forms of resistance. Looking at Addis Ababa as an example, the naming, claiming, and hyper-development of the capital was all done without the consent of the Oromo people, to whom the land originally belonged. Many of my participants made a point to refer to the city only as Finfinnee, the pre-colonial name, and used feminine pronouns when referring to "her." This follows the linguistic patterns of Afan Oromo, but also acts as a way of reclaiming and resisting Ethiopia's exploitation and profiteering, and contrasts with their reference to the government as "he." I argue that these are instances of reclaiming because they deny separation, renaming, and colonial narratives that encourage Habeshization and Oromo suppression. Instead, these short examples 
show the potential for Oromos to take back their autonomy. As Abdi explains, the Oromo people are "yearning for democracy, peace, and justice." And until these yearnings are addressed, they will not stop resisting.

\section{Organizing Themes}

Throughout the history of Ethiopian state cultural relations, there have been attempts to eliminate the Other. This idea organizes and makes sense of many of the other common practices. The elimination of the Other is enacted through eradicating and erasing cultures that don't fit the state created cultural model. In Ethiopia, these attempts were enacted through an unwillingness to "entertain" or even acknowledge other cultures. If the Ethiopian hegemonic model had been successful, all members of the nation would speak the same language, and all other ways of understanding would be erased. More broadly, the elimination of the Other was identifiable in cases of enforced homogeny and intentional erasure. Enforced homogeny can also be understood as the Habeshization or Amharization of the Oromo as a necessary precursor to societal acceptance. Obsee explained that "According to any of the Northern [sic]... the qualification is to be Ethiopian is you have to speak Amharic." She elaborated later that this was a survival tactic more than anything else, referring to the expansion of Finfinnee, during which "the cultures started to be dominated, and people started learning Amharic to survive." By linking cultural qualities to integration into society, and even survival, Ethiopia has sought to create a singular "Ethiopian" identity regardless of the impact on Oromo and other cultures. Participants shared their stories of being forced to learn Amharic, or 
considered lucky to keep their Oromo names, as Ebba shared. These cultural practices sought to homogenize Ethiopia into one Habesha population.

Supporting this drive for homogeneity was an erasure of those identities and practices that wouldn't conform. Intentional erasure is also an educational practice, as discussed in the "Political" section. However, as a cultural practice this can be seen in Ethiopia's presentation of itself in a way that excludes Oromo heritage. This "Northern" image of Ethiopia is flawed because rather than highlighting national diversity, it acts as if there are no differences at all. Biiftu explained that it was because of this erasure that Oromo "history, our culture, and our identity have been hidden for so long." Oromo people challenge this erasure with their very existence, and each attempt at homogeneity and silencing is met with Oromo resistance.

There was not one overarching theme for Oromo cultural resistance, however it can be understood generally as survival itself as a practice of resistance, what Vizenor calls survivance (2009). This Oromo survivance took the shape of two distinct subthemes: an Ethiopia for everybody, and when this was not thought to be feasible, an Oromia reclaimed. These two connecting concepts are both representative of resistance to an elimination of the Other, though they don't necessarily represent the same end result. Ethiopia for everybody is a conceptualization of a national identity and set of ideologies that include and celebrate all peoples. This also means an acknowledgement of the violent historical practices that allowed for the imposition of Habesha hegemony in the first place, a recognition that is made possible through a reclaimed and redesigned state. In many ways, until Oromo institutions and ideas are restored in value, there will continue to be a resistance to state models. Oromos refuse to be the Other, resist all 
efforts of elimination, and continue to seek an equitable voice in the narratives about their existence. As Ebba made clear: “By nature we are democratic... Oromos don't want to oppress anybody. We always like to have equality. Equality over the resources that we have, over power, culture, everything." An Ethiopia for all would make room for these ideas.

In addition, these demands are part of the project of reclaiming Oromiya. An Oromiya reclaimed is an Oromiya that gives respect and legitimacy to the existence and belief of its original inhabitants. In the face of a state that "did not consider you as a human being," as Gifti says, Oromos must assert their rights and the fullness of their culture, including sovereignty over the soul of Oromiya. Until that reclaiming, Badhaassaa insists, "We're really far away from being considered as we're one country or one Ethiopia." As Organizing Themes, recognizing how these concepts make sense of cultural relationships over time is a key step in the analytical process. Denying the historic narratives and theft that mischaracterized and threatened Oromo identity is one of the biggest challenges of the resistance project.
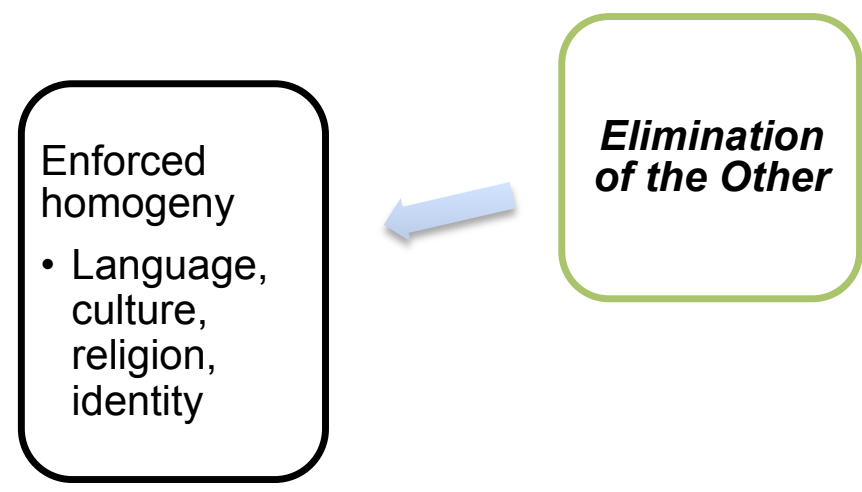
Intentional erasure

- Northern culture on display

FIGURE 5.4: Organizing Themes- Cultural Oppression 

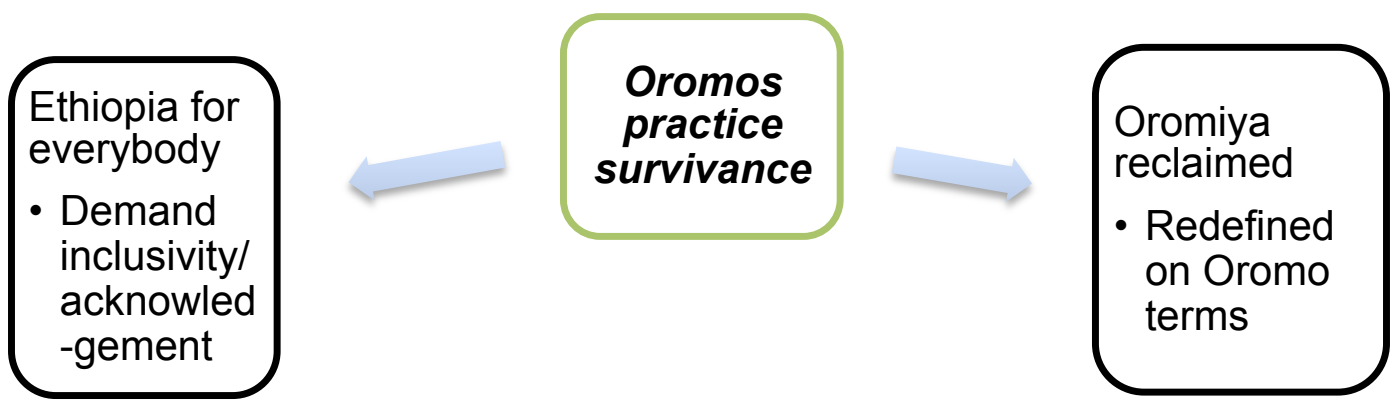

FIGURE 5.5: Organizing Themes- Cultural Resistance

\section{Conclusion}

This chapter has used the voices of my participants to illuminate the way Oromo people in the diaspora understand and make sense of their identity and its relationship to the Ethiopian state. Furthermore, it has painted a picture of the nature of Oromo politicization in the diaspora; with specific attention to the way that politicization as a process works with multiple technologies, institutions, and strategies to enact oppressive tendencies. Politicization of Oromo identity began with the very formation of the state. Interview participants highlighted the way customs and systems were set up to exclude Oromo people from equitable access. Education was a clear example: the government refused to build Oromo schools, and when educational institutions were created they quickly turned into spaces that spread anti-Oromo sentiment and allowed for physical violence against Oromo bodies. As a politicization process, Oromo oppression was normalized and facilitated by the state.

This chapter has also shed light on the way practices of resistance grow alongside and in dialectic with this violent politicization. Oromo people in the diaspora clearly identified the way the state project has treated their people and their homeland, as well as 
the justification behind this treatment. Ethiopia has consistently manipulated Oromo identity for exclusionary, marginalizing, and unjust aims. In analyzing the thematic connections in each domain of oppression, it is clear that Oromumma in the diaspora is deeply politicized. This connection will be elaborated on further in the final chapter. In the Economic domain, Oromo people described the way exploitation and marginalization characterized the nature of their relationships with the state. Ethiopia consistently excluded Oromo people from access to economic advances or over-rewarded Northern elites. As a politicization process, these oppressive tactics have used ethnic identity as the primary means of delineating elite access, thus enshrining Oromos and all others into the margins. A close look at the Political domain makes clear that state institutions and legal policies have failed to create a space for the Oromo people. Instead, these institutions manipulate Oromumma as a way of designating differential citizenships. In response to this, Oromo people organize outside of and against the state model. Thus Oromo identity in the political domain is used as a way to build organizations that resemble state forms and do the work of state institutions, without formal nation-state recognition. The third and final domain, the Cultural, demonstrates most clearly how traits and traditions are used to determine access to power across the Ethiopian state. Oromo people of all ages shared their stories of the pressure to convert or collapse their Oromo identity into the Habesha ideal. Each aspect of Oromumma was Othered, abused, or ostracized. In response, Oromo people are working to take back the power of Oromo identity, and interrupt expectations of what it means to be Ethiopian. Oromo language and heritage are being celebrated in a new way, and this celebration also works to gain back Oromo rights and power. 


\section{CHAPTER VI: DISCUSSION AND CONCLUSION}

\section{Introduction}

The preceding chapters have thoroughly described the historic nature of Oromo politicization, the way it has changed over time, and the way Oromo people understand this process. This chapter will connect these various issues, and, following the thematic network analysis, unite them under a few Global Themes. The Global Themes discussed here address Oromo politicization and also sum up the ideas, including the Organizing Themes, presented throughout the course of the previous analysis. After an explanation of these Global Themes, this chapter will conclude by posing some suggestions for future research.

\section{Global Theme I: All Ethiopian identities are political}

All of the identities that have emerged from or are embedded into the Ethiopian state project are politicized; parts of each group's ethnic heritage have been used to determine their access to rights and power over time. The most salient example of this phenomenon is in the mandated national language policy. Once Amharic became a legally enforced standard form of communication, all other languages became barriers to accessing resources and understanding rights. As a Global Theme, recognizing the political nature of Ethiopian identities makes sense of the way state policies have been implemented against and experienced by the Oromo over time. The foundation of the Ethiopian state and the ideologies that supported it are deeply entrenched in modern state policies, systems of governance, and institutions. The politicizing processes that made the emergence of the Ethiopian state possible have continued to operate. Therefore, 
understanding all identities that emerge from Ethiopia to be political in nature gives a coherence to the way they have been developed, oppressed, and enforced over time. Uniting this Global Theme are three Organizing Themes, described below. The model for this thematic network can be found on page 129.

\section{Social relationships are commoditized}

The commoditization of social relationships is necessary for the colonization, development, and oppression of the Oromo. This idea is best demonstrated through the Nafxanya-Gabbar system and the development of Finfinnee, and the legacies of these processes. Northern Ethiopians moved onto Oromo land, renamed it, and did their best to erase the heritage of the place; Oromo existence was understood only as servant, slave, and economic resource. Given these constructs, relationships were commodified, understood only through the lens of market potential. Once Northerners were settled on Oromo land, and their children had grown up and gone through school with Oromo tenants, never learning Oromo language or culture, the commoditization of social relationships became normalized. Thus reimagining relationships outside of this system is a radical upheaval. Attempting to reframe Oromo land as a home, rather than a producer of profit, and reimagining Oromo people as more than serfs are challenges that elites were not motivated to undertake. There was no financial motivation to learn Afan Oromo or respect Oromo culture. With Finfinnee, the seemingly endless urban expansion fails to make real improvements to the lives of the Oromo community. This prioritization is felt both by evicted farmers and settled outsiders, who see that Finfinnee as a global hub of business and trade is not designed for the Oromo to exist in. In addition to these 
examples, the Ethiopian government's treatment of environmental and social issues also shows an overwhelming focus on protecting commodities, markets, and future profits above all else (Tufa and Gebremariam 2017).

\section{The Other must be eliminated}

The forceful nature of Habeshization, erasure as an educational project with cultural connections, and the illegality of language are all processes that contributed to the elimination of the non-Habesha from the cultural consciousness. As is the case with the commoditization of social relations, it is the long-lasting legacies of these projects that are cause for concern, as much as their current implications. Although state language and cultural policies have become more liberal and open over time, the systematic dismantling of several generations worth of cultural development is not easily undone, nor necessarily being encouraged. Ethiopian nationalists will continue to make the case for assimilation, and even as Oromos take strides towards visibility they are still far from a having an open or equitable voice, despite their population size. This lingering exclusion complicates other marginalized groups' existence as well, and demonstrates the real unwillingness of the Ethiopian state to compromise.

\section{Discrimination is embedded in institutions}

The linguistic and cultural supremacy that the Habesha-dominated Ethiopian state has undertaken since its founding is firmly entrenched in state institutions on all levels. The enforced ethnic hierarchy is seen most clearly in the way education, as a state institution, is run. For decades there were enforced limitations on who could learn, and 
how. Even for universally accessible institutions, like the legal system, there are vast disparities in the way it is carried out and who it serves. The illegality of Oromumma over time justified imprisonment and exclusion. By embedding discrimination into institutions, the state obfuscated its role in discriminatory policies, and the subjective violence of these practices, but it could not hide them altogether. Identifying discrimination in legal policies is the first step to their dismantling, discussed in the following section. The commoditization of social relations, treatment of the Other, and discriminatory state practices demonstrate the way the Ethiopian state uses ethnic traits as a political tool. This politicization, and the oppression embedded in it, works in tandem with the second Global Theme. Figure 6.1 displayed below, shows the thematic network connecting and making sense of the first Global Theme.

The Other must
be eliminated
-Imposition of
Habesha ideals
Erasure

\section{All Ethiopian identities are political identities}

Social relationships are commoditized

- Gabbars

- Finfinnee
Discrimination is embedded in institutions

-Educational access - Legal systems

FIGURE 6.1 Global Theme I 


\section{Global Theme II: Oromo sovereignty is a non-state political project}

This Global Theme is a way of cohering the historic organization and resistance project of the Oromo people, as well as its legitimacy in the eyes of the Oromo. By operating outside and despite the oppressive state, Oromos use politicizing tactics and systems to deny state oppression and create institutional support beyond what Ethiopia

provides. These tools include revitalizing Oromo language and culture as a way to build stronger group connections, and organizing these groups as a coalition for justice. This resistance project has long lived in the shadows and margins, and has been characterized by a constantly evolving response to new state violence. This ability of the resistance to reimagine itself is made possible by its historic exclusion; functioning outside of the state has allowed Oromos to become comfortable with new, and more radical forms of resistance. As a Global Theme, understanding the political legitimacy and need for this movement is essential to making sense of the ways Oromo people operate under the Ethiopian state. There are three connecting networks of ideas that highlight how non-state organization demonstrates the real potential for a liberated or decolonized Oromiya.

\section{Oromiya reclaimed}

Reclaiming Oromiya means specifically addressing each of the ways she has been affected by the Ethiopian state. Reclaiming is not a re-colonization; it does not intend to repeat the process of selective uprooting and erasure that the Abyssinians employed. Rather, Oromiya is reclaimed by a renewed recognition and sense of legitimacy given to the organizations and practices that define the Oromo's ideal state model. The most inspiring example is the possible re-entry of the OLF into mainstream politics, which has 
potential to bring about real change. The OLF, which was born of and very much defined the Oromo struggle, has the ability to truly alter the fabric of Ethiopian state institutions. As a reclaiming, this asserts that Oromo people are in control of their own destiny, and have ideas about their sovereignty that they intend to see actualized. Reclaiming Oromiya also means creating narratives and shared understandings that both celebrate and highlight the rich history of the Oromo people, while honestly portraying their adversities.

\section{Statehood reimagined}

By reimaging statehood and state power, the Oromo attempt to address the needs the state won't fulfill through the creation of alternative institutions. By simultaneously acknowledging Ethiopia's inadequacies, and creating culturally-specific models and ways of addressing them, Oromo people are asserting their sovereign potential. In some ways it is this imagination that most threatens the Ethiopian state. If Oromo people had the ability to leverage their resources and build their own partnerships, they could create institutions that allowed for independent and equitable access to healthcare, roads, education, and other necessary resources. As it currently stands they have limited and restricted access to those goods and services, and thus non-state education and the diaspora have come to function as alternative institutions: the diaspora as a source of media and news, as well as financial resources, and cultural education as a practice that undermines Ethiopian state strategies. Both of these examples undermine the formal state structure, and demonstrate Oromo ability to organize outside of state lines. 


\section{Challenging Ethiopian institutions}

While the previous theme represents a more creative force, this concluding point is more destructive in nature. Ethiopian citizenship is characterized by inequity, from the law to the market. By demanding equal rights within the state, in addition to employing non-state sovereign practices, Oromos seek to rise above Ethiopia's restrictions. They are developing a better state model, and fighting for reform within the existing structures. Although the diasporic nature of Oromo sovereignty has already stretched beyond state borders, finding justice within Ethiopia means addressing each injustice, and the first major violence against the Oromo was Ethiopian colonization. The legitimacy, equity, and structure of many Ethiopian state and political systems still need to be called into question. A full transformation, not just reformation, is necessary to meet the demand of an "Ethiopia for everybody." Without a restructuring of the settler colonial model and the institutions that uphold it, marginalization and oppression will continue to rule. Figure 6.2, displayed on the following page, shows the network of ideas and Organizing Themes that comprise the second Global Theme.

\section{Discussion}

After a thorough analysis of the literature, extensive time spent in Oromiya, and interviews with members of the Oromo diaspora, what is clear is that the violence done to the Oromo may have changed its face, but not its impact. Across generations and geographic distances, Oromo people I interviewed, historical Oromo accounts, and the histories I learned while living in Ethiopia were filled with hauntingly similar stories and were targeted by similar attacks, often at the hands of the state, and justified by their 


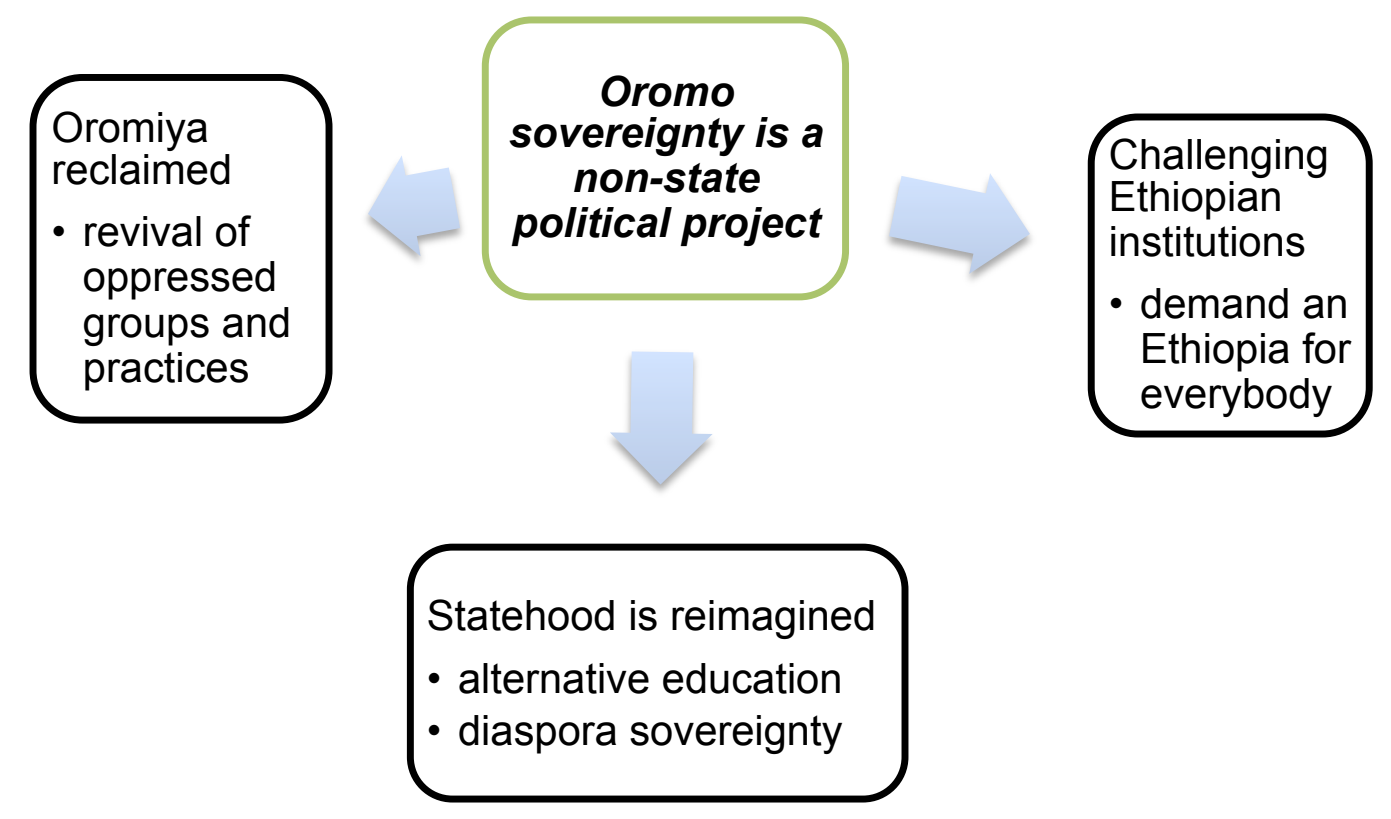

FIGURE 6.2 Global Theme II

Oromumma. Thus, in response to the first research question, I argue that that this relationship with the state has been one of the primary forces affecting the development of Oromumma, Oromo cultural identity. Although it has evolved as a force of resistance in its own right, much of Oromo cultural development occurred despite its erasure and silencing by Ethiopian state, or in spite of it.

This answer leads to the second research question, which asked about the factors most influential on Oromumma in the diaspora. It became clear that to be Oromo anywhere is to carry with one a violent political heritage. Conceptualizing an Oromumma that is separated from the Ethiopian state legally, politically, and economically, is close to impossible. Although the spirit and culture of Oromumma has resisted Habesha hegemony, relationships to the land have wedded these two cultures together in ways that 
are more difficult to untangle. The legacy of the settler colonial project is embedded into every Oromo-Ethiopian interaction, and the options for withdrawal are few, if not nonexistent. Oromo people have not expressed a desire to return any genocidal favors; they know that by uprooting the descendants of settlers they would only continue the cycle of violence, no matter how just their cause. They emphasize a need for peace far more than justice. This was shared by my interview participants, as well as Oromo activists $^{1,2}$. Ebba was insistent on closing his interview with this particular statement, also shared in the previous chapter: "By nature we are democratic... Oromos don't want to oppress anybody. We always like to have equality." It is also true, however, that "justice" as a system and institution of Ethiopia has never been just to the Oromo. They will no longer be appeased by settler logic. Thus, although there is reason to be hopeful, until there are real steps taken to dismantle the entrenched hierarchy and exploitation of the settler state and political elites, this hope is limited.

\section{Conclusion}

In closing, and in order to develop some next steps for this research, I would like to place Ethiopia in the context of its peers, internationally and locally. By understanding Ethiopia as one piece of a larger world system, it becomes clear that the Oromo are not alone in their struggle. How does Ethiopia, as a settler colony, mirror the practices of rule used in more established settler colonies like the United States or Israel, and what lessons

\footnotetext{
1 Oromo Press, via twitter (@oromopress), accessed June 20 2019, https://twitter.com/oromopress/status/791667888763437057

2 OromoRoot, via twitter (@Sanyiikoo_Oromo), accessed June 202019 https://witter.com/Sanyiikoo Oromo/status/1041614782691008513
} 
can be learned from struggles for liberation in these lands? How closely is Ethiopia, as a burgeoning neoliberal nation state, following the steps taken by other economic powerhouses, and what are the risks of this aggressive development? Will the rise of Prime Minster Abiy Ahmed, the "Obama of East Africa", lead to actual tangible change, or serve merely to check a diversity box in a violent demography (Mohammed, Lemma, Giorgis, Nega, Shide 2018)? The global themes that link this research together are also intertwined with these questions. In the face of post-colonial former empires that continue to demonstrate imperial tendencies, struggles for liberation, justice, and freedom that are globally-minded and emphasize solidarity and shared organizing become increasingly important.

A natural continuation of this research project would be to expand it, and push it further east. In many ways the tensions and violence between Somalis and Oromos are a colonial legacy, one which, if mitigated, would have great potential for bringing peace to the Horn of Africa. How has the experience of the Somali diaspora, oppressed by both Ethiopian and British colonial forces, differed from that of the Oromo? Furthermore, along the Ethiopia-Somali-Kenyan borderlands are groups of nomadic peoples like the Ogaden, who may speak languages from all three countries and yet identify with none. How can these people be supported in their struggle to exist outside of three unstable states? What happened to the spirit that supported Somali pirate radio purveyors of the 1960s, the first few souls brave enough to play Oromo voices on the radio? How has the silencing of the Ogaden Nation across the Horn directly contributed to the marginalization of the OLF in Ethiopia? What influence will Ethiopia's moves towards justice have on the Eritrean dictatorship, if any? Are these modern resistance movements, 
the \#OromoProtests and the burgeoning Eritrean \#Yiakl ${ }^{1}$ campaign, part of a global trend against post-colonial state violence? And if so, how will these campaigns connect and interrupt the privileged powers of the global North? These questions are beyond the scope of this thesis. But it is this work that helps to locate and relocate the bones of these bodies, and it is this work that moves towards freedom.

The title of this project describes what I have attempted to do: to locate and relocate the roots of Oromo cultural identity in the face of extensive, oppressive, politicization. Through this exploration, I have also built an understanding of which Oromo bodies belong to these bones, what Ethiopian practices of death allowed these actions, and most importantly, what Oromo life has been created in its wake. The Oromo people have demonstrated extraordinary resilience and grace in the face of generational violence, and they have not yet grown tired. For every condo built on the capital, for every unwritten Oromo historiography, for each and every drop of blood spilled on a school campus; Oromos remember. And for every time a voice sings out in Afan Oromo, for every Oromo student who walks across a graduation stage, and for every season the Odaa tree grows on; Oromos do not forget. This memory, these bones, are what strengthen the Oromo people and carry them onward towards liberation. ${ }^{1}$ The hashtag \#Yiakl, meaning Enough in Tigrigna, is part of a social media movement that is slowly
gaining traction, accessed May 15, 2019: https://twitter.com/emdhrorg/status/1087428940501843969 


\section{REFERENCES}

Aalen, Lovise. 2006. "Ethnic Federalism and Self-Determination for Nationalities in a Semi-Authoritarian State: the Case of Ethiopia." International Journal on Minority and Group Rights. 13:243-261

Aalen, Lovise. 2014. "Ethiopia After Meles: Stability for How Long?" Current History.113(763):192-196.

Armed Conflict Location and Event Data Project (ACLED). 2016. "Real-Time Analysis of African Political Violence." Conflict Trends. 48.

Armed Conflict Location and Event Data Project (ACLED). 2016. "Real-Time Analysis of African Political Violence." Conflict Trends. 53.

Africa Research Bulletin. 2016. "Ethiopia: State of Emergency." Africa Research Bulletin Oct. 1, p. 21167-21170.

Amnesty International. 2014. "Because I am Oromo:' Sweeping Repression in the Oromia Region of Ethiopia." London, UK.

“Angry Ethiopians Foiled TPLF/ EPRDF Delegation's Mission in North America." 1997. Ethiopian Review. 17(4): 20.

Antwi-Boateng, Osman. 2011. "The Political Participation of the U.S.-Based Liberian Diaspora and Its Implication for Peace Building." Africa Today. 58(1): 3-26.

Ararssa, Tsegaye R. 2018 "A Hollow Constitutional Promise, an empty legal rhetoric: The Draft Law on the interest that is not so special" Addis Standard. Special Edition: February.

Arriola, Leonardo R. and Terrence Lyons. 2016. "The 100\% Election." Journal of Democracy. 27(1): 76-88.

Attride-Stirling, Jennifer. 2001. "Thematic networks: an analytical tool for qualitative research." Qualitative Research 1(3): 384-405.

Ayele, Zemelak. "EPRDF's 'menu of institutional manipulations' and the 2015 regional elections." Regional \& Federal Studies. 1-26.

Bariagaber, Assefaw. 1998. "The politics of cultural pluralism in Ethiopia and Eritrea: trajectories of ethnicity and constitutional experiments." Ethnic and Racial Studies. 21(6): 1056-1073.

Bassi, Marco. 2010. "The politics of space in Borana Oromo, Ethiopia: demographics, elections, identitiy and customary institutions." Journal of Eastern African Studies. 42(2):221-246.

Bassi, Marco and Gemetchu Megerssa. 2008. "Failed Modernization of the Ethiopian State: Oromo Perspectives on Ethiopian Political Culture." Journal of Oromo Studies. 15(1):79-113.

Best, Stephen and Saidiya Hartman. 2005. "Fugitive Justice." Representations. 92(1): 115.

Blackhawk, Ned. 2006. Violence Over the Land. Cambridge, MA: Harvard University 
Borkena. 2017. "Ethiopian Security Forces Killed Six Civilians in Chelenko, Oromo Region of Ethiopia.” Borkena. Retrieved June 20, 2019 (https://borkena.com/2017/12/11/ethiopian-security-forces-killed-six-civilianschelenko-oromo-region-ethiopia)

Brah, Avtar. 1996. Cartographies of Diaspora. Trowbridge, Wiltshire, UK. Redwood Books.

British Broadcasting Corporation (BBC). 2017. "BBC Afaan Oromo service receives traditional blessing." Retrieved Oct. 15, 2017

(http://www.bbc.com/news/av/world-africa-41307907/bbc-afaan-oromo-servicereceives-traditional-blessing).

Bulcha, Mekuria. 1997. "The Politics of Linguistic Homogenization in Ethiopia and the Conflict over the Status of “Afaan Oromoo." African Affairs 96(384): 325-352.

Bulcha, Mekuria. 2002. The Making of the Oromo Diaspora: A History of Forced Migration. Minneapolis, MN: Kirk Tree Publishers.

Burchard, Stephanie M. 2017. "What Does Unrest in Oromia Signify?" Institute for Defense Analyses: Africa Watch. Vol 17: December 21, 2017.

Byrd, Jodi. 2011. The Transit of Empire. Minneapolis, MN: University of Minnesota Press.

Carboni, Andrea. 2016. "Ethiopia - September 2016 Update." Armed Conflict Location and Event Data Blog. Retrieved June 25, 2019

(http://www.crisis.acleddata.com/ethiopia-september-2016-update)

Central Statistical Agency of Ethiopia. 2007. Census Report. (http://www.csa.gov.et/census-report/complete-report/census-2007.html)

Clapham, Christopher. 2009. "Post-war Ethiopia: The Trajectories of Crisis." Review of African Political Economy. 36(120):181-192.

Cohen, John M. and Nils-Ivar Isaksson. 1988. "Food Production Strategy Debates in Revolutionary Ethiopia." World Development. 16(3):323-348.

Connell, Raewyn and Nour Dados. 2012. "The Global South.” Contexts. 11(1):12-13.

Connell, Raewyn and Nour Dados. 2014. "Where in the world does neoliberalism come from?" Theory and Society 43(2): 117-138.

Deer, Sarah. 2015. The Beginning and End of Rape. Minneapolis, MN: University of Minnesota Press.

Donovan, Dolores A. and Getachew Asseda. 2003. "Homicide in Ethiopia: Human Rights, Federalism and Legal Pluralism." The American Journal of Comparative Law. 51(3):505-552.

Dugassa, Begna Fufa. 2008. "Indigenous Knowledge, Colonialism and Epistemological Violences: The Experience of the Oromo people Under Abyssinian Colonial Rule." PhD dissertation. University of Toronto. 
Dugo, Habtamu. 2016. "Violence Against Free Media and Knowledge Dissemination in Ethiopia: An Analysis of the Mechanisms of Restrictions on Information Flow." The Journal of Pan African Studies. 9(10):395-410.

Edwards, Jon R. 1982. "Slavery, the Slave Trade, and the Economic Reorganization of Ethiopia 1916-1935." African Economic History. 11:3-14.

Ejara, Demissew. 2003. "TPLF Repression Against Oromos and Consequences." Cultural Survival Voices 2(1): 11-14.

Ellison, James. 2009. "Governmentality and the Family: Neoliberal Choices and Emergent Kin Relations in Southern Ethiopia." American Anthropologist. 111(1):81-92.

Fanon, Franz. 1986. Black Skin, White Masks. London: Pluto Press.

Fanon 1994 A Dying Colonialism. New York, NY. Grove Press.

Feyissa, Dereje and Bruce B. Lawrence. 2014. "Muslims Renegotiating Marginality in Contemporary Ethiopia." The Muslim World 104: 281-305.

Flintan, Fiona. 2010. "Sitting at the table: securing benefits for pastoral women from land tenure reform in Ethiopia" Journal of Eastern African Studies. 4(1):153-178.

Freire, Paulo. 2000. Pedagogy of the Oppressed $30^{\text {th }}$ Anniversary Edition. New York, NY: The Continuum International Publishing Group Inc.

Gebissa, Ezekiel. 2002. "The Italian Invasion, the Ethiopian Empire, and Oromo Nationalism: The Significance of the Western Oromo Confederation of 1936." Northeast African Studies 9(3): 75-96.

Gebissa, Ezekiel. 2008. “Thematic Overview: Gadaa as a Point of Departure in Oromo Studies." Journal of Oromo Studies. 15(1):1-18.

Gebissa, Ezekiel. 2017. "Opinion: Protest Resignation: Ramifications of a Political Act." Addis Standard, Oct. 2017. Retrieved Oct. 20, 2017

(http://addisstandard.com/opinion-protest-resignation-ramifications-political-act/).

Gemeda, Guluma. 2002. "The Rise of Coffee and the Demise of Colonial Autonomy: The Oromo Kingdom of Jimma and Political Centralization in Ethiopia." Northeast African Studies. 9(3):51-74.

Gibb, Camilla. 2002. "Deterritorialized People in Hyperspace: Creating and Debating Harari Identity over the Internet." Anthropologica. 44(1):55-67.

Gilroy, Paul. 1993. The Black Atlantic: Modernity and Double Consciousness. New York, NY: Verso.

Giorgis, Elizabeth Wolde. 2010. "Charting Out Ethiopian Modernity and Modernism." Callaloo. 33(1):82-99.

Gudina, Merera. 1997. "The New Directions of Ethiopian Politics: Are we facing the essential challenge?" Ethiopian Review. 7(5):25.

Gudina, Merera. 2007. "Ethnicity, Democratisation, and Decentralization in Ethiopia: The Case of Oromia." Eastern Africa Social Science Research Review. 23(1): 81106. 
Gudina, Merera. 2011. "Elections and democratization in Ethiopia, 1991-2010." Journal of Eastern African Studies. 5(4): 664-680.

Gunder Frank, Andre. 1969. Latin America: Underdevelopment or Revolution. New York, NY: Monthly Review Press.

Hagmann, Tobias and Jon Abbink. 2011. "Twenty years of revolutionary democratic Ethiopia, 1991 to 2011." Journal of East African Studies. 5(4):579-595.

Halliday, Fred and Maxine Molyneux. 1982. "Ethiopia's Revolution from Above." MERIP Reports. 106:5-15.

Harney, Stefano and Moten, Fred. 2013. The Undercommons. Brooklyn, NY:

Autonomedia

Hartman, Saidiya V. 1997. Scenes of Subjection: Terror, Slavery, and Self-Making in Nineteenth-Century America. New York, NY: Oxford University Press.

Harvey, David. 2005. A Brief History of Neoliberalism. New York, NY: Oxford University Press.

Hassen, Mohammed. 2002. "Conquest, Tyranny, and Ethnocide against the Oromo: A Historical Assessment of Human Rights Conditions in Ethiopia." Northeast African Studies 9(3): 15-49.

Hassen, Mohammed. 2007. "The Significance of Antoine d'Abbadie in Oromo Studies: A Commentary." Journal of Oromo Studies 14(1):147-164

Hassen, Mohammed. 2012. "Revisiting Abba Bahrey's 'The News of the Galla." The International Journal of African Historical Studies. 45(2):273-294.

Henze, Paul B. 2003. "Reflections on Development in Ethiopia." Northeast African Studies. 10(2):189-201.

Herbst, Jeffrey. 2000. States and Power in Africa: Comparative Lessons in Authority and Control. Princeton, NJ: Princeton University Press.

Hill Collins, Patricia. 2000. Black Feminist Thought: Knowledge, Consciousness, and the Politics of Empowerment $2^{\text {nd }}$ Edition. New York, NY: Routledge.

hooks, bell. 2015. Talking Back: Thinking Feminist, Thinking Black. New York, NY: Routledge.

Horne, Felix. 2015. Dispatches: Alarm Bells for Ethiopia's 100\% Election Victory. Human Rights Watch. New York, NY: Human Rights Watch. Retrieved Oct. 28, 2017 (https://www.hrw.org/news/2015/06/23/dispatches-alarm-bells-ethiopias100-election-victory).

Huntingford, George Wynn Brereton. 1955. The Galla of Ethiopia: the Kingdoms of Kafa and Janjero. London: International Africa Institute.

Hussein, Hassen and Mohammed Ademo. 2016. "Ethiopia's Original Sin." World Policy Journal. 33(3): 22-28.

Jaenen, Cornelius J. 1956. "The Galla or Oromo of East Africa." Southwestern Journal of Anthropology. 12(2):171-190.

Jalata, Asafa. 2001. Fighting Against the Injustice of the State and Globalization. New 
York, NY: Palgrave.

Jalata, Asafa. 2002. "The Place of the Oromo Diaspora in the Oromo National

Movement: Lessons from the Agency of the 'Old' African Diaspora in the United States." Northeast African Studies. 9(3): 133-160.

Jalata, Asafa. 2003. "Comparing the African American and Oromo Movements in the Global Context." Social Justice 30(1): 67-111.

Jalata, Asafa. 2009. "Being in and out of Africa." Journal of Black Studies. 40(2): 189214.

Jalata, Asafa. 2015. "The triple causes of African Underdevelopment: Colonial capitalism, state terrorism, and racism." International Journal of Sociology and Anthropology 7(3): 75-91.

Jalata, Asafa and Harwood Schaffer. 2013. "The Oromo, Gadaa/ Siqqee Democracy and the Liberation of Ethiopian Colonial Subjects" AlterNative: An International Journal of Indigenous Peoples. 9(4):277-295.

Jesman, Czeslaw. 1963. The Ethiopian Paradox. Oxford University Press: London.

Joireman, Sandra Fullerton. 1997. "Opposition Politics and Ethnicity in Ethiopia: We Will All Go Down Together." The Journal of Modern African Studies 35(3): 387407.

Kebedde, Girma. 1987. "State Capitalism and Development: The Case of Ethiopia." The Journal of Developing Areas. 22(1):1-24.

Keller, Edmond J. 1995. "The Ethnogenesis of the Oromo Nation and Its Implications for Politics in Ethiopia." The Journal of Modern African Studies 33(4): 621-634.

Knutsson, Karl Eric. 1963. "Social Structure of the Mecca Galla." Ethnology 2(4): 506511.

Lavers, Tom. 2012. "'Land Grab' as development strategy? The political economy of agricultural investment in Ethiopia." The Journal of Peasant Studies 39(1): 105132.

Lilesa, Feyisa. 2017. "Why I run.” Al Jazeera Online. 19 May 2017. (https://www.aljazeera.com/indepth/opinion/2017/05/feyisa-lilesa-protestethiopia-170519080825926.html)

Lewis, Herbert S. 1965. A Galla Monarchy: Jimma Abba Jifar, Ethiopia. University of Wisconsin Press: Madison and Milwaukee.

Mamdani, Mahmood. 1996. Citizen and Subject. Princeton, NJ: Princeton University Press.

Mamdani, Mahmood. 2001. "Beyond Settler and Native as Political Identities: Overcoming the Political Legacy of Colonialism." Comparative Studies in Society and History 43(4): 651-664.

Mamdani, Mahmood. 2001. When Victims Become Killers. Princeton, NJ: Princeton University Press. 
Markakis, John. 1989. "Nationalities and the State in Ethiopia." Third World Quarterly. 11(4):118-130.

Matsuoaka, Atsuko and Sorenson, John. 2001. Ghosts and Shadows: Construction of Identity and Community in an African Diaspora. Canada: University of Toronto Press.

Mbembé, Achille. 2003. "Necropolitics.” Public Culture. 15(1):11-40.

Mesfin, Seyoum. 2017. "Ethiopian Ethnic Federalism: Without a Space for 'Indigenous Peoples?" Ethnopolitics. 16(3):246-259.

Michael, Mackonen. 2008. "Who is Amhara?" African Identities. 6(4):393-404.

Mergo, Lemessa. 2012. “The Scene Does Not Speak' The Demise of the Odaa Bulluq Sacred Forest in Horro Guduru, Northwestern Oromia, Ethiopia." Journal of Oromo Studies. 19(1/2):101-137.

Mohammed, Jawar, Tsedale Lemma, Tamrat G. Giorgis, Eskinder Nega, Ahmed Shide. 2018. "How social media shaped calles for political change in Ethiopia." AlJazeera Online.

(https://www.aljazeera.com/programmes/listeningpost/2018/08/social-mediashaped-calls-political-change-ethiopia-180811084501289.html)

Mozaffar, Shaheen, ad Scarritt, James R. 2007. "Why territorial autonomy is not a viable option for managing ethnic conflict in African plural societies." Nationalism and Ethnic Politics 5(3/4): 230-253.

Oromo Liberation Front. 1974. Bakkalcha Oromo- OLF Program. Finfinnee, Oromia.

Orlowska, Izabela. 2013. "Forging a nation: the Ethiopian millennium celebration and the multiethnic state." Nations and Nationalism 19(2): 296-316.

Pankhurst, Richard 1961. "Transport and Communications in Ethiopia, 1835-1935." The Journal of Transport History. 5(2), pp.69-88

Pankhurst, Richard. 1965. "Guns in Ethiopia." Transition. 20: 26-33.

paperson, la. 2010. "The Postcolonial Ghetto: Seeing Her Shape and His Hand." Berkeley Review of Education. 1(1): 5-34.

paperson, la. 2017. A Third University is Possible. Minneapolis, MN: University of Minnesota Press.

Polanyi, Karl. 1944. The Great Transformation: The Political and Economic Origins of Our Time. New York, NY: Beacon Press.

Polson Newman, E.W. 1935. "Slavery in Abyssinia." The Contemporary Review. 148.

Reid, Richard J. 2011. Frontiers of Violence in North-East Africa: Genealogies of Change since c.1800. Oxford University Press. New York, NY.

Rowe, Aimee Carillo and Eve Tuck. 2017. "Settler Colonialism and Cultural Studies: Ongoing Settlement, Cultural Production, and Resistance." Cultural Studies $\leftrightarrow$ Critical Methodologies. 1(1): 3-13.

Ruda, Megerssa. 1993. "Knowledge, Identity, and the Colonizing Structure: The Case of the Oromo in East and Northeast Africa." PhD dissertation, Department of 
Anthropology, University of London.

Semela, Tesfaye. 2012. "Intergroup Relations among Ethiopian Youth: Effects of Ethnicity, Language, and Religious Background." Journal of Developing Societies 28(3): 323-354.

Sharp, Gene. 2013. How Nonviolent Struggle Works. Boston, MA: The Albert Einstein Institute.

Sibilu, Temesgen and Lawrie Barnes. 2015. "Conflict and controversy in the development of the Oromo language." Language Matters. 46(3): 418-435.

"Slaughter in Ethiopia."1974. New York Times (1923-Current file), Nov 27, (http://stats.lib.pdx.edu/proxy.php?url=http://search.proquest.com.proxy.lib.pdx.e $\mathrm{du} /$ docview/119982648?accountid=13265).

Smith, Linda Tuhiwai. 2012. Decolonizing Methodologies: Research and Indigenous Peoples $2^{\text {nd }}$ Edition. New York, NY: Zed Books.

Sorenson, John. 1996. "Learning to be Oromo: Nationalist Discourse in the Diaspora." Social Identities: Journal for the Study of Race, Nation and Culture. 2(3):439468.

Ta'a, Tesema. 2008. "Defending Regional Autonomy and Cultural Identity: The Case of Leeqaa Naqamtee and Leeqaa Qellem (1882-1937)" Journal of Oromo Studies. 15(1):41-79.

Tadesse, Medhane and John Young. 2003. “TPLF: Reform or Decline?” Review of African Political Economy. 30(97):389-403.

Tareke, Gebru. 2008. "The Red Terror in Ethiopia: A Historical Aberration.” The Journal of Developing Societies. 24(2):183-206.

Tasammaa, Tolera and Hundasa Waaqwayyaa. 1995. Seenaa Saba Oromoo fi Sirna Gadaa. Finfinee, Oromia.

Tibebu, Teshale. 1996. “Ethiopia: The 'Anomaly' and 'Paradox' of Africa." Journal of Black Studies 26(4): 414-430.

Tolossa, Fikre. 1997. "A Historical Explanation as to Why Members \& Supporters of the TPLF are Ethnocentric." Ethiopian Review. 7(1): 37.

Tufa and Gebremariam 2017.

Virtanen, Pekka. 2009. "Rewriting Oromo History in the North: Diasporic Discourse about National Identity and Democracy in Ethiopia." Diaspora: A Journal of Transnational Studies. 18(3): 253-286.

Vizenor, Gerald. 2009. Native Liberty: Natural Reason and Cultural Survivance. University of Nebraska Press.

Weldemichael, Awet Tewelde. 2013. Third World Colonialism and Strategies of Liberation: Eritrea and East Timor Compared. New York, NY: Cambridge University Press.

Woolbert, Robert Gale. 1935. "Italy in Abyssinia." Foreign Affairs. 13(3): 499-508. Wright, Erik Olin. 1997. Class Counts. Cambridge, England: Cambridge University 
Press.

Yates, Brian J. 2013. "From White Males to Black Females: Understanding the National Bodies of Ethiopia (1896-1936)." Journal of Black Studies 44(1): 81-100.

Young, Iris Marion. 2011. Justice and the Politics of Difference. Princeton, NJ. Princeton University Press.

Yusuf, Semir. 2009. "Contending Nationalisms in a Transnational Era: The Case of Oromo Nationalisms" Journal of Asian \& African Studies 44(3): 299-318.

Zahorik, Jan. 2011. "Territoriality and Identity: Opposing Views on Oromo Nationalism" Oriental Archive 79(3): 261- 280.

Zegeye, Abebe. 2017. Neither Reform nor Revolution: Social Change and Security in Post-1991 Ethiopia.” Journal of Developing Societies. 33(3):278-290.

Zelalem, Zacharias. 2017. "“FINISH HIM OFF': Horrifying audio of Ethiopian security forces killing unarmed protesters in Ambo.” OPride. Retrieved June 25, 2019 (https://www.opride.com/2017/10/30/horrifying-audio-ethiopian-security-forceskilling-protesters-ambo) 


\section{APPENDIX A: NAMES}

Oromos and Ethiopia people do not use family names in the same way as Americans. Instead, one's second name is that of their father, then his father, and going back. When signing official documents the first name is followed by the father's name, and then the grandfather's. Even in formal settings, an honorific would be followed by the individual's first name. Referring to the former Prime Minister as Mr. Zenawi, for example, would be incorrect according to both Oromo and Ethiopian custom. However, this practice typically stops when individuals enter the diaspora. Without personal knowledge of an individual's background it is impossible to discern if they have adopted the Western practice of a family name, or prefer to be referenced by their first name. As such, and for the sake of uniformity, I have followed Western practices and used second names for all in-text citations. 


\section{APPENDIX B: MAPS}

The following pages show a series of maps. The first map, Figure 1, was made by Bulcha, an Oromo scholar, in 2002, and shows a larger version of Oromia, with lines through it that indicate the path of state formation. This version, Huntingford's 1955 map

(Figure 2), and the map completed by the Oromo Liberation Front (Figure 3), all similarly show the historic Oromo land stretching much further North into Amhara. Of importance about Huntingford's map in particular is that he had no vested interest in Ethiopian state politics, and if anything showed pro-Ethiopian state or anti-Oromo tendencies, as evidenced by his reference to the Oromo people as Galla, and his descriptions throughout the text from which this map was taken. The fact that this depiction aligns closely with the OLF model, designed decades later, grants it further validity, and further challenges Ethiopia's chosen boundaries. 


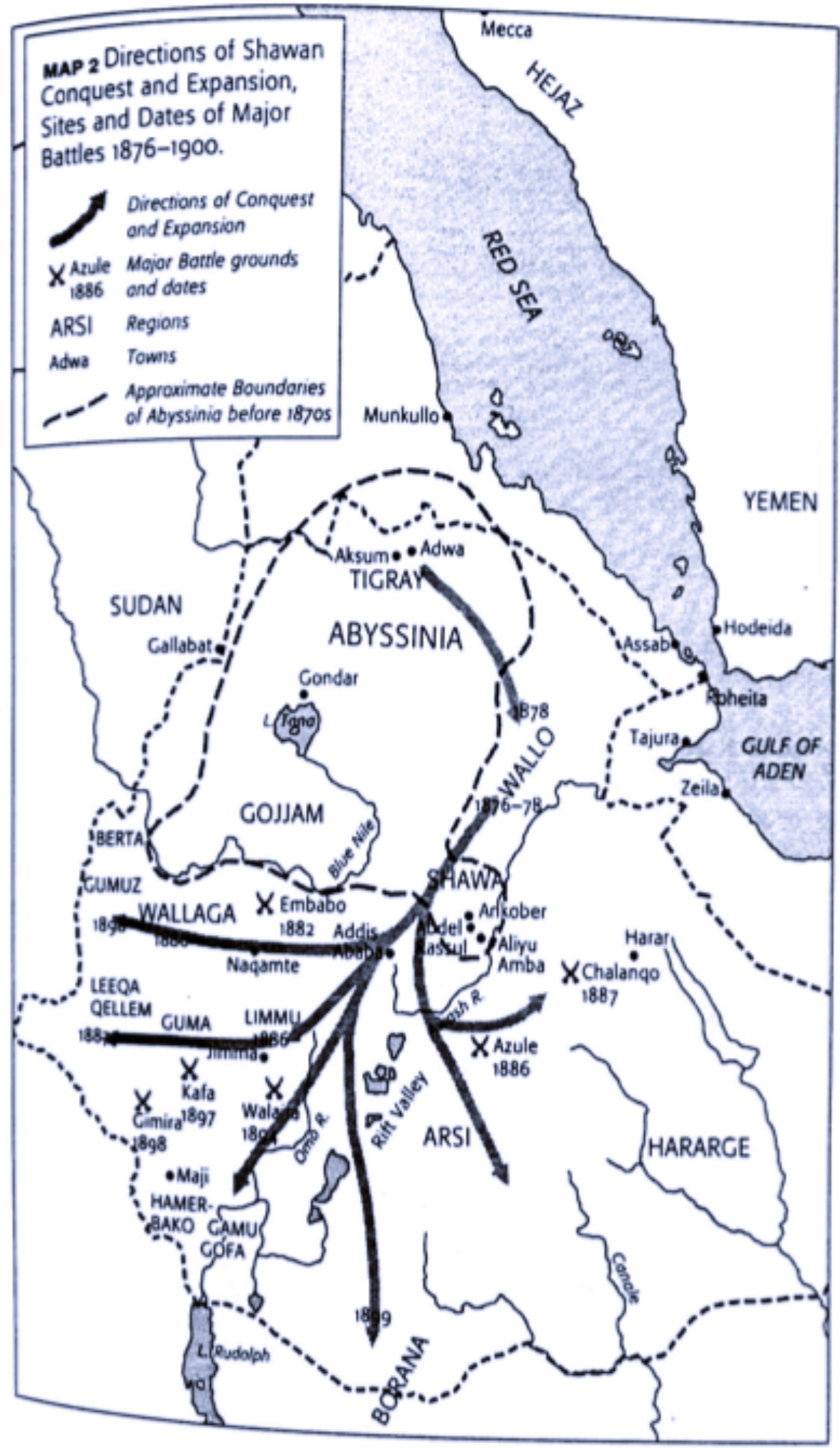

Figure 1: Bulcha Map Made by Bulcha (2002) an Oromo scholar, depicting Shoan (Shawan) expansion during the colonial era. 


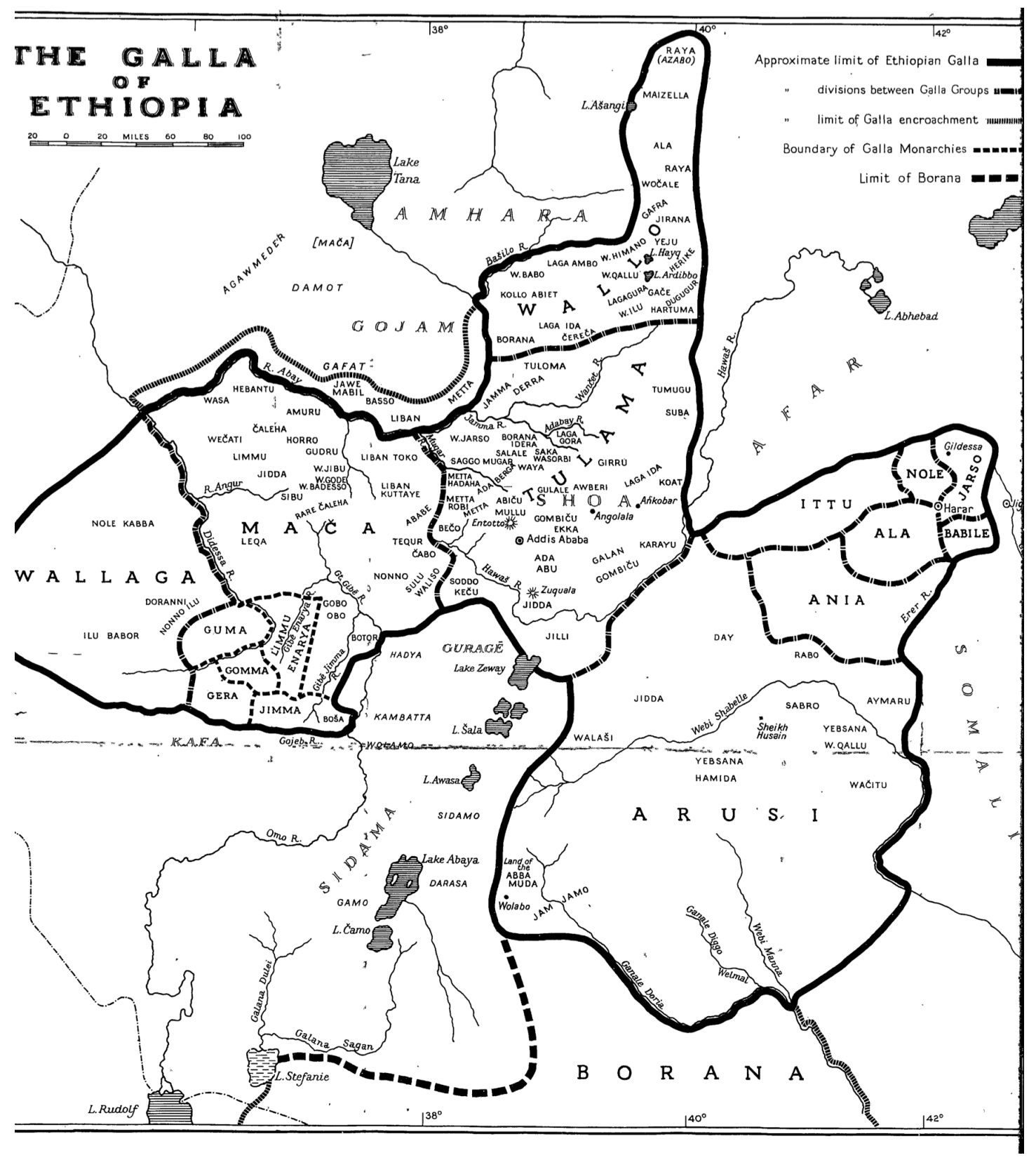

Figure 2: Map from Huntingford (1955) The Galla of Ethiopia and the Kingdoms of Kaffa and Janjero. The clearest difference is that Huntingford depicts Oromo territory, called Galla by him, as including the Wollo people, stretching all the way North into Tigray (Raya). 


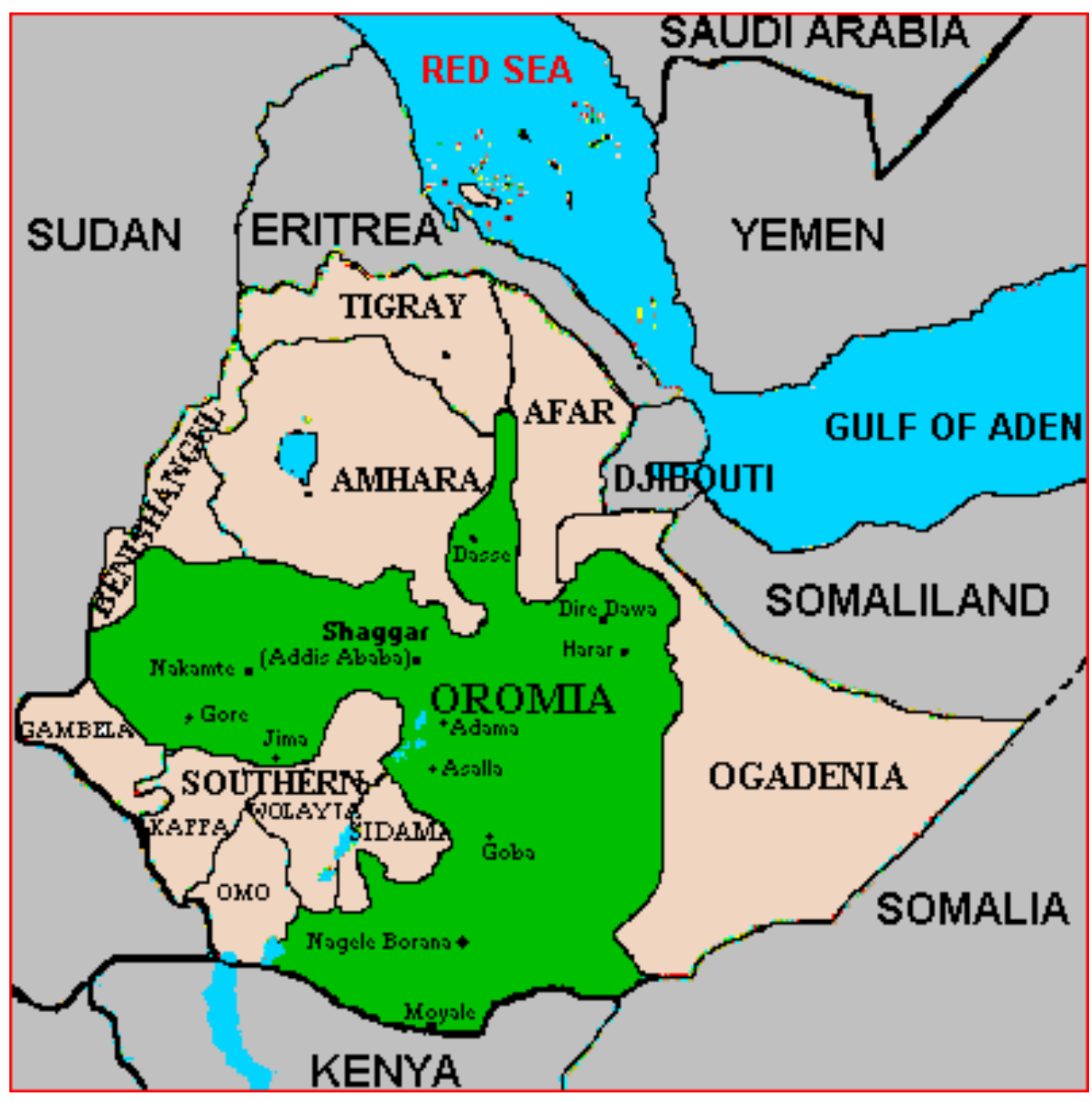

Figure 3: Oromo Liberation Front Map taken from their website (no date provided) Accessed 20 May 2019: (http://oromoliberationfront.org/OromiaBriefs.htm) 


\section{APPENDIX C: METHODS}

Table 1: Sample of transcription (with preliminary codes added)

\begin{tabular}{|c|c|c|c|c|c|}
\hline TIME & QUOTE & E & $\mathrm{S}$ & $\mathrm{C}$ & B \\
\hline 1335 & Education is the same, work is even worse. & & 1 & & \\
\hline \multirow[t]{2}{*}{1342} & $\begin{array}{l}\text { That's why you don't see many Oromos living in the Central or } \\
\text { in the biggest cities. [Lists cities }+ \text { regions] }\end{array}$ & 1 & & & \\
\hline & $\begin{array}{l}\text { Most of the time they give up even education. Because you're } \\
\text { not gonna get anywhere. It doesn't matter. }\end{array}$ & & 1 & & \\
\hline 1400 & $\begin{array}{l}\text { That [exclusion from education and jobs] was very intentionally } \\
\text { designed to keep the Oromos down. }\end{array}$ & 1 & 1 & & \\
\hline \multirow[t]{3}{*}{1420} & $\begin{array}{l}\text { Even in the military, they're kind of not really confident, if } \\
\text { Oromos get this position, because they're the largest population } \\
\text { in the country, they're kind of worried they might take over. } \\
\text { Historically the Oromos did have these well-known fighters. } \\
\text { And no one could beat them. [historical data/ years] }\end{array}$ & & 1 & 1 & \\
\hline & $\begin{array}{l}\text { They [the government] knew that history [Oromo fighters] so } \\
\text { for that reason that really keeps them down because if those } \\
\text { people get a chance they will take over the country. }\end{array}$ & & & 1 & \\
\hline & $\begin{array}{l}\text { No matter what. Educationally, job and business, everything. } \\
\text { They try to keep them down. }\end{array}$ & & 1 & & \\
\hline 1500 & $\begin{array}{l}\text { TADESSE BIRU - Selassie advisor, hid his Oromo identity, then } \\
\text { switched to rebel party, killed by government }\end{array}$ & & & 1 & \\
\hline 1820 & $\begin{array}{l}\text { Even though the resources, everything is from Oromo region, } \\
\text { from Oromos, still they don't appreciate it. And then they try to } \\
\text { put you down. }\end{array}$ & 1 & & & \\
\hline
\end{tabular}

Table 2: Sample of Coding, Political

\begin{tabular}{|c|c|c|c|}
\hline EXCERPT: & \begin{tabular}{|l|l}
$N S$ \\
\end{tabular} & $\mathrm{O}$ & $\mathrm{Sv}$ \\
\hline $\begin{array}{l}\text { This intentional kind of eradicating Oromos from their land. } \\
\text { It's not really about the plan, it's to really really wipe out } \\
\text { Oromos from that region. And the expansion just continues } \\
\text { nonstop. }\end{array}$ & 1 & & \\
\hline $\begin{array}{l}\text { The reason behind that... if they expand from corner to corner } \\
\text { in all ways, limitlessly, the ultimate goal was to split Oromos } \\
\text { into different regions. }\end{array}$ & 1 & & \\
\hline $\begin{array}{l}\text { This kind of is to make Oromos powerless, I think that's the } \\
\text { plan }\end{array}$ & 1 & & \\
\hline $\begin{array}{l}\text { That is why the young generation, the Qeerro, they start to } \\
\text { protest about that. }\end{array}$ & & 1 & \\
\hline
\end{tabular}




\begin{tabular}{|c|c|c|c|c|}
\hline $\begin{array}{l}\text { All the northerners were happy about it because this is the } \\
\text { intention was to split Oromos into } 5 \text { different regions. Because, } \\
\text { back in the days, like I said, the West started from Wollega all } \\
\text { the way to Harar, and then all the way north to Wollo, like the } \\
\text { majority of the country was Oromo. What they used to do was } \\
\text { they divided it by region: Arsi, Wollega, Jimma, or something } \\
\text { like this. This was intentionally designed in a way, they used to } \\
\text { give them different names. The Harar Oromos they used to call } \\
\text { them Qootuu... so the Arsis or the Harars they never thought } \\
\text { that Wellegas are also Oromos like them. }\end{array}$ & 1 & & & $\begin{array}{l}\text { Also } \\
\text { C.I. }\end{array}$ \\
\hline $\begin{array}{l}\text { They divided the country all this time. That's what gives them } \\
\text { [northerners] a chance to keep Oromos down all these years. }\end{array}$ & 1 & & & \\
\hline $\begin{array}{l}\text { Now Oromos become aware of who they are, they know their } \\
\text { identity; Oromos are Oromos. They became together. }\end{array}$ & & 1 & 1 & \\
\hline
\end{tabular}

Table 3: Basic Themes and Key Features

\begin{tabular}{|c|c|c|}
\hline Organizing themes: & Theoretical: & Specific: \\
\hline Economic & $\begin{array}{c}\text { Exploitation } \\
\text { Marginalization } \\
\text { Mobilization } \\
\text { Transformation } \\
\text { Business } \\
\text { Trade } \\
\text { Commodification }\end{array}$ & $\begin{array}{l}\text { Nafxanya/ Gabbar } \\
\text { Addis Ababa Master Plan } \\
\text { Grand Renaissance Dam }\end{array}$ \\
\hline Political & $\begin{array}{c}\text { Subordination } \\
\text { Necropower } \\
\text { Organization } \\
\text { Sovereignty } \\
\text { Education } \\
\text { Law } \\
\text { Political parties }\end{array}$ & $\begin{array}{c}\text { Oromo Protests } \\
\text { Irreecha } \\
\text { OLF } \\
\text { TPLF } \\
\text { EPRDF }\end{array}$ \\
\hline Cultural & $\begin{array}{c}\text { Cultural Imperialism } \\
\text { Other-ing } \\
\text { Reclaiming } \\
\text { Survivance } \\
\text { Language } \\
\text { Religion } \\
\text { Culture }\end{array}$ & $\begin{array}{l}\text { Habesha } \\
\text { Orthodox Christian } \\
\text { Oromumma (language, } \\
\text { religion, homeland) }\end{array}$ \\
\hline
\end{tabular}

